\title{
THE ROLE OF FILTRATION IN MAINTAINING CLEAN HEAT EXCHANGER COILS
}

\author{
Final Report
}

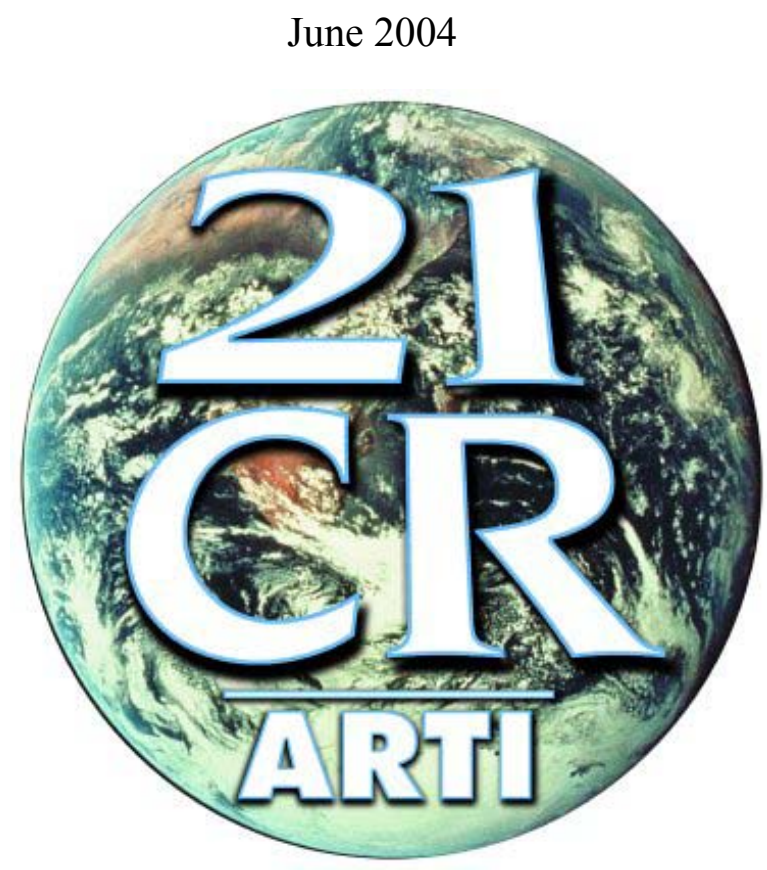

Submitted by

Li Yang, James E. Braun and Eckhard A. Groll

PURDUE UNIVERSITY

Ray W. Herrick Laboratories, 140 S. Intramural Drive, West Lafayette, IN 47907

Prepared for the

AIR-CONDITIONING AND REFRIGERATION TECHNOLOGY INSTITUTE 4100 N. Fairfax Drive, Suite 200, Arlington, Virginia 22203

Distribution A - Approved for public release; further dissemination unlimited. 


\section{DISCLAIMER}

This report was prepared as an account of work sponsored by the Air-Conditioning and Refrigeration Technology Institute (ARTI) under its "HVAC\&R Research for the $21^{\text {st }}$ Century" (21CR) program. Neither ARTI, the financial supporters of the 21CR program, or any agency thereof, nor any of their employees, contractors, subcontractors or employees thereof - makes any warranty, expressed or implied; assumes any legal liability or responsibility for the accuracy, completeness, any third party's use of, or the results of such use of any information, apparatus, product, or process disclosed in this report; or represents that its use would not infringe privately owned rights. Reference herein to any specific commercial product, process, or service by trade name, trademark, manufacturer, or otherwise, does not necessarily constitute nor imply its endorsement, recommendation, or favoring by ARTI, its sponsors, or any agency thereof or their contractors or subcontractors. The views and opinions of authors expressed herein do not necessarily state or reflect those of ARTI, the $21 \mathrm{CR}$ program sponsors, or any agency thereof.

Funding for the 21CR program provided by (listed in order of support magnitude):

- U.S. Department of Energy (DOE Cooperative Agreement No. DE-FC05-99OR22674)

- Air-Conditioning \& Refrigeration Institute (ARI)

- Copper Development Association (CDA)

- New York State Energy Research and Development Authority (NYSERDA)

- California Energy Commission (CEC)

- Refrigeration Service Engineers Society (RSES)

- Heating, Refrigeration and Air Conditioning Institute of Canada (HRAI)

Available to the public from

U.S. Department of Commerce

National Technical Information Service

5285 Port Royal Road

Springfield, VA 22161

(703) 487-4650

Available to U.S. Department of Energy and its contractors in paper from

U.S. Department of Energy

Office of Scientific and Technical Information

P.O. Box 62

Oak Ridge, TN 37831

(423) 576-8401 


\title{
THE ROLE OF FILTRATION IN MAINTAINING CLEAN HEAT EXCHANGER COILS
}

\author{
Final Report
}

June 2004

Li Yang

James E. Braun

Eckhard A. Groll

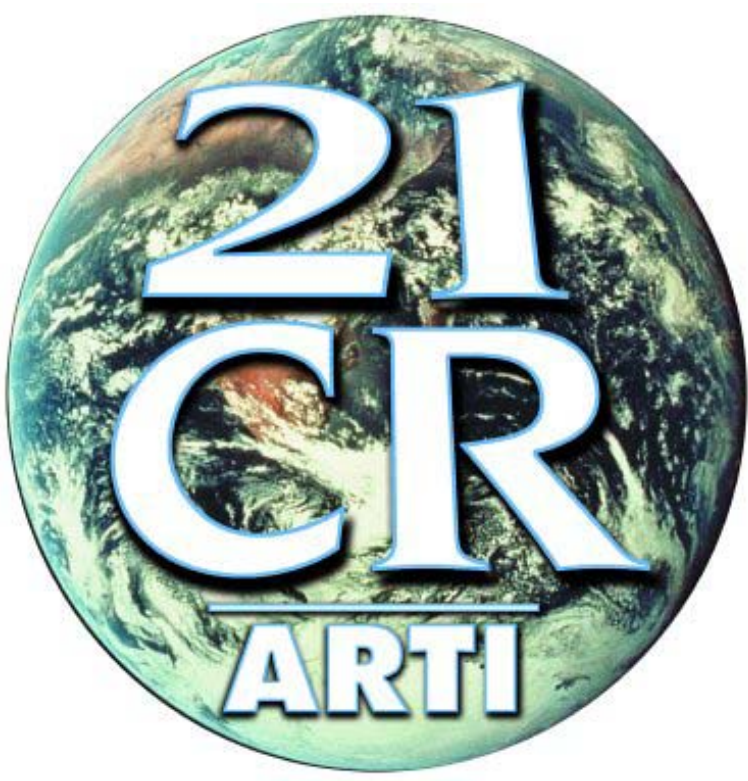

Prepared for the

AIR-CONDITIONING AND REFRIGERATION TECHNOLOGY INSTITUTE

Under ARTI 21CR Program Contract Number 611-40050 


\section{EXECUTIVE SUMMARY}

The main purpose of the study was to investigate the role of filtration in maintaining clean heat exchanger coils and overall performance. Combinations of 6 different levels of filtration (MERV 14, 11, 8, 6, 4, and no filter) and 4 different coils (an eight-row lanced-fin coil, HX8L), (an eight-row wavy-fin coil, HX8W), (a four-row lanced-fin coil, HX4L) and (a two-row lanced-fin coil, HX2L) were tested at 4 different air velocities (1.52, 2.03, 2.54, $3.05 \mathrm{~m} / \mathrm{s}(300,400,500,600 \mathrm{ft} / \mathrm{min}))$. The fouled conditions were obtained after injection of 600 grams of ASHRAE standard dust upstream of the filter/coil combination. This magnitude of dust is representative of a year of normal operation for an air conditioning system. The air-side pressure drops of the coils and filters and air-side heat transfer coefficients of the coils were determined from the measurements under the clean and fouled conditions. Depending upon the filter and coil test, the coil pressure drops increased in the range of $6 \%-30 \%$ for an air velocity at $2.54 \mathrm{~m} / \mathrm{s}(500 \mathrm{ft} / \mathrm{min})$. The impact was significantly greater for tests performed without a filter. The largest relative effect of fouling on pressure drop occurs for coils with fewer rows and having lanced fins. Coils with a greater number of rows can hold more dust so that a fixed amount of dust has a relatively smaller impact. The impact of fouling on air-side heat transfer coefficients was found to be relatively small. In some cases, heat transfer was actually enhanced due to additional turbulence caused by the presence of dust.

The experimental results for pressure drops and heat transfer coefficients were correlated and the correlations were implemented within computer models of prototypical rooftop air conditioners and used to evaluate the impact of fouling on cooling capacity and EER. The equipment cooling capacity is reduced with fouling primarily because of a decrease in air flow due to the increase pressure drop rather than due to changes in heat transfer coefficient. In most cases, the EER was reduced with fouling primarily due to increased fan power. However, the changes in EER were relatively small, in the range of 1\%-9\% (10\%). For most cases, equipment having low efficiency filters had higher EER after fouling than equipment with high efficiency filters, because the high efficiency filter caused significantly higher pressure drops than the low efficiency filters. The extra filter pressure drop outweighed the reduced coil pressure drop after fouling. The impact of fan efficiency 
curves was also investigated in the study. The energy penalty associated with high efficiency filters was reduced considerably with higher efficiency fans.

There is an energy penalty associated with the use of high efficiency filtration. However, the primary reason for selecting high efficiency filters for a particular application would be improved air quality. For HX8L, the quantity of dust passing through the coil with a MERV4 filter was approximately 30 times the dust passing the coil with a MERV14 filter. Without an upstream filter, the quantity of dust passing through the coil was approximately 60 times the value for a MERV14 filter. 


\section{LIST OF CONTENTS}

EXECUTIVE SUMMARY 4

LIST OF CONTENTS $\quad 6$

LIST OF TABLES $\quad 8$

LIST OF FIGURES $\quad 9$

NOMENCLATURE 12

1. INTRODUCTION 14

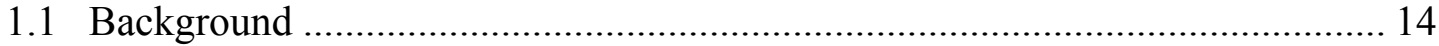

1.2 Descriptions of Terms Used in the Study ……............................................. 15

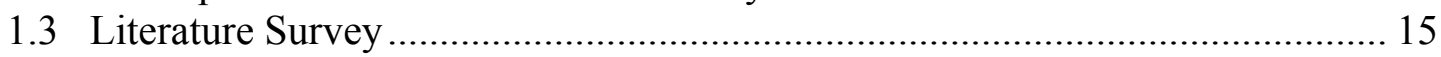

1.3.1 Overview of Papers Related to Fouling in Heat Exchangers .................. 15

1.3.2 Overview of Papers Related to Filter Performance in HVAC Systems.... 21

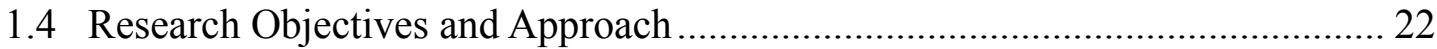

2. EXPERIMENTAL EQUIPMENT AND PROCEDURES 25

2.1 Selection of Test Coils, Filters and Equipment ............................................. 25

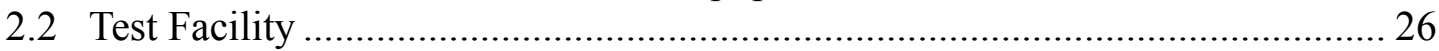

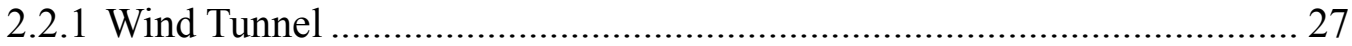

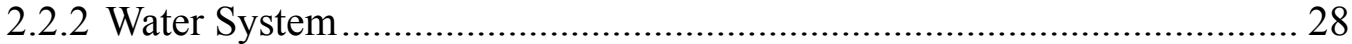

2.2.3 Dust Injecting System........................................................................ 29

2.2.4 Test Coils and Filters ....................................................................... 31

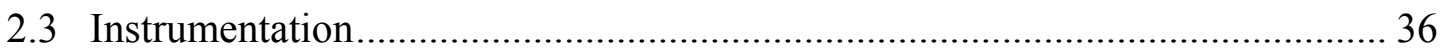

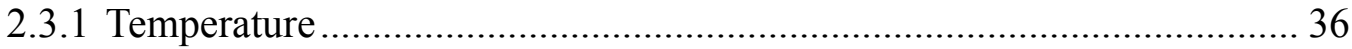

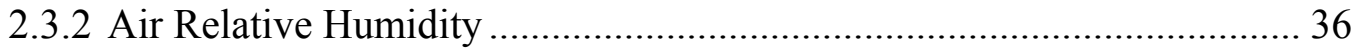

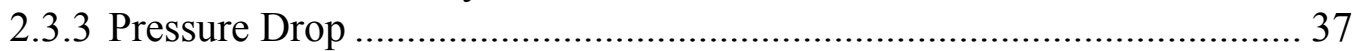

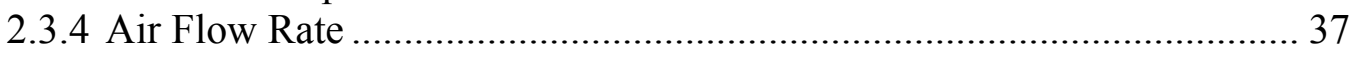

2.3.5 Water Flow Rate ................................................................................. 39

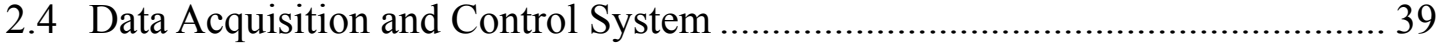

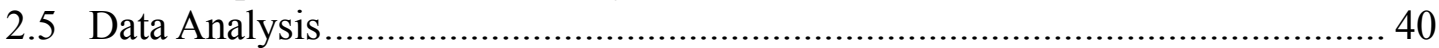

2.5.1 Coil Air-side Pressure Drop and Error Analysis................................... 40

2.5.2 Coil Air-side Effective Heat Transfer Coefficient and Error Analysis ..... 43

2.6 Filter Evaluation and ASHRAE Standard Dust .................................................. 49

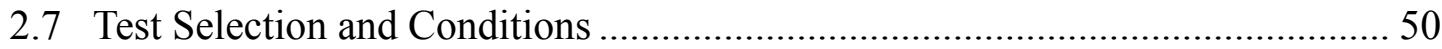

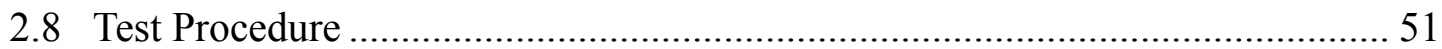

3. TEST RESULTS 54

3.1 Air-side Pressure Drops and Fouling Factors for Wet Conditions .................... 54

3.2 Heat Transfer Coefficients and Fouling Factors for Wet Conditions ................. 62

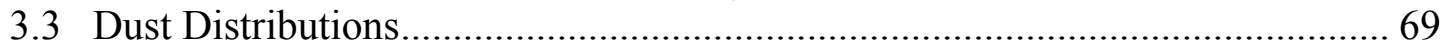

3.4 Comparison between Dry and Wet Conditions ............................................ 71

3.4.1 Coil Pressure Drops at Dry and Wet Conditions .................................. 71

3.4.2 Coil Effective Heat Transfer Coefficients at Dry and Wet Conditions..... 73

4. IAQ EFFECTS 75 
5. EQUIPMENT PERFORMANCE EFFECTS

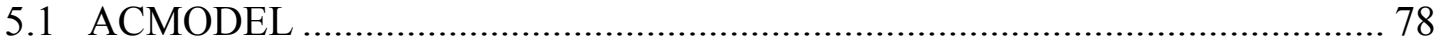

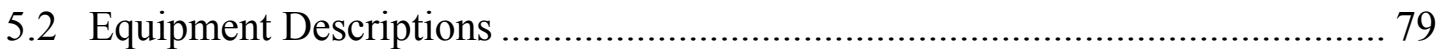

5.3 Modeling Process .................................................................................. 80

5.4 Fouling Impact on Equipment Capacity and EER .................................... 85

5.4 .1 Capacity Impact ................................................................... 85

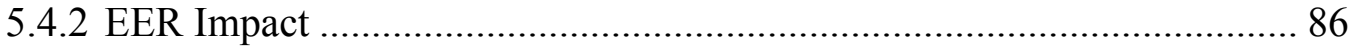

5.4.3 Influence of Fan Efficiency Curve on EER ........................................ 88

6. CONCLUSIONS AND RECOMMENDATIONS 94

REFERENCES 96

APPENDIX 1: ADDITIONAL DATA TABLES 98

APPENDIX 2: ADDITIONAL DATA FIGURES 102

APPENDIX 3: TEST OPERATION PROCEDURE 110

APPENDIX 4: LIST OF PURCHASED APPARATUS 115 


\section{LIST OF TABLES}

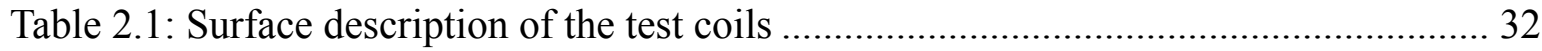

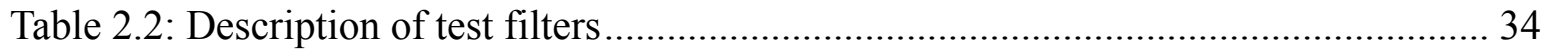

Table 2.3: The error of air velocity $(d V)$ vs. air velocity ........................................... 41

Table 2.4: Relative pressure drop errors of different coil cases at four air velocities for baseline tests ................................................................... 42

Table 2.5: Uncertainties of measurements used to determine effective heat transfer coefficients........................................................................... 47

Table 2.6: Sensitivity of effective heat transfer coefficient to the measurements

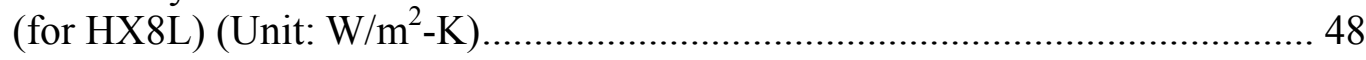

Table 2.7: Relative error in effective heat transfer coefficient for different coils at four air velocity levels for baseline tests................................................. 48

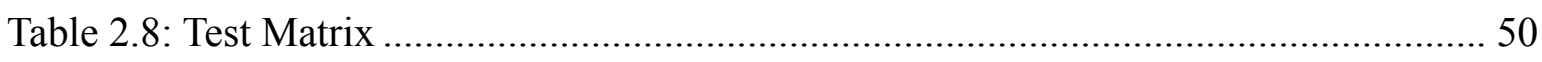

Table 3.1: Pressure drop fouling factor of all test cases................................................. 59

Table 3.2: Effective heat transfer coefficient fouling factor of all test cases ..................... 68

Table 3.3: Dust distribution of the six test cases of HX8L ......................................... 71

Table 3.4: Weight of dust captured by the coil for all test cases ................................... 71

Table 5.1: Descriptions of simulated equipment........................................................ 80

Table A1: Coil air-side pressure drop factors............................................................ 98

Table A2: Coil air-side effective heat transfer coefficient factors ................................. 99

Table A3: Filter pressure drop factors ...................................................................... 99

Table A4: Equipment system additional pressure drop $\Delta P_{\text {dist }}$ and factor $K \ldots \ldots \ldots \ldots \ldots \ldots \ldots . . . . . . . .100$

Table A5: Dust distributions for all test cases......................................................... 100 


\section{LIST OF FIGURES}

Figure 2.1: Schematic of experimental wind tunnel .................................................. 27

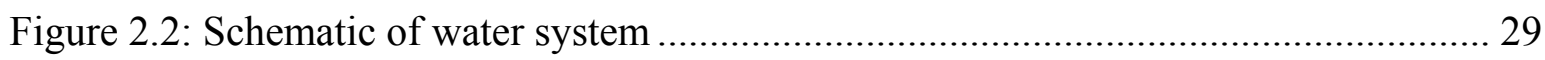

Figure 2.3: Photograph of the dust injector........................................................... 30

Figure 2.4: Location of the spray nozzle in the wind tunnel........................................ 31

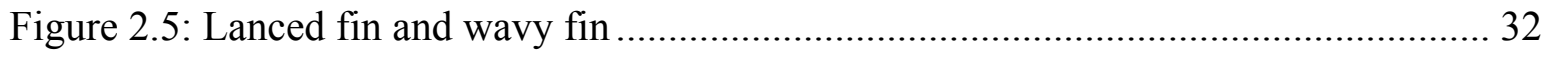

Figure 2.6: Photographs of coils HX4L and HX8L .................................................. 32

Figure 2.7: Water Circuit Arrangements of Test Coils ................................................. 33

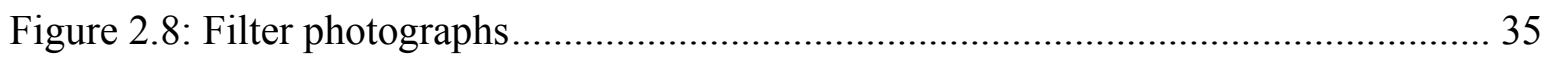

Figure 2.9: Thermocouple locations within the temperature grid................................. 36

Figure 2.10: The locations of the test cross-sections ............................................... 38

Figure 2.11: The velocity measurement locations ......................................................... 38

Figure 2.12: Air velocity distribution at line B of measuring section without filter........... 38

Figure 2.13: Air velocity distribution at line B of measuring section for the

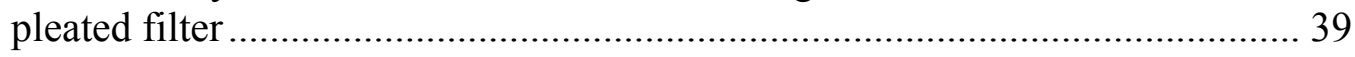

Figure 2.14: Schematic diagram of data acquisition and control system........................ 40

Figure 2.15: Pressure drop baseline and error bounds for HX8L .................................. 42

Figure 2.16: Thermal Diagram for General Case When Coil Surface Operates

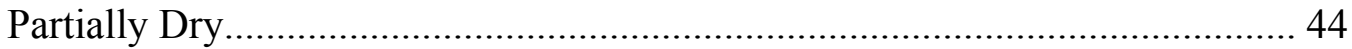

Figure 2.17: Effective heat transfer coefficient baseline and error bounds for

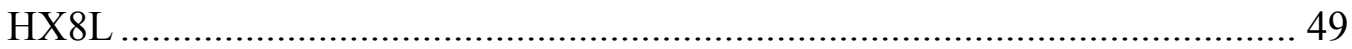

Figure 3.1: Baseline pressure drop vs air velocity for four test coils................................ 54

Figure 3.2: Air-side pressure drop vs air velocity of HX8W ...................................... 56

Figure 3.3: Air-side pressure drop vs air velocity of HX8L ........................................ 56

Figure 3.4: Air-side pressure drop vs air velocity of HX4L ...................................... 57

Figure 3.5: Air-side pressure drop vs air velocity of HX2L ....................................... 57

Figure 3.6: Comparison of pressure drop fouling factors of four coils at air

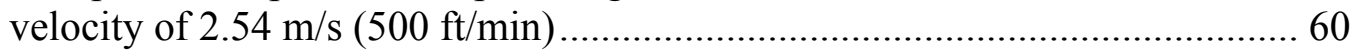

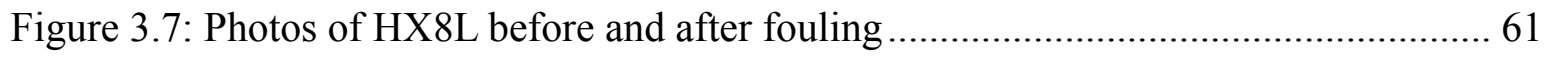

Figure 3.8: Baseline effective heat transfer coefficient vs air velocity for four test

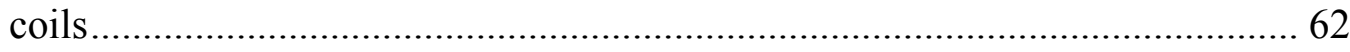

Figure 3.9: Effective heat transfer coefficient vs air velocity of HX8W ......................... 64

Figure 3.10: Effective heat transfer coefficient vs air velocity of HX8L ........................ 65

Figure 3.11: Effective heat transfer coefficient vs air velocity of HX4L.......................... 65

Figure 3.12: Effective heat transfer coefficient vs air velocity of HX2L ......................... 66

Figure 3.13: Effective heat transfer coefficient vs. injected dust quantity of HX8L .......... 66 
Figure 3.14: Comparison of pressure drop fouling factors of four coils at a same

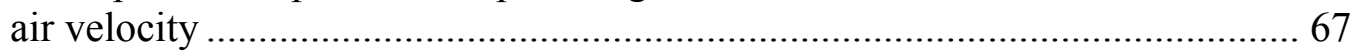

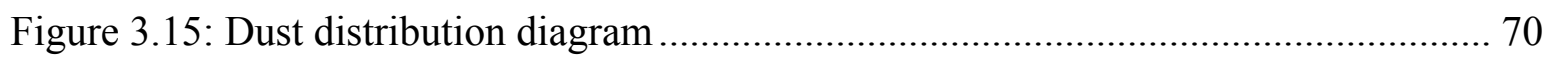

Figure 3.16: Baseline pressure drop vs air velocity of HX8L-No-filter-C at dry

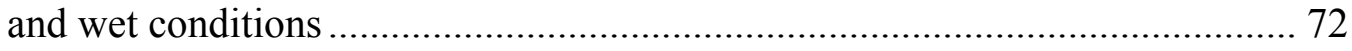

Figure 3.17: Pressure drop fouling factor vs. air velocity of HX8L-MERV11-F at dry and wet conditions..................................................................................... 73

Figure 3.18: Effective heat transfer coefficient vs air velocity of HX8L-No-filter-C at dry and wet conditions. 74

Figure 3.19: Effective heat transfer coefficient fouling factor vs. air velocity of

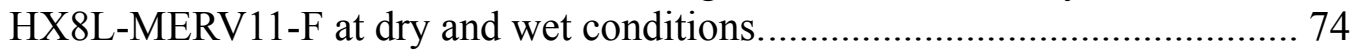

Figure 4.1: Dust quantities passing coil and filter for HX8W cases................................... 76

Figure 4.2: Dust quantities passing coil and filter for HX8L cases .................................... 76

Figure 4.3: Dust quantities passing coil and filter for HX4L cases ..................................... 77

Figure 4.4: Dust quantities passing coil and filter for HX2L cases .................................... 77

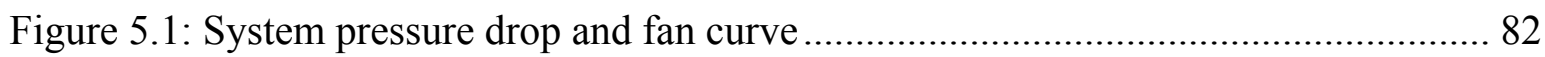

Figure 5.2: Baseline cooling capacity vs. condenser side inlet temperature for all

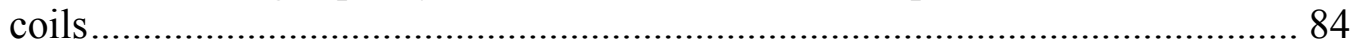

Figure 5.3: Baseline EER vs. condenser side inlet temperature for all coils …................ 84

Figure 5.4: Capacity ratio of all coil-filter cases for HX2L $\left(\mathrm{Tci}=35^{\circ} \mathrm{C}\right)$........................... 86

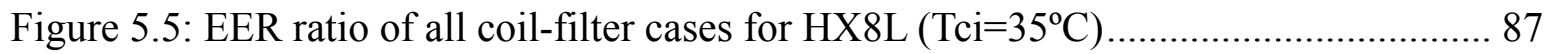

Figure 5.6: EER ratio of all coil-filter cases for $\mathrm{HX} 8 \mathrm{~W}\left(\mathrm{Tci}=35^{\circ} \mathrm{C}\right)$............................. 87

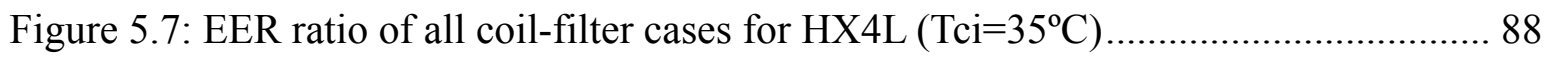

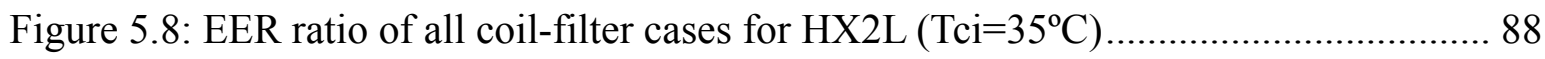

Figure 5.9: EER ratio of all coil-filter cases for $\mathrm{HX} 8 \mathrm{~L}$ when fan efficiencies at constant $38 \%\left(\mathrm{Tci}=35^{\circ} \mathrm{C}\right)$

Figure 5.10: EER ratio of all coil-filter cases for HX2L when fan efficiencies at constant $29 \%\left(\mathrm{Tci}=35^{\circ} \mathrm{C}\right)$

Figure 5.11: EER ratio of all coil-filter cases for $\mathrm{HX} 8 \mathrm{~L}$ when fan efficiencies at constant $100 \%\left(\mathrm{Tci}=35^{\circ} \mathrm{C}\right)$

Figure 5.12: EER ratio of all coil-filter cases for $\mathrm{HX} 2 \mathrm{~L}$ when fan efficiencies at constant $100 \%\left(\mathrm{Tci}=35^{\circ} \mathrm{C}\right)$

Figure 5.13: Comparison of EER values for HX8L at clean conditions for the three cases.....

Figure 5.14: Comparison of EER values for HX8L at fouled conditions for the three cases

Figure 5.15: Comparison of EER values for HX2L at clean conditions for the three cases

Figure 5.16: Comparison of EER values for HX2L at fouled conditions for the three cases. 
Figure A1: Pressure drop baseline and error bounds for HX8W .................................... 102

Figure A2: Pressure drop baseline and error bounds for HX8L …………...................... 102

Figure A3: Pressure drop baseline and error bounds for HX4L ........................................ 103

Figure A4: Pressure drop baseline and error bounds for HX2L …………...................... 103

Figure A5: Effective heat transfer coefficient baseline and error bounds for

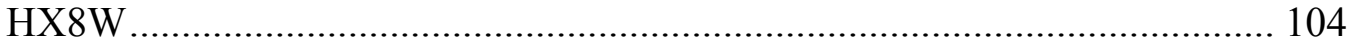

Figure A6: Effective heat transfer coefficient baseline and error bounds for HX8L ......... 104

Figure A7: Effective heat transfer coefficient baseline and error bounds for HX4L ......... 105

Figure A8: Effective heat transfer coefficient baseline and error bounds for HX2L ......... 105

Figure A9: Capacity ratio of all filter cases for $\mathrm{HX} 8 \mathrm{~W}\left(\mathrm{Tci}=35^{\circ} \mathrm{C}\right)$................................ 106

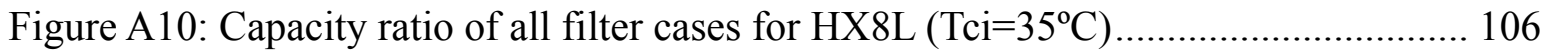

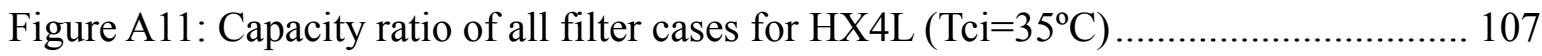

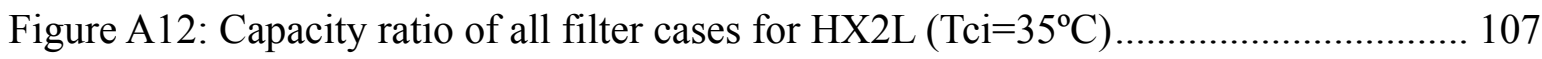

Figure A13: EER ratio of all coil-filter cases for $\mathrm{HX} 8 \mathrm{~W}$ with fan efficiency at

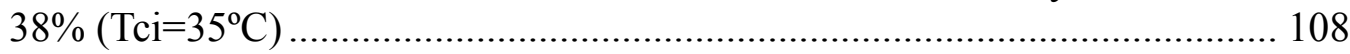

Figure A14: EER ratio of all coil-filter cases for HX4L with fan efficiency at $28 \%$

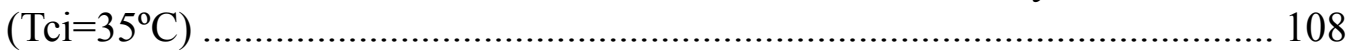

Figure A15: EER ratio of all coil-filter cases for $\mathrm{HX} 8 \mathrm{~W}$ with fan efficiency at $100 \%\left(\mathrm{Tci}=35^{\circ} \mathrm{C}\right)$

Figure A16: EER ratio of all coil-filter cases for HX4L with fan efficiency at $100 \%\left(\mathrm{Tci}=35^{\circ} \mathrm{C}\right)$ 109 


\section{NOMENCLATURE}

$$
\begin{aligned}
& A \quad=\text { area, } \mathrm{m}^{2} \\
& =\text { coil pressure drop factor, } \mathrm{Pa} \cdot \mathrm{s}^{b_{c(f)}} / \mathrm{m}^{b_{c(f)}} \\
& =\text { coil pressure drop exponent, dimensionless } \\
& =\text { total outside surface area, } \mathrm{m}^{2} \\
& =\text { ratio of external to internal surface area, dimensionless } \\
& =\text { coil characteristic, } \mathrm{kg}-\mathrm{K} / \mathrm{kJ} \\
& =\text { coil effective heat transfer coefficient factors, } W \cdot s^{d_{c(f)}} / m^{2+d_{c(f)}} \cdot K \\
& =\text { specific heat of air, } \mathrm{J} / \mathrm{kg}-\mathrm{K} \\
& =\text { specific heat of water, } \mathrm{J} / \mathrm{kg}-\mathrm{K} \\
& =\text { tube diameter, } \mathrm{mm} \\
& =\text { coil effective heat transfer coefficient exponent, dimensionless } \\
& =\text { filter pressure drop factor, } \mathrm{Pa} \cdot \mathrm{s}^{g_{c(f)}} / \mathrm{m}^{\mathrm{g}_{c(f)}} \\
& =\text { friction factor or fouling factor, dimensionless } \\
& =\text { filter pressure drop exponent, dimensionless } \\
& =\text { heat transfer coefficient, } \mathrm{W} / \mathrm{m}^{2}-\mathrm{K} \text {, or enthalpy, } \mathrm{kJ} / \mathrm{kg} \\
& =\text { air duct pressure drop factor, } \mathrm{Pa}-\mathrm{s}^{2} / \mathrm{m}^{2} \\
& =\text { water or air mass flow rate, } \mathrm{kg} / \mathrm{s} \\
& =\text { Nusselt number, dimensionless } \\
& =\text { longitudinal tube pitch, } \mathrm{mm} \\
& =\text { Prandtl number, dimensionless } \\
& =\text { transverse tube pitch, } \mathrm{mm} \\
& =\text { air velocity pressure, } \mathrm{Pa} \\
& \text { = heat transfer capacity, } \mathrm{W} \\
& =\text { heat resistance, } \mathrm{m}^{2}-\mathrm{K} / \mathrm{W} \\
& \begin{array}{ll}
R e_{D} & =\text { Reynolds number, dimensionless } \\
R H & =\text { relative humidity, dimensionless }
\end{array} \\
& T(t) \quad=\text { temperature, }{ }^{\circ} \mathrm{C} \\
& U_{o} \quad=\text { overall heat transfer coefficient, } \mathrm{W} / \mathrm{m}^{2}-\mathrm{K} \\
& V \quad=\text { air velocity, } \mathrm{m} / \mathrm{s} \\
& \Delta h_{m} \quad=\log \text {-mean enthalpy difference, } \mathrm{kJ} / \mathrm{kg}
\end{aligned}
$$




$$
\begin{array}{ll}
\Delta P & =\text { pressure drop, } \mathrm{Pa} \\
\Delta t_{m} & =\text { log-mean temperature difference, }{ }^{\circ} \mathrm{C} \\
\rho & =\text { air density, } \mathrm{kg} / \mathrm{m}^{3} \\
\eta & =\text { fin effectiveness, dimensionless }
\end{array}
$$

Subscripts:

$\begin{array}{ll}a & =\text { air or air-side } \\ b & =\text { boundary } \\ c & =\text { coil or clean } \\ d & =\text { dry } \\ d i s t & =\text { distribution pressure drop } \\ d p & =\text { pressure drop } \\ h & =\text { effective heat transfer coefficient } \\ f c & =\text { condenser side fan } \\ f e & =\text { evaporator side fan } \\ f & =\text { fouled } \\ i & =\text { out } \\ o & =\text { surface } \\ s & =\text { wet or water } \\ m & \end{array}$




\section{INTRODUCTION}

\subsection{Background}

In HVAC systems, evaporator coils for cooling air can collect dust on the heat transfer surface. The buildup affects the heat transfer coefficient, reduces system air flow rate, and leads to premature failure, increased energy consumption and expensive services. In addition, dust passing through the coil can have a significant effect on the indoor air quality (IAQ).

Due to these problems, filters are generally used before evaporator coils to reduce fouling effects and increase IAQ. However, the filter contributes to increased energy consumption because of increased HVAC system pressure drop. Therefore, it is important to study the overall impact of filters on system performance.

This project investigated the effect of the level of filtration on the overall dust removal and on the performance of unitary systems.

Four different coils were studied in connection with six different levels of filtration (MERV $14,11,8,6,4$, and no filter). The filters were representative of the different efficiencies generally used in commercial applications. The four different coils were representative of the different capacities of evaporators used in commercial and residential rooftop air conditioners. Each of these coil-filter combinations was tested under clean and fouled conditions. The fouled conditions were obtained after injection of 600 grams of ASHRAE standard dust upstream of the filter. The measured data were used to determine correlations of coil pressure drops and air-side effective heat transfer coefficients for the different tests. These correlations were implemented within computer models of prototypical rooftop air conditioners and used to evaluate the impact of fouling on cooling capacity and energy efficiency ratio (EER). Fan performance, which was found to play a significant role, was also investigated in the study. 


\subsection{Descriptions of Terms Used in the Study}

For convenience, some terms were employed throughout the study. They are:

1. $\mathrm{HXnL}(\mathrm{W})-\mathrm{MERVm}-\mathrm{C}(\mathrm{F})-\mathrm{D}(\mathrm{W})$ :

$\mathrm{HX}=$ heat exchanger coil

$\mathrm{n}=$ coil row number

$\mathrm{L}(\mathrm{W})=$ lanced (wavy) fin type

$\mathrm{MERVm}=$ the upstream filter of MERV value $m$

$\mathrm{C}(\mathrm{F})=$ clean (fouling) test

$\mathrm{D}(\mathrm{W})=$ dry (wet) condition

2. MERV: Minimum Efficiency Reporting Value, set forth in ASHRAE standard 52.2-1999. A MERV value represents an average filter efficiency over a range of particle sizes.

3. Coil: test evaporator coil; even though water was used as the working fluid

\subsection{Literature Survey}

\subsubsection{Overview of Papers Related to Fouling in Heat Exchangers}

Most of the fouling studies in the literature have focused on liquid-side fouling. In particular, precipitation fouling, particulate fouling, chemical reaction/corrosion fouling, and fouling monitoring systems have been investigated extensively. Only a few studies were found that focused on air-side fouling.

\subsubsection{Fouling Fundamentals}

Taborek et al. (1972) surveyed the fouling mechanisms, secondary factors (such as surface roughness) and effects of flow patterns to fouling, which is probably one of the earliest systematic discussions on fouling. Several ways were suggested to prevent fouling behavior: employ various additives to diminish or retard the fouling build-up; make proper equipment design and equipment type selection; avoid unrealistically low pressure drops and therefore low flow velocities which resulted in unnecessary high fouling rates. 
However, this discussion was mainly applicable to industry processes and did not mention any air-side fouling of HVAC systems.

Marner (1990) presented a review of developments in gas-side fouling, which might be defined as the deposition of an insulating layer of material onto a heat-transfer surface in the presence of a dirty gas stream. A detailed review of the mechanisms of gas-side fouling was given in this paper. Six classifications for fouling (precipitation, particulate, chemical reaction, corrosion, biological and solidification) and five main fouling mechanisms (initiation of fouling, transport to the surface, attachment to the surface, removal from the surface, aging of the deposit) were provided in this paper. The author suggested that a wet heat exchanger surface resulting from moisture condensation would enhance the initiation of gas-side fouling.

Analytical models were presented to predict the various gas-side fouling processes described above. Three kinds of fouling models were investigated in this paper: (1) deposition models (predicting the deposition coefficient) (2) heat transfer models and (3) pressure drop models. A considerable amount of work has been done in the area of deposition process models but less work has been done for the latter two.

Siegel and Nazaroff (2003) built a model for fouling of fin-and-tube heat exchangers to estimate the overall deposition fraction that was related to the penetration factors of impaction on fins edges, impaction on refrigerant tubes, gravitational setting, air turbulence and Brownian diffusion. An experiment was conducted to verify the modeling prediction. The test heat exchanger was typical of those found in residential and light commercial buildings with a 4.7 fin/cm (12 fin/inch) fin spacing. The test particles were oil particles tagged with fluorescein so that the airborne particle concentration and the amount of particles remained on the coil surfaces were analyzed by fluorometric techniques. Air velocity was changed from $1.5 \mathrm{~m} / \mathrm{s}(295 \mathrm{ft} / \mathrm{min})$ to $5.2 \mathrm{~m} / \mathrm{s}(1024 \mathrm{ft} / \mathrm{min})$.

The paper predicted that less than $2 \%$ of submicron particles $(<1 \mu \mathrm{m})$ would deposit on heat exchangers while for supermicron particles, deposition increases quickly with particle size. Higher air flow rates led to increased deposition by impaction on fin edges and tubes by air turbulence, while lower air flow rate increased deposition by Brownian diffusion and gravitational settling. Larger fin spacing caused increased deposition for all mechanisms 
except for impaction on tubes.

\subsubsection{Experimental Studies}

Because of the complexity of the fouling phenomenon, relatively few theoretical models have been developed. After 1980, several experiments were carried out to study the fouling impact on heat exchangers.

There are some general conclusions resulting from these experiments: (1) The effect of gas-side fouling on pressure drop is more pronounced than on heat transfer. (2) The fouling rate is directly proportional to bulk concentrations and after an initiation period there is a rapid fouling process. (3) Small size particles seem to increase fouling compared to larger particles. (4) Fouling is enhanced by higher air velocities. (5) The surfaces that are least susceptible to fouling are those with the largest values of hydraulic diameter (lowest fin density) of the basic orifices in the front face.

Marner (1990) presented a review of developments of experimental studies including gas-side fouling measuring devices and experimental results. The descriptions and results of those experimental studies are given below:

1. Impacts of fouling from exhaust gases on pressure drop and heat transfer for various types of heat exchangers suitable for use in heat recovery systems (by Mort (1966)):

Description:

Mort reported on a study of the impact of fouling of exhaust gases for seventeen compact heat exchangers. The test parameters were: inlet gas temperature, $316{ }^{\circ} \mathrm{C}-760 \quad{ }^{\circ} \mathrm{C}\left(600{ }^{\circ} \mathrm{F}\right.$ $\left.-1400{ }^{\circ} \mathrm{F}\right)$; face velocity, $3.35 \mathrm{~m} / \mathrm{s}-18.3 \mathrm{~m} / \mathrm{s}(660 \mathrm{ft} / \mathrm{min}-3600 \mathrm{ft} / \mathrm{min})$; fuel-air ratio, 0.009-0.020; metal temperature, $121{ }^{\circ} \mathrm{C}-482^{\circ} \mathrm{C}\left(250^{\circ} \mathrm{F}-900{ }^{\circ} \mathrm{F}\right)$; and fuel type, JP-4 and Combat. Tests for various surface roughness on the gas side were also carried out.

Results:

(1) Fouling rates increased with an increase in the air-fuel ratio and a decrease in exhaust gas temperature.

(2) Fouling deposition increased with the gas velocity decreased.

(3) The straight plate-fin units produced the highest-pressure drop increases due to fouling, 
followed in order by the ruffled plate-fin units, the tube bundles, and the coil tubes.

(4) No significant trends or reductions in heat transfer were apparent for the different configurations tested.

2. Investigation of fouling effects on heat transfer rates, pressure drops characteristics, and surface cleaning methods in compact gas turbine regenerator geometries (by Miller (1967)):

Description:

The heat exchangers tested were very compact plate-fin units. The temperature of the exhaust gas was up to $566{ }^{\circ} \mathrm{C}\left(1050{ }^{\circ} \mathrm{F}\right)$ and velocities were up to $16.8 \mathrm{~m} / \mathrm{s}(3307 \mathrm{ft} / \mathrm{min})$.

Results:

(1) The pressure drop through the heat exchanger unit was nearly inversely proportional to the hydraulic diameter to the 4.5 power.

(2) The increase in friction factor was the greatest for the coolest module, and least for the hottest.

(3) The effect of fouling on pressure drop was more pronounced than that on heat transfer.

3. A report on two cleaning techniques developed for use with the AiResearch plate-fin and offset-fin recuperator (by Burgmeier and Leung (1981)):

Description:

AiResearch Manufacturing Company has developed a series of high-performance metallic plate-fin recuperators for use in industrial gases of up to approximately $815{ }^{\circ} \mathrm{C}\left(1500{ }^{\circ} \mathrm{F}\right)$. An offset rectangular fin and a plain fin pattern were used for applications with relatively clean gases and dirty gases, respectively. This report focused on two cleaning techniques developed for use with these recuperators: (1) an air lance blowing in the same direction as the hot gases, and (2) an air cannon using a sudden blow-off with the cleaning air blowing from the opposite direction to the hot gas stream. 
Results:

(1) For the hot end, the dust deposits on the core surfaces were light and fluffy and easily cleaned away. Because the gas-side fouling rate of the offset-fin was approximately 8 to 10 times higher than that of the plain-fin design, the air lance was not very effective in cleaning the offset fins while it was able to clean the plain fins.

(2) For the cold end, the combined condensate-flue dust deposit was hard to be removed with either the air cannon or the air lance.

4. An experimental study on the gas-side fouling of a finned-tube module in the exhaust of a stationary Diesel engine (by Henslee and Bogue(1983) and Semler et al.(1983)):

Description:

Experiments were carried out using a No. 2 Diesel fuel for the following parameters: gas velocity was $3.05 \mathrm{~m} / \mathrm{s}-9.14 \mathrm{~m} / \mathrm{s}(600 \mathrm{ft} / \mathrm{min}-1800 \mathrm{ft} / \mathrm{min})$; inlet gas temperature was $104{ }^{\circ} \mathrm{C}$ $-221{ }^{\circ} \mathrm{C}\left(220^{\circ} \mathrm{F}-430^{\circ} \mathrm{F}\right)$. Three series of tests were carried out for durations of 300,320 and 430 hours.

Results:

(1) The increase in pressure drop is substantially greater than the reduction in heat transfer. The pressure drop doubled after approximately 400 hours' operation.

(2) Asymptotic fouling was achieved after approximately 200-300 hours of operation.

According to the analyses in this paper, gas-side fouling is an extremely complex, multifaceted process. However, this paper focused on air-side fouling in boilers and gas turbines at very high temperatures. Thus, the results may be very different for HVAC applications.

Bott and Bemrose (1983) conducted a systematic study of air-side fouling in finned tube bundles using fin densities of $3.54 \mathrm{fins} / \mathrm{cm}$ to $4.33 \mathrm{fins} / \mathrm{cm}$ ( 8 fins/inch to 12 fins/inch), fin heights of $12.7 \mathrm{~mm}$ to $15.9 \mathrm{~mm}$, fin thicknesses of $0.406 \mathrm{~mm}$ to $0.457 \mathrm{~mm}$, fin arrays of 1 , 2,3 , and 4 rows, and air velocities of $1.85 \mathrm{~m} / \mathrm{s}$ to $5.99 \mathrm{~m} / \mathrm{s}(364 \mathrm{ft} / \mathrm{min}-1180 \mathrm{ft} / \mathrm{min})$. As the contaminant, they used calcium carbonate with average diameters of 14 micrometer. Fouling tests were carried out under predetermined conditions of surface heat flux (by 
setting air and water temperatures) and air velocity. Condensation in the heat exchanger in this experiment was not likely under the designed conditions. Periodical fouling (i.e., dust injection) was stopped while full performance data were obtained over the available range of air velocities. Apart from two tests at $3.7 \mathrm{~g} / \mathrm{min}$, a constant dust injection rate of 21 $\mathrm{g} / \mathrm{min}$ was used. A total of thirty performance tests were carried out before, during and after the fouling. The authors concluded that air-side fouling has a pronounced effect on the air-side pressure drop $\left(f_{\text {foul }}=1.4-2.5 f_{\text {clean }}\right)$ and that the heat transfer performance, as measured in the form of the $\mathrm{j}$-factor, decreased only slightly with time. They also concluded that the first and last rows of the heat exchanger coils fouled more heavily than the middle rows.

Zhang, Bott and Bemrose (1990) tested the particle fouling of a diesel air charge cooler. The tests were performed under two air velocities: $7.8 \mathrm{~m} / \mathrm{s}(1535 \mathrm{ft} / \mathrm{min})$ and $3.6 \mathrm{~m} / \mathrm{s}(709$ $\mathrm{ft} / \mathrm{min}$ ), and the air was contaminated with $\mathrm{CaCO}_{3}$ particles of two sizes: $5 \mu \mathrm{m}$ and $12 \mu \mathrm{m}$. Hot or cold water was passed through the exchanger to be cooled or heated by the air stream. An eight-row coil of louvered plate fins was used in the experiment. Fourteen tests were performed to determine the characteristics of the heat exchanger under clean conditions and sixteen tests were performed under fouled conditions. A general equation $Y=a R e^{b}$ was found for all the dependent variables $Y$ (e.g., fan power, colburn $\mathrm{j}$ factor, friction factor or heat transfer coefficient). $a$ and $b$ were two constants determined by experiments.

The following conclusions for this particular finned tube diesel engine air charge cooler were summarized in this paper:

(1) Fouling rate was directly proportional to bulk concentrations and after an initiation period (this process was defined as "induction period" by Taborek et al. (1972), during which only negligible fouling deposition is observed) there was a rapid fouling process.

(2) Small particles seemed to increase fouling compared to the larger particles. (The larger particles made the deposit loose and easy to remove.)

(3) Fouling was enhanced by higher air velocities. (Air velocity increases inertial impaction as well as removal mechanisms, but the former is dominant. More precise 
conclusions are difficult to derive because only the effects of two velocities were studied.) This result was opposite to Mort (1966)'s study, which concluded that fouling deposition increased with the gas velocity decreased. However, Mort's experimental condition was at very high air inlet temperature $\left(316^{\circ} \mathrm{C}-760^{\circ} \mathrm{C}\left(600^{\circ} \mathrm{F}-1400{ }^{\circ} \mathrm{F}\right)\right)$.

(4) Heat flux direction (cooling mode or heating mode) did not appear to affect the fouling. However, moisture condensation was not considered for the cooling mode tests.

\subsubsection{Overview of Papers Related to Filter Performance in HVAC Systems}

There are many references related to filtration, but there appear to be relatively few that address the effects of filter and coil fouling on overall air conditioning system performance. Krafthefer et al. (1986) studied the buildup rate on coil surfaces and the fouling effect on the air pressure drop and the system energy consumption. The HFROST heat pump simulation computer program was used to show the undesirable consequences of operating a heat pump with a partially degraded heat transfer coil. Different filter technologies were compared from the point of view of reducing soiling rate and maximizing heat pump or air conditioner operating time under performance conditions. Experiments were performed with a finned coil and the amount of ASHRAE standard dust fed into the duct was approximately 300 grams (represented one year's quantity of dust flowing into the heat pump unit at $1000 \mathrm{ft}^{3} / \mathrm{min}$ ).

The paper showed that the particulate accumulation influenced the peak electricity demand rates by reducing indoor fan power and compressor power in the cooling mode while reducing indoor fan power and increasing compressor power in the heating mode. The use of an air cleaner sharply reduced these effects. They estimated a $10-13 \%$ decrease in COP for typical evaporator filter fouling of a heat pump. Furthermore, they estimated operating cost savings of $10-25 \%$ through use of a high efficiency air filter upstream of the evaporator.

Rossi and Braun (1996) developed a practical, near-optimal scheduling technique through comparing the combined service and energy costs associated with different maintenance scheduling for cleaning the condensers and evaporators of rooftop air conditioners. There were four schedules discussed in this paper: (1) optimal maintenance schedule (the lifetime 
costs of energy and service were minimized through cost equation analysis while maintaining comfort, safety and environmental protection as constraints), (2) regular service schedule (maintenance was performed at regular time intervals) (3) constrained service schedule (service was only performed when a comfort or equipment safety constraint is violated) and (4) simplified near-optimal service schedule (which was very similar to the optimal schedule but with less computational requirements and without weather and load forecasters). It was found that optimal service scheduling reduced lifetime operating costs by as much as a factor of two over regular service intervals, and by $50 \%$ when compared to constrained only service. The near-optimal algorithm gave operating costs that were within $1 \%$ of optimal.

Breuker and Braun (1998) conducted an experiment with a three-ton rooftop unit under 96 conditions (4 load levels $\times 24$ fault levels, including fouling fault). For the case of fouling, uniform condenser fouling was simulated in the test by blocking the condenser coil with strips of paper. The level of condenser fouling was expressed as a total percent reduction in the surface area. Evaporator fouling was simulated by reducing the air flow rate and it was expressed as a percent reduction from the nominal air flow rate. It was found that approximately a $12 \%$ reduction in both cooling capacity and COP with a $25 \%$ loss of

evaporator air flow caused by fouling, while only approximately a 5\% loss in capacity and an $8 \%$ loss in COP when approximately $25 \%$ of the condenser coil was blocked due to fouling.

\subsection{Research Objectives and Approach}

Most of the available literature relating to air-side fouling focused on industrial processes and only a few studied fouling in HVAC systems. In addition, no literature was found on air-side fouling of coils under conditions where moisture condenses. Therefore, the objectives of this project were to:

(1) Determine the change in cooling capacity of commonly used extended surface type evaporator coils for three different conditions: clean as received, during and after dust loading, and after cleaning. 
(2) Determine the coil air-side effective heat transfer coefficient and pressure drop for each test coil within the three test conditions.

(3) Determine overall indoor air quality (IAQ) impact by investigating the mass of dust passing the filter-coil combination.

(4) Predict the system performance impact including capacity and energy efficiency ratio (EER), when operating with clean vs. dirty filter-coil combinations by use of existing computer modeling programs.

(5) Determine the effects of several levels of filtration and the efficiency curve of evaporator-side fan on the predicted energy usage.

In order to achieve the research objectives the following approach was used:

Task 1: Literature search on fouling impact for coils and equipment performance.

As described in section 1.3, a literature search was conducted that focused on the heat exchanger performance impact of air-side fouling and the impact of heat exchanger and filter fouling on HVAC system performance.

Task 2: Developed test plan.

Several practice tests were carried out using an existing setup and test coils from a previous project. Based on this experience, a detailed test plan for measuring the performance impact of coil cleanliness with several levels of filtration was developed. The test coils were designed to fit into the test section and be representative of the range of equipment found in the present market.

Task 3: Modified the existing setup.

The performance testing of the filter-coil combinations took place using the Purdue Air Coil Testing (PACT) facility located at the Ray W. Herrick Laboratories at Purdue University. Several modifications to the test facility were necessary. A detailed description of the test setup using the PACT facility, including measurement instrumentation, instrument accuracy, and data reduction is given in next section.

Task 4: Conducted Tests.

All selected test coils were tested at three conditions: "as manufactured" without an 
upstream filter and without dust loading, during and after dust loading with an upstream filter (without filter for no-filter case), and after cleaning. The data was collected using a data acquisition system and coil air-side pressure drop and effective heat transfer coefficient were computed from the data.

Task 5: Developed modeling approach and conduct modeling study.

A Purdue program called "ACMODEL" was employed for predicting cooling capacities and compressor powers for different rooftop air conditioners with different filtration levels. Evaporator-side and condenser-side fan powers were computed separately. EERs for the different equipment were obtained. The impact of fouling on cooling capacity and EER was evaluated. 


\section{EXPERIMENTAL EQUIPMENT AND PROCEDURES}

In order to investigate the impacts of air-side fouling on the performance of coil and filter combinations, which include the filter pressure drop, coil air-side pressure drop and coil air-side effective heat transfer coefficient, the existing Purdue Air Coil Test (PACT) facility was modified. This chapter describes the details of the test equipment, the experimental apparatus, data reduction and test procedures.

\subsection{Selection of Test Coils, Filters and Equipment}

Water coils were tested instead of refrigerant coils for the following reasons: (1) heat transfer rates determined from measurements are more accurate using water than a refrigerant that changes phase during the heat transfer process; (2) the coils needed to be removed manually during experiments and it is much easier and cheaper to remove and reinstall each coil with water as the working fluid than a refrigerant; and (3) the goal was to determine air-side fouling effects, which are independent of working fluid flowing through the tubes.

Two types of fins were involved in the tests: wavy and lanced. These are the most common fin types used in evaporator coils as of today. The original plan was to test six different coils. They were: eight-row wavy-fin coil (HX8W), eight-row lanced-fin coil (HX8L), four-row wavy-fin coil (HX4W), four-row lanced-fin coil (HX4L), two-row wavy-fin coil (HX2W) and two-row lanced-fin coil (HX2L). However, the HX4W and HX2W were eliminated for two reasons: (1) From the test results of HX8L and HX8W, it was found that fouling has a very similar impact for these two types of fins. (2) Although these two fin types are both popular in evaporator coils, wavy-fin coils are generally used in large equipment while lanced-fin coils are used in smaller systems. Four-row and two-row coils are used primarily in the small systems. Thus, only lanced fins were considered for these two coils. Section 2.2.4 gives detailed coil descriptions.

A MERV14 pocket filter was selected as the downstream filter in the experiments. It was used to capture dust that passed through the upstream test filter and test coil. Five types of filters with different MERV ratings, which represent the efficiency range of those used in 
general ventilation applications, were tested as upstream filters in the study. They were: MERV14, MERV11, MERV8, MERV6 and MERV4. These filters were chosen for their small depths (2 inches for MERV 4, 6, 8 and 4 inches for MERV 11, 14) and relatively uniform structures, so that the air stream was distributed evenly after the filter.

Corresponding to eight-row, four-row and two-row coils, three types of equipment units were chosen for modeling: a 35-ton rooftop unit (medium to large commercial), a 5-ton rooftop unit (small commercial) and a 3-ton rooftop unit (small commercial or residential). All units were R-22 units and detailed descriptions are presented in Section 5.2.

\subsection{Test Facility}

The original PACT facility was modified as follows:

(1) Constructed a new standard-size air duct of $0.61 \mathrm{~m} \times 0.61 \mathrm{~m}(24$ inch $\times 24$ inch) to replace the old air duct, which was $0.9 \mathrm{~m} \times 0.44 \mathrm{~m}(35.5 \mathrm{inch} \times 17.3 \mathrm{inch})$.

(2) Added duct insulation for the whole test section. The whole air duct was uninsulated before modification, and the ratio of heat loss from the wind tunnel to the total heat transfer was approximately $17 \%$. After insulating the test section, the heat loss was reduced to approximately $3 \%$.

(3) A pitot tube array was installed in place of nozzles to measure air flow rate in order to reduce the overall pressure drop. The use of a pitot tube array conforms to ASHRAE standard 41.2.

(4) The preconditioning section was moved before the fan. The section included a four-row precooler coil and a set of heaters. This change reduced the maximum pressure in the duct work.

(5) The water loop was divided into two loops: a chilled water loop and a cooling water loop, which displaced the previous hot water loop. A new water pump and a corriolis-effect mass flow meter were employed to work under higher water flow rates $(0.5 \mathrm{~kg} / \mathrm{s}(8 \mathrm{gallon} / \mathrm{min}))$ than before $(0.2 \mathrm{~kg} / \mathrm{s}(3 \mathrm{gallon} / \mathrm{min}))$.

Additional details of the experimental test setup are presented in the following sections. 


\subsubsection{Wind Tunnel}

Figure 2.1 shows a sketch of the wind tunnel test facility. The cross-sectional dimension of the main duct is $0.61 \mathrm{~m} \times 0.61 \mathrm{~m}(24 \mathrm{inch} \times 24 \mathrm{inch})$. The indoor air is drawn by the variable speed fan through the inlet of the wind tunnel. The air passes through the preconditioned section first, which includes a precooler and three electrical heaters. Then, the air goes through the humidifier, flow straightner, pitot tube array, air mixer and enters the test section. The test section includes a thermocouple grid, a dust injector, the test filter-coil combination, a downstream filter, a mixer and another thermocouple grid. After the test section, the air is discharged outdoors. Following is a description of the function of each component in the wind tunnel.

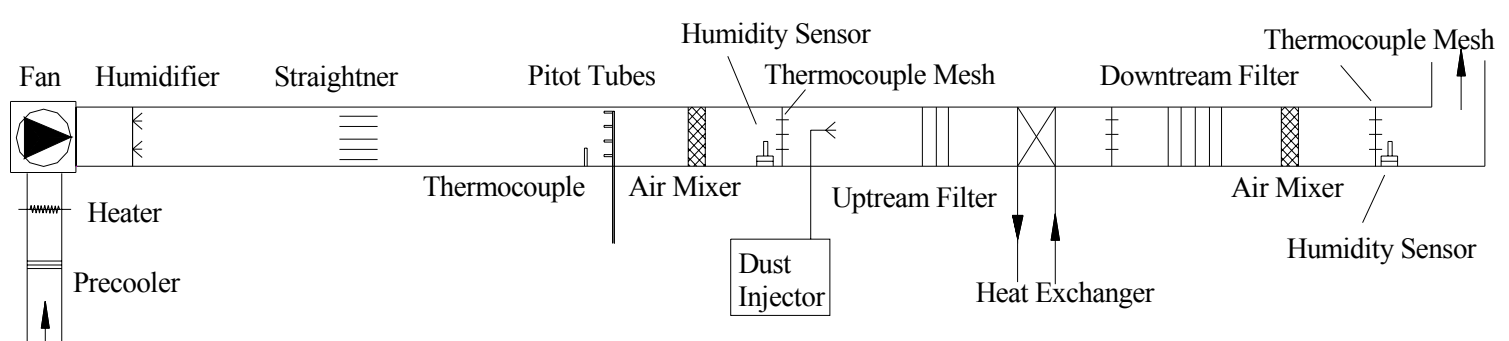

Figure 2.1: Schematic of experimental wind tunnel

Precooler: It operates as a dehumidifier with $10.5 \mathrm{~kW}$ (3 tons) cooling capacity. It was usually employed during moist summer conditions when the inlet air humidity was higher than the test requirement.

Electric Heaters: There are three electrical heaters with a current of 20 Amps, 240 VAC and $5 \mathrm{~kW}$ capacity each. They were used to heat the air to $26.7{ }^{\circ} \mathrm{C}\left(80^{\circ} \mathrm{F}\right)$ (dry bulb temperature).

Humidifier: The humidifier was connected to a steam pipe in the building and controlled by the Labview control program in a $\mathrm{PC}$ to provide a proper humidity condition $(\mathrm{RH}=0.61$ for most of the tests).

Flow Straightner: The straightner (ASHRAE Standard 41.2-1987, Section 5.2.1, P10) was constructed and installed in the wind tunnel to eliminate eddies and the rotation of the air 
stream and produce a uniform velocity profile at the inlet to the pitot tube array.

Pitot Tubes: Five pitot tubes were spread evenly across the diagonal of the cross section of the air duct to measure the air pressure drop. The formula $V(\mathrm{~m} / \mathrm{s})=1.414 \sqrt{\frac{P_{v}(\mathrm{~Pa})}{\rho\left(\mathrm{kg} / \mathrm{m}^{3}\right)}}$ was used for calculating the air velocity.

Air Mixer: An air mixer (ASHRAE Standard 41.1-1986, Section 6.3, P4) was used to reduce non-uniformities in temperature, humidity and velocity of the air stream. It consists of two sets of louvers that disperse the adjacent areas of air flow through the mixer.

Test Section: It mainly included a dust injector, an upstream filter, a test coil and a downstream filter. The test coil was directly connected to the closed water flow loop. For test measurements, two thermocouple grids (measuring the inlet air temperature and outlet air temperature), two humidity sensors (measuring the inlet and outlet air relative humidifies) and a total of sixteen pressure tap holes were located in this section. The sixteen pressure tap holes were divided into four groups in order to measure the static pressure drops across the upstream filter, test coil and downstream filter. Each group was located at a particular cross-section at the duct and contained a tap for each face of the duct. More details about the dust injector, filters and coils are described in sections 2.2.3 and 2.2.4.

\subsubsection{Water System}

Figure 2.2 shows the water system diagram. The water system included a chilled water loop and a cooling water loop. The main components of the water system included a chiller, a pump, a mass flow meter, and a surge tank. The chiller had the capacity of 15 tons and it was used to chill water as low as $2{ }^{\circ} \mathrm{C}\left(35^{\circ} \mathrm{F}\right)$. The setpoint temperature was controlled using on/off control of the chiller. The pump was a flexible impeller pump, which was coupled to a $1 \mathrm{hp}$ motor. The variable speed controller connected to a motor was used to adjust the flow rate. The surge tank was a 200-gallon insulated tank, which was inserted between the chilled water loop and cooling water loop. It was used to store water and minimize the temperature fluctuations caused by start-stop of the chiller (the coil water inlet temperature fluctuated in the range of $\pm 0.5^{\circ} \mathrm{C}\left( \pm 0.9^{\circ} \mathrm{F}\right)$ of the set temperature $)$. 
Temperature measurements on the water side were also critical to determine the cooling capacity of the test coil. Hence two thermistors, both calibrated to an accuracy of $0.2^{\circ} \mathrm{C}$ were used to measure the water inlet and outlet temperatures. A pressure relief valve was mounted at the top of inlet manifold of the test coil for safety reasons.

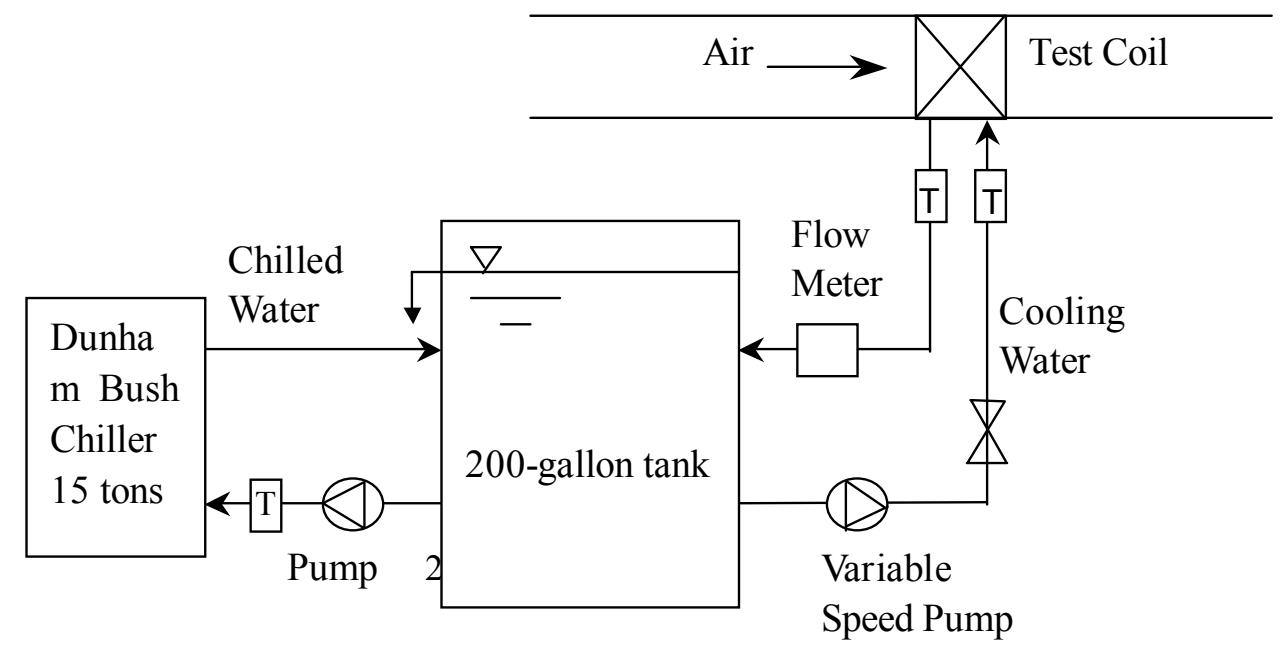

Figure 2.2: Schematic of water system

\subsubsection{Dust Injecting System}

The dust injecting system consisted of a dust injector and a spray nozzle mounted inside the wind tunnel. The dust feeder was manufactured according to ASHRAE specifications (ASHRAE Standard 52.1-1992, Sec.5.4). The main components of the dust feeder were a dust tray, a tooth paddle wheel, a dust pickup tube and a control box. Figure 2.3 shows a photograph of the dust injector. The dust was weighed and arranged evenly on the tray feeder. The tooth paddle wheel picked up uniform amounts of dust from the tray feeder and moved it to the dust pick-up tube by rotation. The tray advanced about $17.6 \mathrm{~cm}(6.9 \mathrm{inch})$ in 10 minutes at the normal condition. The dust was then sucked into the dust pick-up tube by an inside nozzle using compressed air and sprayed into the air duct through a spray nozzle located in the center of the duct. A filter dryer was inserted in the compressed air pressure line to provide clean, oil-free air.

The spray nozzle was mounted at $1.829 \mathrm{~m}$ (72 inches) upstream of the test filter according 
to ASHRAE Standard 52.1-1992. Figure 2.4 shows the schematic diagram of the installation of the spray nozzles in the air duct. ASHRAE standard 52.1-1992 also requires a mixing plate after the spray nozzle to ensure good mixing of the dust in the air stream. A perforated circular disk, having a $40 \%$ open area, was used as a mixing device as shown in Figure 2.4.

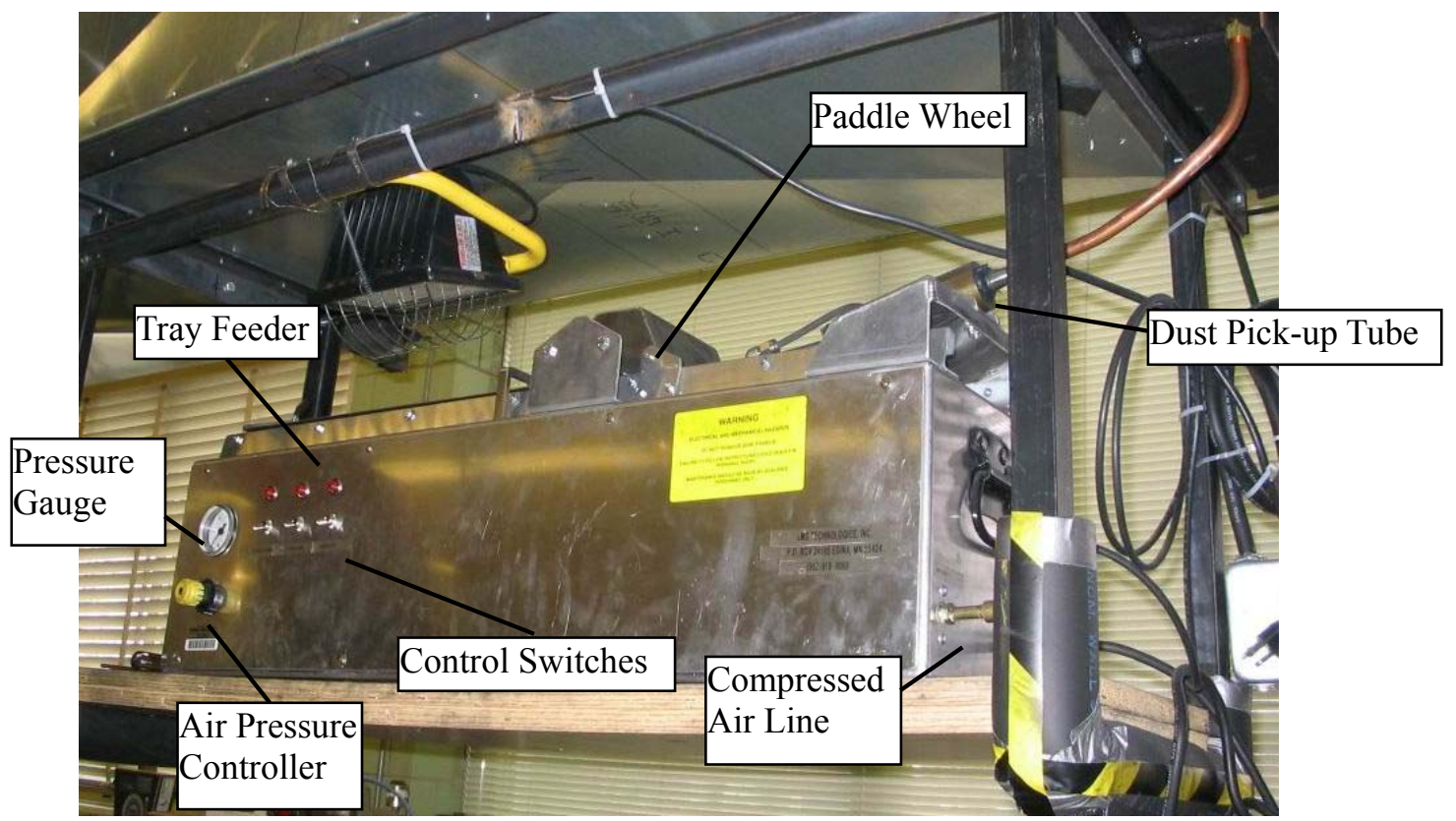

Figure 2.3: Photograph of the dust injector 


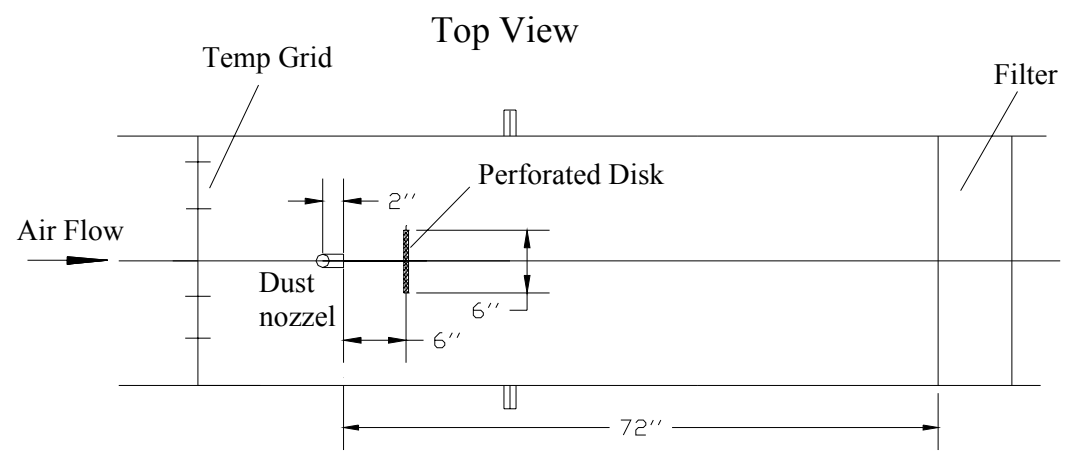

Side View

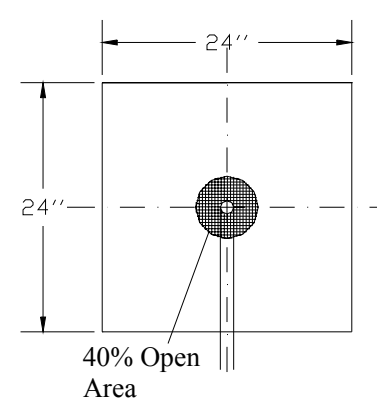

Figure 2.4: Location of the spray nozzle in the wind tunnel

\subsubsection{Test Coils and Filters}

\subsubsection{Test coils}

Four types of evaporator coils were tested in the experiment, which are shown in Table 2.1. They were eight-row, four-row and two-row coils. The eight-row and four-row coils had 8 circuits and 16 tubes in each row and the two-row coil had 6 circuits and 24 tubes in each row. Each coil was degreased using evaporator detergent before the testing started. Figures 2.5 and 2.6 show photographs of fin geometries and coils HX4L and HX8L. Figure 2.7 shows the water circuit arrangements of the eight-row, four-row and two-row coils. 
Table 2.1: Surface description of the test coils

\begin{tabular}{|c|c|c|c|c|}
\hline Coil No. & Fin Geometries & $\begin{array}{c}\text { Tube Geometries } \\
(\mathrm{cm})\end{array}$ & No. of Rows & $\begin{array}{c}\text { Fin Density } \\
(\mathrm{fin} / \mathrm{cm})\end{array}$ \\
\hline HX2L & Lanced & $0.95(3 / 8 \mathrm{in})$ & 2 & $5.51(14 \mathrm{fin} / \mathrm{inch})$ \\
\hline HX4L & Lanced & $1.27(1 / 2 \mathrm{in})$ & 4 & $4.72(12 \mathrm{fin} / \mathrm{inch})$ \\
\hline HX8W & Wavy & $1.27(1 / 2 \mathrm{in})$ & 8 & $3.15(8 \mathrm{fin} / \mathrm{inch})$ \\
\hline HX8L & Lanced & $1.27(1 / 2 \mathrm{in})$ & 8 & $3.15(8 \mathrm{fin} / \mathrm{inch})$ \\
\hline
\end{tabular}

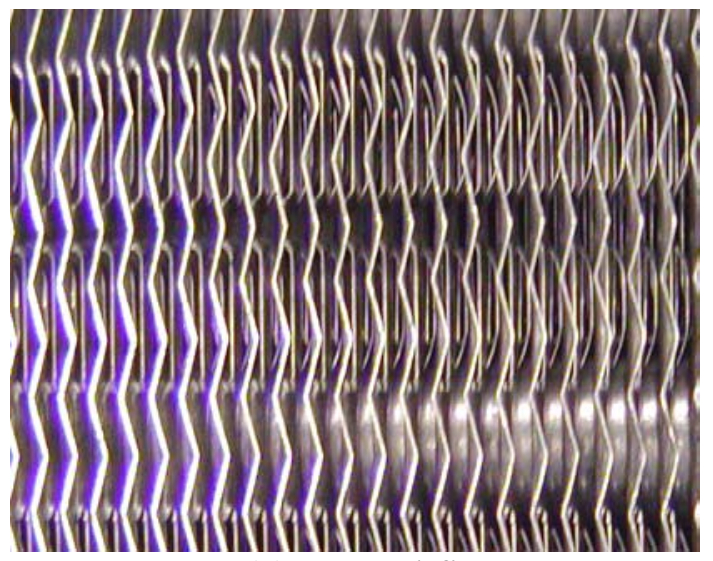

(a) Lanced fin

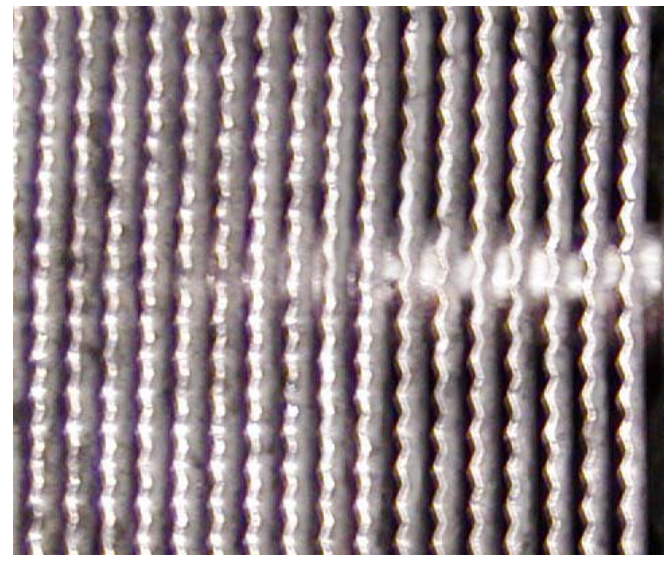

(b) Wavy fin

Figure 2.5: Lanced fin and wavy fin

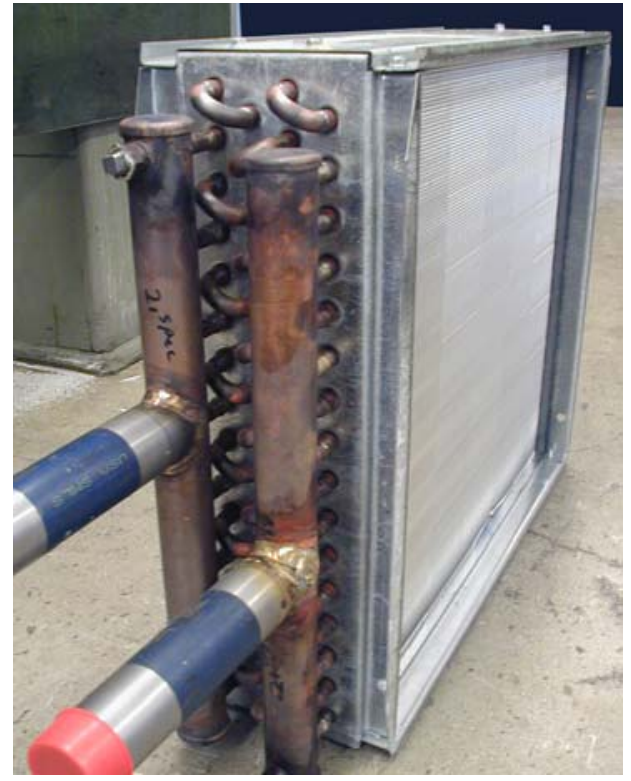

(a) HX4L

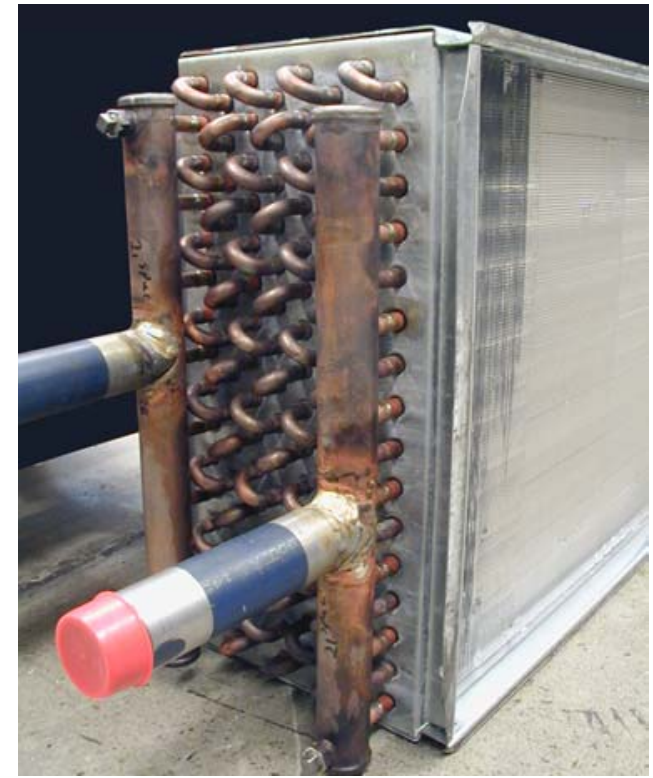

(b) HX8L

Figure 2.6: Photographs of coils HX4L and HX8L 


$$
\begin{aligned}
& \text { 8-row: Fin Spacing: } 8 \\
& \mathrm{D}: 12.7 \mathrm{~mm}(0.5 \text { inch }) \\
& \mathrm{Pt}=33 \mathrm{~mm}(1.3 \text { inch }) \\
& \mathrm{Pl}=38.1 \mathrm{~mm}(1.5 \mathrm{inch}) \\
& \text { circuit: } 8
\end{aligned}
$$

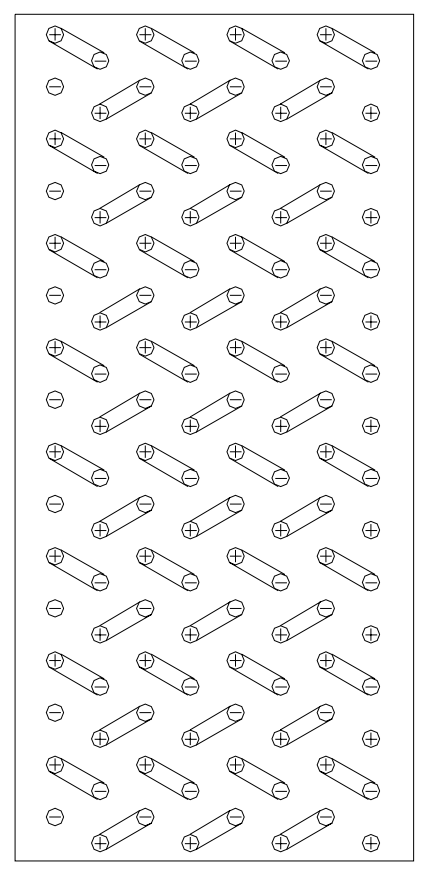

4-row: Fin Spacing:12

D: $12.7 \mathrm{~mm}(0.5$ inch $)$

$\mathrm{Pt}=33 \mathrm{~mm}(1.3 \mathrm{inch})$

$\mathrm{Pl}=38.1 \mathrm{~mm}(1.5 \mathrm{inch})$

circuit:8

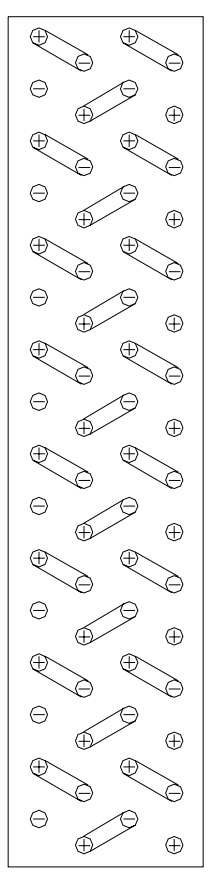

2-row: Fin Spacing:14

D: $9.5 \mathrm{~mm}(3 / 8$ inch $)$

$\mathrm{Pt}=22 \mathrm{~mm}(0.866$ inch $)$

$\mathrm{Pl}=25.4 \mathrm{~mm}(1 \mathrm{inch})$

circuit: 6

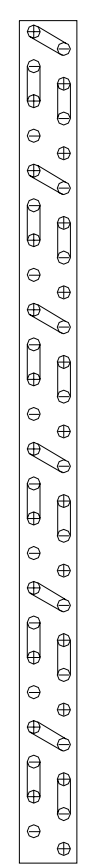

Figure 2.7: Water Circuit Arrangements of Test Coils

( $D$ : tube diameter; $P_{l}$ : longitudinal tube pitch; $P t$ : transverse tube pitch)

\subsubsection{Test filters}

A total of six types of filters were used in this project. Five types of filters were tested as upstream filters located before the test coil and another type of filter (pocket filter) was used as the final filter located downstream of the test coil. The MERV values of the filters ranged from 4 to 14 . All these filters were clean when originally inserted in the wind tunnel and replaced with new ones when the pressure drop at a rated velocity reached a manufacturer specified value. Table 2.2 gives details regarding the test filters. Figure 2.8 shows photographs of these filters. 
Table 2.2: Description of test filters

\begin{tabular}{|c|c|c|c|c|c|c|}
\hline & MERV4 & MERV6 & MERV8 & MERV11 & MERV14 & MERV14 \\
\hline Manufacturer & A & B & $\mathrm{C}$ & $\mathrm{C}$ & $\mathrm{C}$ & A \\
\hline Type & $\begin{array}{c}\text { Fiberglass } \\
\text { Media }\end{array}$ & $\begin{array}{c}\text { Pleated } \\
\text { Filters }\end{array}$ & $\begin{array}{l}\text { Pleated } \\
\text { Filter }\end{array}$ & $\begin{array}{l}\text { Mini-Pleat } \\
\text { Filter }\end{array}$ & $\begin{array}{l}\text { Mini-Plea } \\
\text { t Filter }\end{array}$ & Pocket Filter \\
\hline Arrestance & $75-80 \%$ & $90-95 \%$ & $95 \%$ & $99 \%$ & $99 \%$ & $99 \%$ \\
\hline Efficiency & $<20 \%$ & $25-30 \%$ & $30-40 \%$ & $60-65 \%$ & $90-95 \%$ & $90-95 \%$ \\
\hline Size $(\mathrm{mm})$ & \multicolumn{3}{|c|}{$\begin{array}{l}610 \times 610 \times 51 \\
(24 ” \times 24 ” \times 2 ”)\end{array}$} & \multicolumn{2}{|c|}{$\begin{array}{l}610 \times 610 \times 102 \\
(24 ” \times 24 ” \times 4 ”)\end{array}$} & $\begin{array}{l}610 \times 610 \times 559 \\
(24 " \times 24 " \times 22 ")\end{array}$ \\
\hline $\begin{array}{c}\text { Clean Pressure Drop } \\
\text { at } 2.54 \mathrm{~m} / \mathrm{s} \\
(500 \mathrm{ft} / \mathrm{min})\end{array}$ & $\begin{array}{l}59.8 \mathrm{~Pa} \\
(0.24 ”)\end{array}$ & $\begin{array}{l}79.7 \mathrm{~Pa} \\
(0.32 ”)\end{array}$ & $\begin{array}{l}59.8 \mathrm{~Pa} \\
(0.24 ”)\end{array}$ & $\begin{array}{c}93.4 \mathrm{~Pa} \\
\left(0.375^{\prime \prime}\right)\end{array}$ & $\begin{array}{l}190.6 \mathrm{~Pa} \\
\left(0.765^{\prime \prime}\right)\end{array}$ & $\begin{array}{c}124.6 \mathrm{~Pa} \\
\left(0.5^{\prime}\right)\end{array}$ \\
\hline $\begin{array}{c}\text { Replacement } \\
\text { Pressure Drop at } \\
2.54 \mathrm{~m} / \mathrm{s}(500 \mathrm{ft} / \mathrm{min})\end{array}$ & $\begin{array}{c}124.6 \mathrm{~Pa} \\
(0.5 ”)\end{array}$ & $\begin{array}{c}249.1 \mathrm{~Pa} \\
(1.0 ”)\end{array}$ & $\begin{array}{c}249.1 \mathrm{~Pa} \\
\left(1.0^{\prime \prime}\right)\end{array}$ & $\begin{array}{c}373.7 \mathrm{~Pa} \\
(1.5 ")\end{array}$ & $\begin{array}{c}373.7 \mathrm{~Pa} \\
(1.5 ”)\end{array}$ & $\begin{array}{c}373.7 \mathrm{~Pa} \\
(1.5 ”)\end{array}$ \\
\hline
\end{tabular}




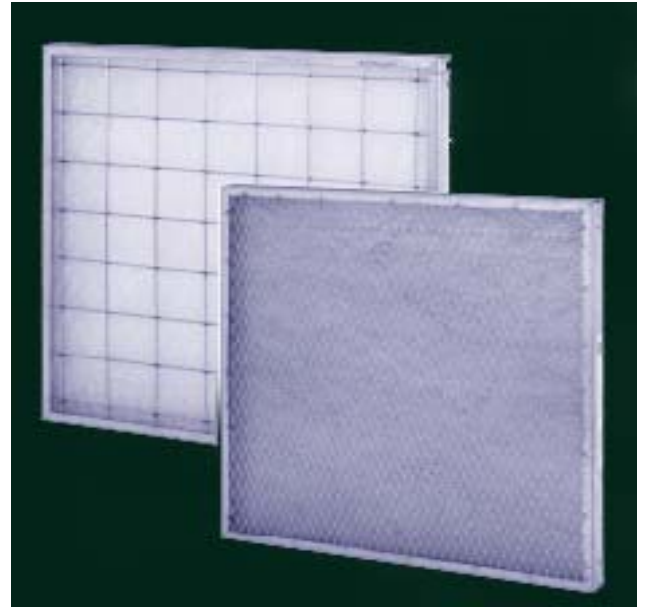

(1) MERV 4

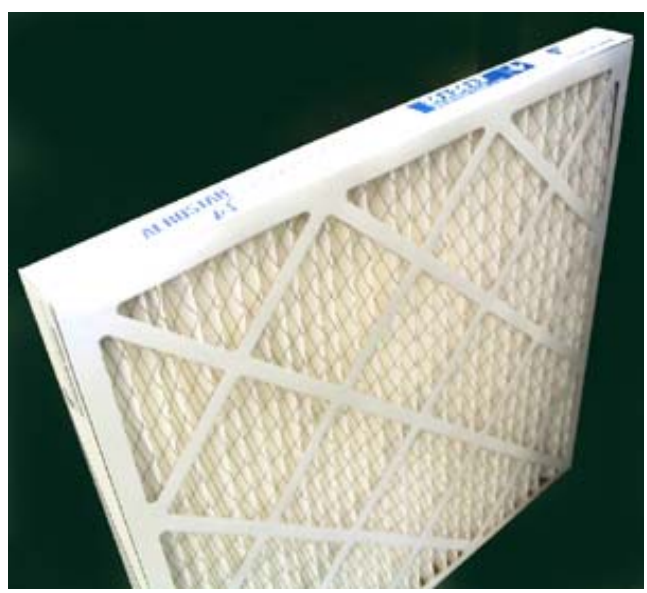

(3) MERV 8

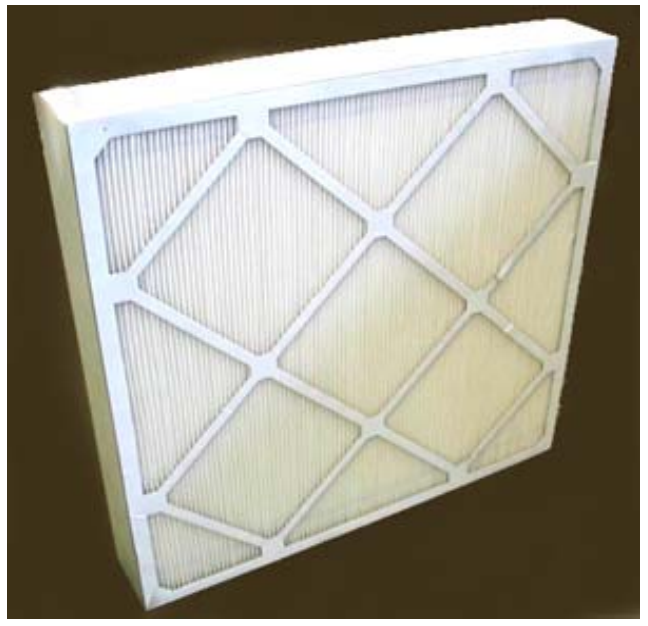

(5) MERV 14

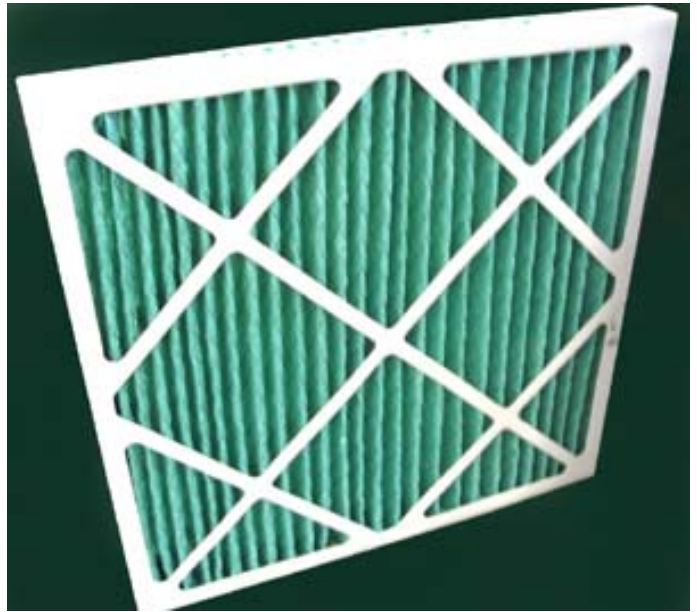

(2) MERV 6

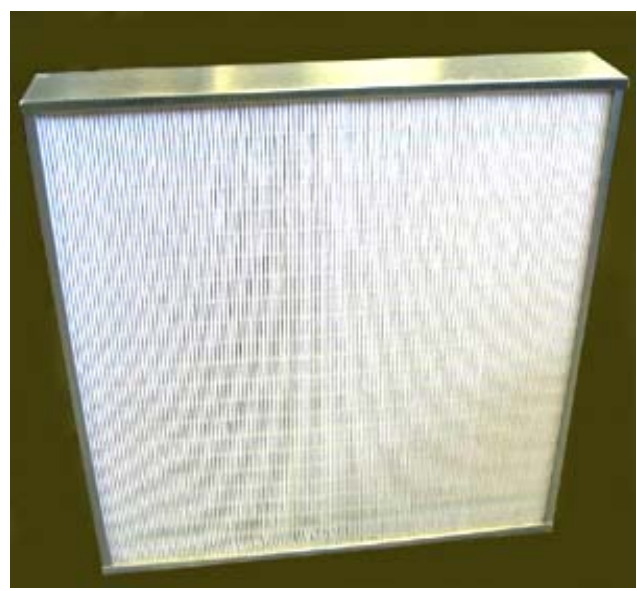

(4) MERV 11

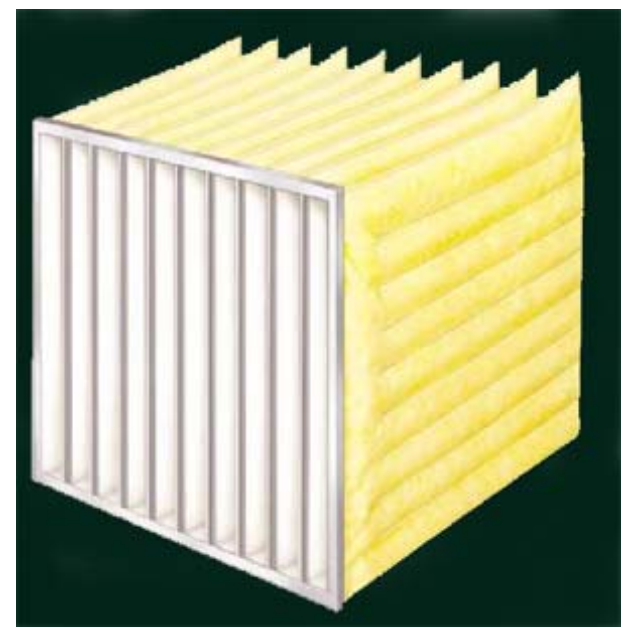

(6) MERV 14 (downstream filter)

Figure 2.8: Filter photographs 


\subsection{Instrumentation}

\subsubsection{Temperature}

A total of 28 K-type thermocouples and 2 thermistors were used to measure temperatures of air and water. In order to get accurate air temperatures, three thermocouple grids, each comprised of 9 thermocouples, were located before and after the test coil (see Figure 2.1) to measure the inlet and outlet air dry bulb temperature. For this project, only the upstream and the second downstream grids were used. Figure 2.9 shows the thermocouple locations within each grid. The dry bulb air temperatures were measured with an accuracy of $\pm 0.2^{\circ} \mathrm{C}$ $\left( \pm 0.36^{\circ} \mathrm{F}\right)$. The method for determining the air temperature was in accordance with the ASHRAE Standard 41.1-1986.

Another K-type thermocouple was located before the pitot tubes to provide a temperature value for calculating air density, which was used to obtain the air velocity.

Two thermistors were submerged in the centerline of the water flow at the inlet and outlet of the coil. They were designed to measure liquid temperature and the accuracy was calibrated to $\pm 0.2{ }^{\circ} \mathrm{C}\left( \pm 0.36^{\circ} \mathrm{F}\right)$.

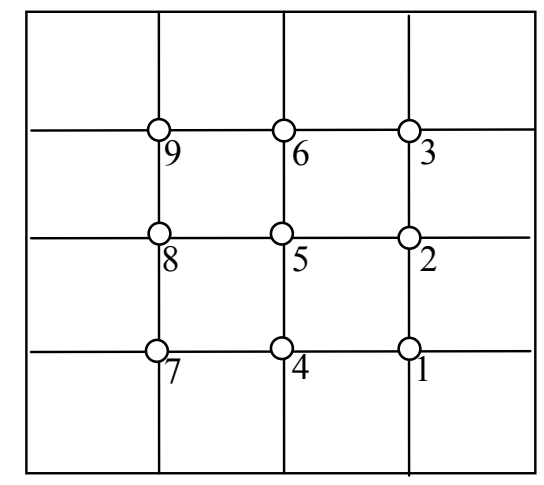

Figure 2.9: Thermocouple locations within the temperature grid

\subsubsection{Air Relative Humidity}

Most tests were performed at conditions where moisture condensed on the coil. Hence, the air relative humidity was a critical value to calculate the air-side total heat transfer rate. Two relative humidity transmitters were mounted beside the two thermocouple grids (see 
Figure 2.1). A sensor is incorporated with the humidity transmitter and measures the relative humidity by a thin polymer film that can either absorb or release water vapor from the ambient air. The accuracy of the instrument is $\pm 1 \%$ of the reading when RH is below $90 \%$, and $\pm 2 \%$ when $\mathrm{RH}$ is above $90 \%$.

\subsubsection{Pressure Drop}

Three differential pressure transducers were used to measure the static pressure drop of the upstream filter, downstream filter and test coil. There were four groups of pressure tap holes located before and after these components. For each group, four tap holes were located on each face of the duct and connected to a common hose. The average pressure signal was transmitted into the inlet or outlet of the differential pressure transducer through the hose. The range of these pressure transducers was 0-1246 $\mathrm{Pa}\left(0-5 \mathrm{inH}_{2} \mathrm{O}\right)$, and the accuracy was $\pm 1.0 \%$ of full scale.

Another differential pressure transducer was used to measure the average velocity pressure of the pitot tube array. The range was $0-24.9 \mathrm{~Pa}\left(0-0.1 \mathrm{inH}_{2} \mathrm{O}\right)$, and the accuracy was $\pm 0.25 \%$ of full scale.

\subsubsection{Air Flow Rate}

The test air flow rates ranged from $0.6 \mathrm{~m}^{3} / \mathrm{s}\left(1200 \mathrm{ft}^{3} / \mathrm{min}\right)$ to $1.1 \mathrm{~m}^{3} / \mathrm{s}\left(2400 \mathrm{ft}^{3} / \mathrm{min}\right)$. It was obtained from the average air velocity measured by the pitot tube array. The equation $V(m / s)=1.414 \sqrt{\frac{P_{v}(P a)}{\rho\left(k g / m^{3}\right)}}$ was used to calculate the average air velocity, where $P_{v}$ was obtained from the differential pressure transducer of the pitot tube array and $\rho$ was air density at the location of the pitot tubes.

In order to investigate the impact of the upstream filter on air velocity distribution, the distribution was measured for both no filter and filter conditions. The location of the cross section where the velocity measurements were taken, as well as the location of the velocity measurements within the cross sections is shown in Figures 2.10 and 2.11. The test filter was an extended surface pleated panel filter with the thickness of $102 \mathrm{~mm}$ (4"). Figure 2.12 indicates the velocity distribution without upstream filter and Figure 2.13 indicates the velocity distribution with the filter in place. Both distributions were measured from line B, 
shown in Figure 2.11.

From Figures 2.12 and 2.13 , the velocities vary approximately $7 \%$ for the no-filter case and approximately $34 \%$ for filter case. The measurements from lines A, C and D had similar range of variations.

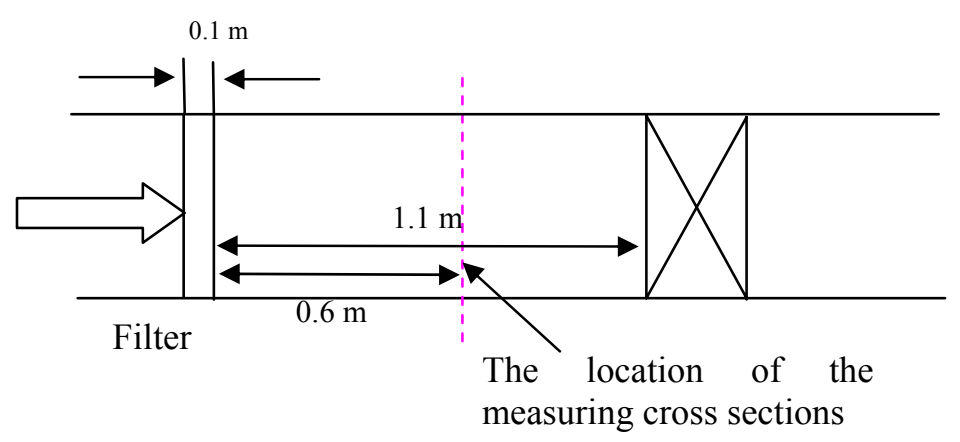

Figure 2.10: The locations of the test cross-sections

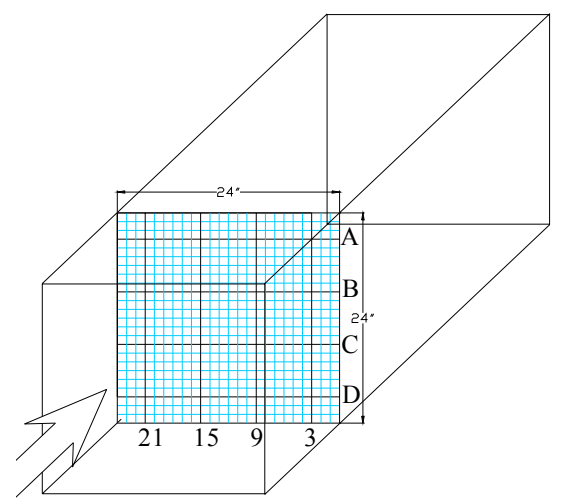

Figure 2.11: The velocity measurement locations

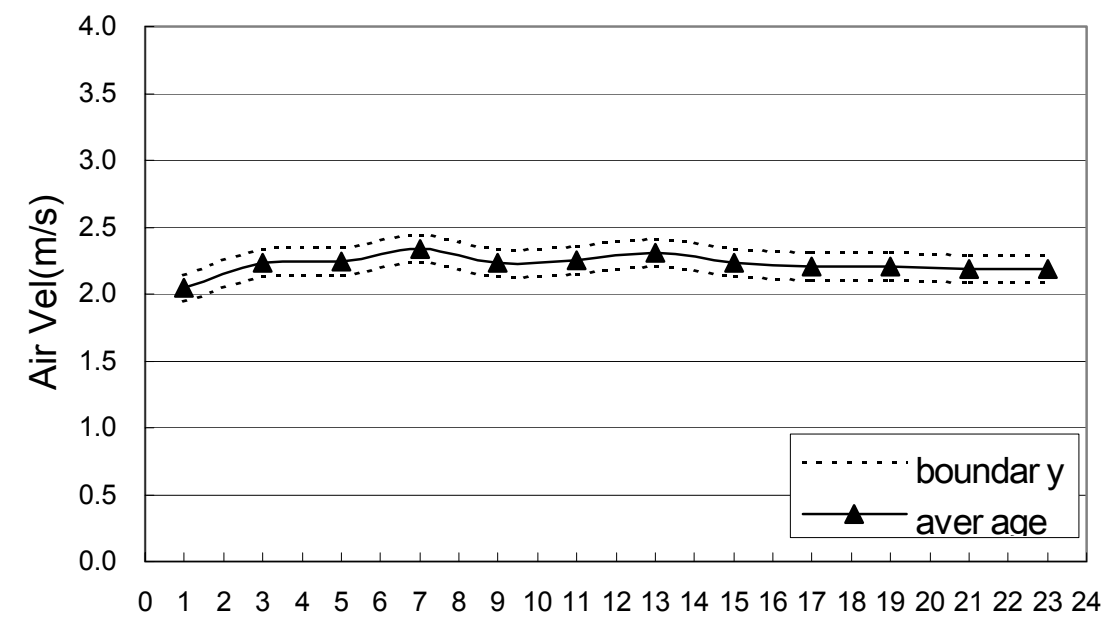

Figure 2.12: Air velocity distribution at line B of measuring section without filter 


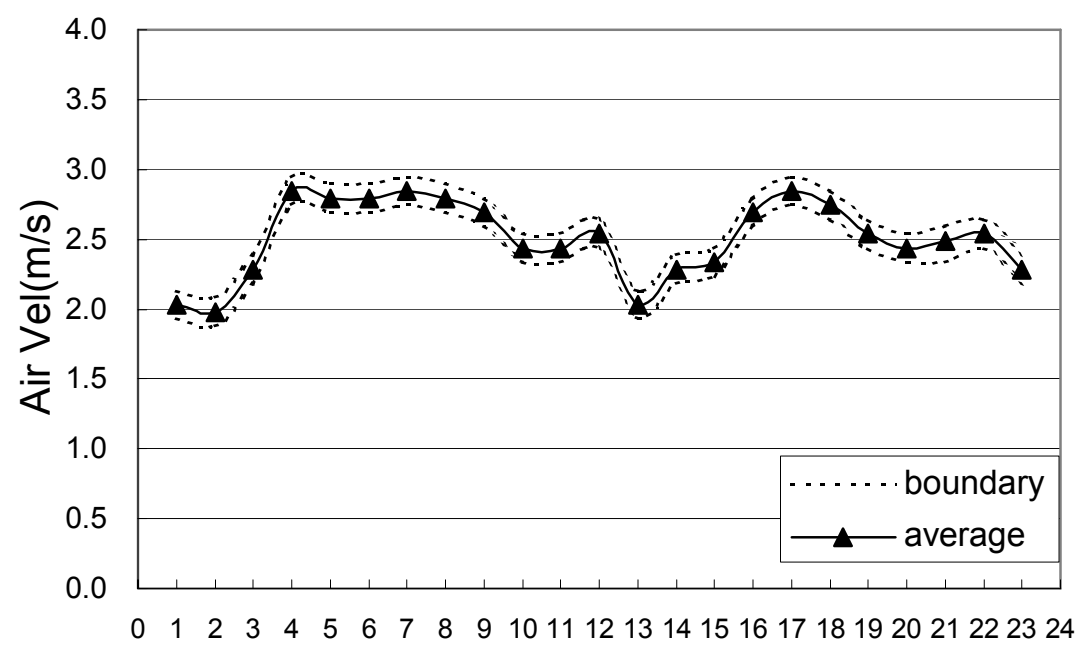

Figure 2.13: Air velocity distribution at line B of measuring section for the pleated filter

\subsubsection{Water Flow Rate}

The water mass flow rate was measured using a Micro Motion mass flow meter. The nominal flow rate of the mass flow meter ranges from 0 to $0.0045 \mathrm{~m}^{3} / \mathrm{s}$ (72 GPM). The accuracy is $\pm 0.5 \%$ of the indicated value.

\subsection{Data Acquisition and Control System}

The output of voltages and amperes of the instrumentation was collected by a Hewlett Packard Model 75000 Series B data acquisition system and converted to digital signals. The data acquisition software HP VEE (Visual Engineering Environment) was used to read the signals from the PC. All the measurement data was displayed in real time within the HP VEE windows and stored in a data file simultaneously. MicroSoft Excel and EES (Engineering Equation Solver) were applied for further calculations.

A LabVIEW control program was written to access the measurement data through the data acquisition system and outputted the control commands using a PCI analog output board. The controlled devices were:

(1) Variable speed fan for delivering different air flow rates

(2) Humidifier for achieving different air humidity ratios

(3) Electric heater for maintaining air inlet temperature 
The air flow rate control was an open-loop control while air inlet humidity and temperature control were close-loop controls. The fan speed needed to be adjusted manually using the computer interface to obtain a specific air flow rate, whereas the temperature and humidity controls were automatically adjusted to adhere to a set point. The water flow rate was adjusted manually because it was constant for all test cases. Figure 2.14 shows a simplified schematic of the data acquisition and control system.

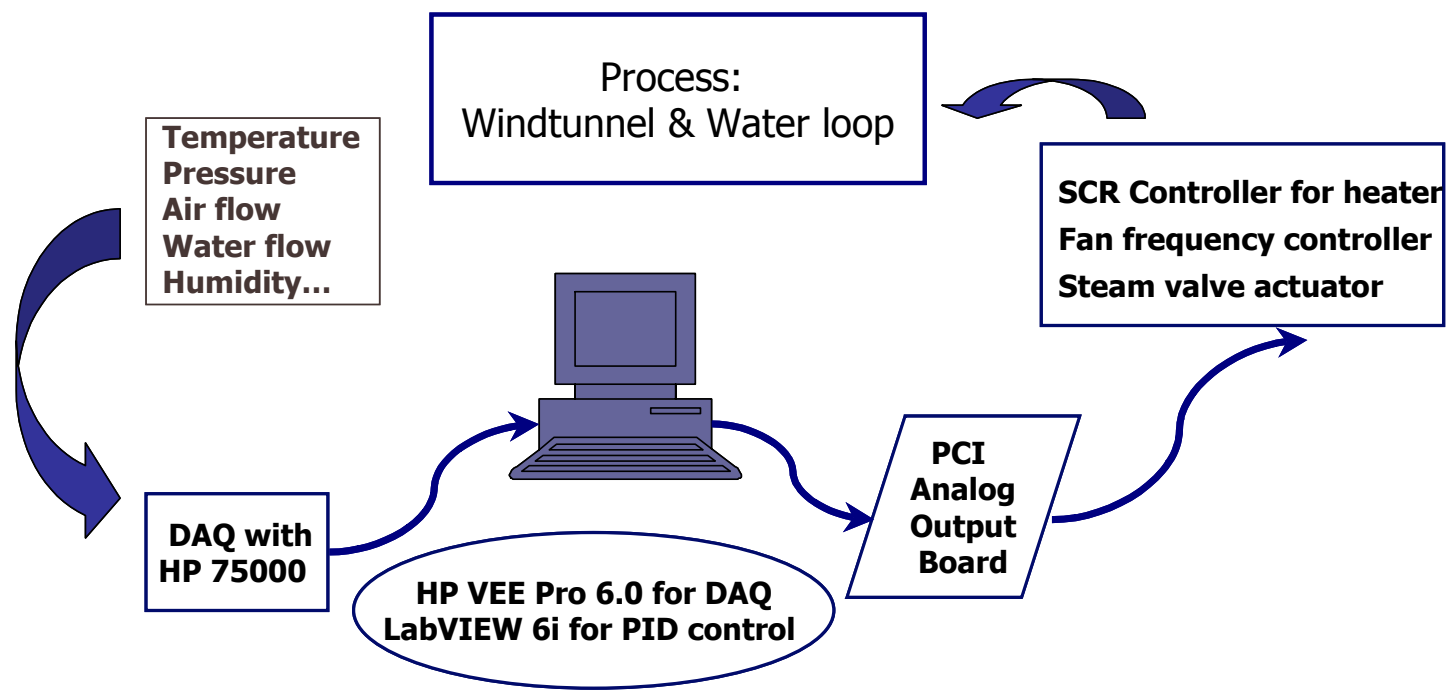

Figure 2.14: Schematic diagram of data acquisition and control system

\subsection{Data Analysis}

\subsubsection{Coil Air-side Pressure Drop and Error Analysis}

\subsubsection{Coil air-side pressure drop}

The coil air-side pressure drop was obtained directly in HP VEE program by converting the pressure transducer voltage signal to a digital signal. Pressure drop correlations were determined for the coils under clean and fouled condition using:

$$
\Delta P_{c, c}=a_{c} V^{b_{c}} \text { or } \Delta P_{c, f}=a_{f} V^{b_{f}}
$$

where $\Delta P_{c, c}$ is the coil air-side pressure drop at clean conditions and $\Delta P_{c, f}$ is the coil air-side pressure drop at fouled conditions. The coefficients $a_{c}, b_{c}, a_{f}, b_{f}$ were determined using regression for each coil and set of tests. (See Appendix 1, Table A1) 


\subsubsection{Pressure drop error analysis}

The measurement error of the coil air-side pressure drop results from the uncertainty of two differential pressure transducers: one was employed to measure coil pressure drop and ranged from $0 \mathrm{~Pa}\left(0 \mathrm{inH}_{2} \mathrm{O}\right)$ to $1246 \mathrm{~Pa}\left(5 \mathrm{inH}_{2} \mathrm{O}\right)$ with an accuracy of $\pm 1.0 \%$ of full scale; another was used to measure the velocity pressure through the pitot tubes and ranged from $0 \mathrm{~Pa}\left(0 \mathrm{inH}_{2} \mathrm{O}\right)$ to $24.9 \mathrm{~Pa}\left(0.1 \mathrm{inH}_{2} \mathrm{O}\right)$ with an accuracy of $\pm 0.25 \%$ of full scale. The measured coil air-side pressure drop had an error of $\pm 12.5 \mathrm{~Pa}\left( \pm 0.05 \mathrm{inH}_{2} \mathrm{O}\right)$ and the error of measured air velocity was obtained by:

$$
d V=\sqrt{\frac{2}{\rho P_{v}}} d P_{v}
$$

where $P_{v}$ is the pitot tubes pressure measurement; $\rho$ is air density, which is regarded as a constant $1.176 \mathrm{~kg} / \mathrm{m}^{3}\left(0.0734 \mathrm{lbm} / \mathrm{ft}^{3}\right) ; d P_{v}$ is the error of the pressure transducer which was estimated as $\pm 0.062 \mathrm{~Pa}\left( \pm 2.5 \times 10^{-4} \mathrm{inH}_{2} \mathrm{O}\right) . \quad d V=\sqrt{\frac{2}{\rho P_{v}}} d P_{v}$ was estimated as shown in Table 2.3. From Equation (2.2) it can be seen that when $P_{v}$ is greater (higher velocity), $d V$ is smaller.

Table 2.3: The error of air velocity $(d V)$ vs. air velocity

\begin{tabular}{|l|l|l|l|l|}
\hline$V(\mathrm{~m} / \mathrm{s})$ & $\begin{array}{l}1.52 \\
(300 \mathrm{ft} / \mathrm{min})\end{array}$ & $\begin{array}{l}2.03 \\
(400 \mathrm{ft} / \mathrm{min})\end{array}$ & $\begin{array}{l}2.54 \\
(500 \mathrm{ft} / \mathrm{min})\end{array}$ & $\begin{array}{l}3.05 \\
(600 \mathrm{ft} / \mathrm{min})\end{array}$ \\
\hline$d V(\mathrm{~m} / \mathrm{s})$ & $\begin{array}{l}0.035 \\
(6.9 \mathrm{ft} / \mathrm{min})\end{array}$ & $\begin{array}{l}0.027 \\
(5.3 \mathrm{ft} / \mathrm{min})\end{array}$ & $\begin{array}{l}0.021 \\
(4.1 \mathrm{ft} / \mathrm{min})\end{array}$ & $\begin{array}{l}0.018 \\
(3.5 \mathrm{ft} / \mathrm{min})\end{array}$ \\
\hline
\end{tabular}

The error analysis was used to obtain the error bounds for the data. Figure 2.15 shows the baseline pressure drops and error bounds for HX8L. Six sets of baseline tests were conducted with HX8L corresponding to each fouling case. The baseline pressure drop results are all within the error range except for the two cases at the highest airflow. Thus, differences in the baselines were most likely caused by instrument errors and not by inadequate cleaning procedures following the fouling tests. (See Appendix 2, Figures A1-A4 for the error bounds for all coil cases) 


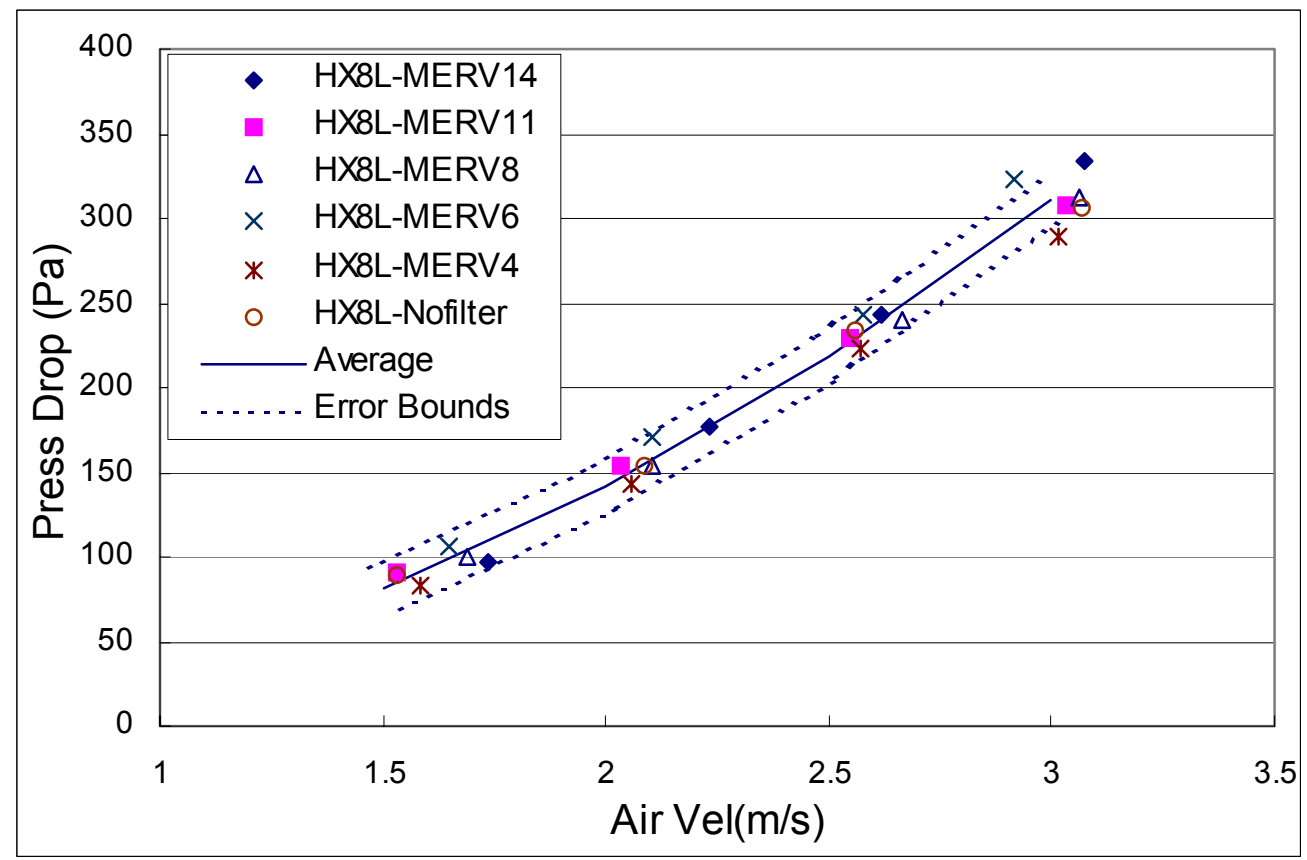

Figure 2.15: Pressure drop baseline and error bounds for HX8L

The relative pressure drop errors for the baseline tests of all the coils appear in Table 2.4. At lower air velocity and lower coil air-side pressure drop, the relative error is higher, because the absolute error caused by the two pressure transducers is the same for all air velocities.

Table 2.4: Relative pressure drop errors of different coil cases at four air velocities for baseline tests

\begin{tabular}{|c|c|c|c|c|}
\hline Air Vel (m/s) & HX8L & HX8W & HX4L & HX2L \\
\hline 1.53 & $12.4 \%$ & $15.4 \%$ & $20.0 \%$ & $27.9 \%$ \\
\hline 2.04 & $7.6 \%$ & $8.8 \%$ & $12.2 \%$ & $19.1 \%$ \\
\hline 2.54 & $5.2 \%$ & $5.7 \%$ & $8.3 \%$ & $14.3 \%$ \\
\hline 3.05 & $3.8 \%$ & $4.0 \%$ & $6.1 \%$ & $11.2 \%$ \\
\hline
\end{tabular}




\subsubsection{Coil Air-side Effective Heat Transfer Coefficient and Error Analysis}

2.5.2.1 Coil air-side effective heat transfer coefficient

The coil air-side effective heat transfer coefficient is determined from an overall model of the coil assuming that the coil waterside heat transfer coefficients is known.

A general formula for calculating the liquid heat transfer coefficients is:

$$
N u_{D}=h_{w} \frac{D_{i}}{k_{w}}
$$

For turbulent flow, the Nusselt number $N u_{D}$ can be determined by the Gnielinski correlation:

$$
N u_{D}=\frac{(f / 8)\left(\operatorname{Re}_{D}-1000\right) \operatorname{Pr}}{1+12.7(f / 8)^{1 / 2}\left(\operatorname{Pr}^{2 / 3}-1\right)}
$$

where $f$, the friction factor, is given by Petukhov equation:

$$
f=\left(0.790 \ln \mathrm{Re}_{D}-1.64\right)^{-2}
$$

For Equations (2.4) and (2.5) the fluid condition should be:

$3000<\operatorname{Re}_{D}<5 \times 10^{6}$ and $0.5<\operatorname{Pr}<2000$

The air-side effective heat transfer coefficients for the coils were deduced using the model given in ASHRAE Handbook: "2000 HVAC Systems and Equipment”, Chapter 21.

Figure 2.16 shows a typical thermal diagram of a coil surface that is partially wet and dry. Condensation occurs at the point within the coil where the surface temperature equals the dewpoint of the air. For completeness, the analysis described in the ASHRAE Equipment Handbook that was used to determined air-side heat transfer coefficients is repeated below. 


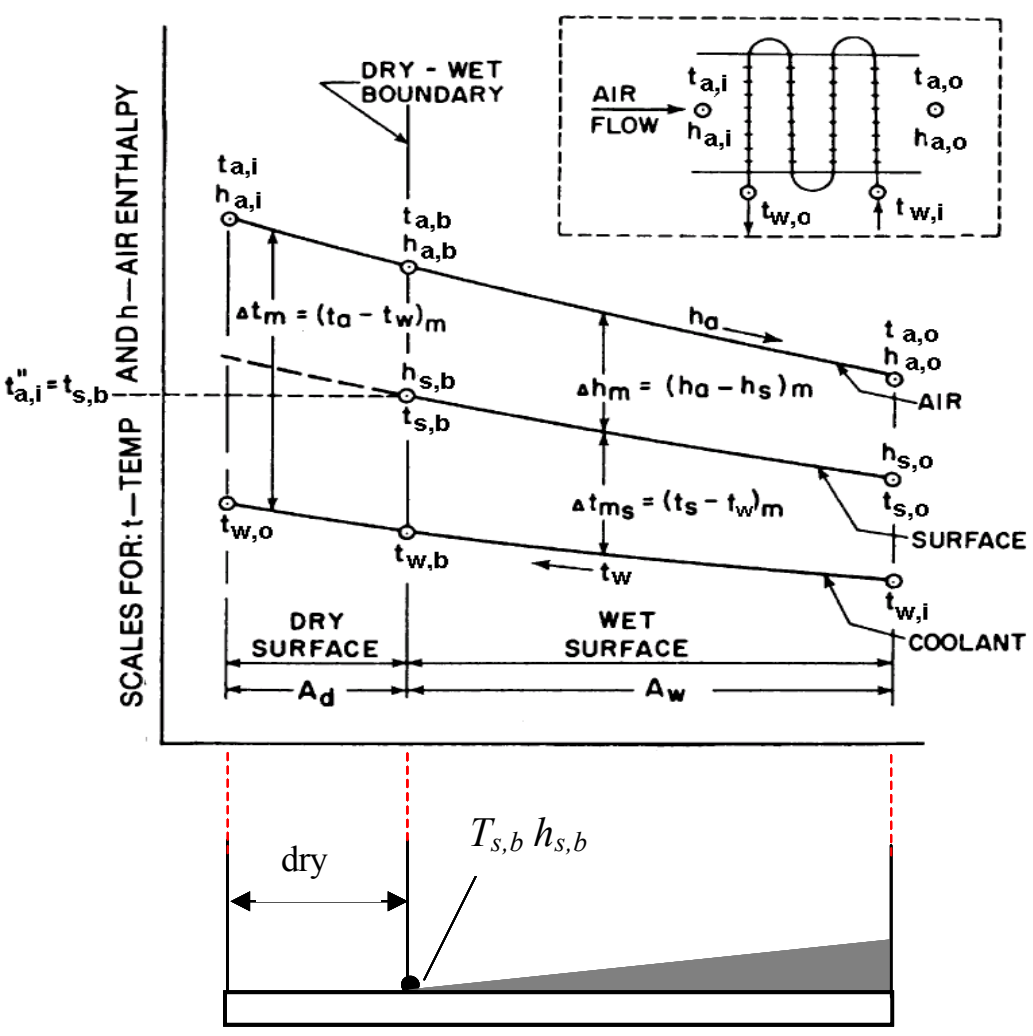

Figure 2.16: Thermal Diagram for General Case When Coil Surface Operates Partially Dry

(Fig. 9, ASHRAE Handbook: "2000 HVAC Systems and Equipment”, Chapter 21)

If $h_{a, b} \geqslant h_{a, i}$, the surface is fully wetted

If $h_{a, i}>h_{a, b}>h_{a, o}$, the surface is partially wet

If $h_{a, b} \leqslant h_{a, o}$, the surface is completely dry

The surface area of the dry portion of the coil is determined from:

$$
A_{d}=q_{d} R_{o} / \Delta t_{m}
$$

where $q_{d}$ is the heat transfer rate for the dry surface. $R_{o}$ is defined as:

$$
R_{o}=R_{a d}+R_{m d}+R_{w}
$$

where:

$$
\begin{aligned}
R_{a d} & =1 / \eta_{d} h_{a d} \\
R_{w} & =B / h_{w} \\
\Delta t_{m} & =\frac{\left(t_{a, i}-t_{w, o}\right)-\left(t_{a, b}-t_{w, b}\right)}{\ln \left[\left(t_{a, i}-t_{w, o}\right) /\left(t_{a, b}-t_{w, b}\right)\right]}
\end{aligned}
$$


$\eta_{d} h_{a d}$ is the effective heat transfer coefficient at dry conditions. For partially wet coils, the dry and wet effective heat transfer coefficients $\left(\eta_{w} h_{a w}\right)$ were assumed to be the same for two reasons: (1) Test data for all dry and wet conditions indicated that $\eta_{d} h_{a d}$ and $\eta_{w} h_{a w}$ were within 5\% except for one measurement at the lowest air velocity. (2) For partially wet coil conditions, the dry area was much smaller than the wet area for the conditions considered in this study. The ratio of dry area to the wet area was less than 0.1 for all partially wet cases considered in this study. $R_{m d}$ is the dry metal resistance, which was estimated to be $0.004 \mathrm{~m}^{2} \mathrm{~K} / \mathrm{W} . B$ is the ratio of external to internal surface area.

The wet surface area can be obtained from:

$$
\begin{aligned}
& A_{w}=q_{w} R_{a w} C_{p} / \Delta h_{m} \\
& \text { where: } R_{a w}=1 / \eta_{w} h_{a w}
\end{aligned}
$$

$\eta_{w} h_{a w}$ is coil air-side effective heat transfer coefficient at wet conditions, which was desired in the study and expressed as $h_{a, c}$ or $h_{a, f}$ in the following sections. The mean effective difference in air enthalpy between air stream and surface is:

$$
\Delta h_{m}=\frac{\left(h_{a, b}-h_{s, b}\right)-\left(h_{a, o}-h_{s, o}\right)}{\ln \left[\left(h_{a, b}-h_{s, b}\right) /\left(h_{a, o}-h_{s, o}\right)\right]}
$$

where $h_{a, b}$ is the air stream enthalpy at the dry-wet boundary; $h_{s, b}$ is the air enthalpy of saturated air corresponding to the coil surface temperature at the boundary; $h_{a, o}$ and $h_{s, o}$ are the air outlet enthalpy and air outlet enthalpy of saturated air corresponding to the surface temperature, respectively. (See Figure 2.16)

The dry-wet boundary conditions can be determined from the following relationships:

$$
\begin{aligned}
& y=\frac{t_{w, o}-t_{w, i}}{h_{a, i}-h_{a, o}} \\
& h_{a, b}=\frac{t_{s, b}-t_{w, o}+y h_{a, i}+C h_{a, i}^{\prime \prime}}{C+y}
\end{aligned}
$$




$$
C=\frac{R_{m w}+R_{w}}{C_{p} R_{a w}}
$$

The coil surface temperature at boundary $t_{s, b}$ equals the inlet air dew-point temperature $t_{a, i}$. $h_{a, i}^{\prime \prime}$ is air enthalpy at the inlet air dew-point temperature. $R_{m w}$ is the wet metal resistance, which was estimated to be $0.003 \mathrm{~m}^{2} \mathrm{~K} / \mathrm{W}$.

Another two equations are necessary to complete the model:

$$
\begin{aligned}
& A_{o}=A_{d}+A_{w} \\
& q=q_{d}+q_{w}
\end{aligned}
$$

where $A_{o}$ is coil total external surface area and $q$ is the total heat capacity.

Because the coil surface condition and dry-wet boundary were both unknown, a trial-and-error solution was necessary. The model was implemented in the EES program and used to determine effective heat transfer coefficients from air-side and water-side measurements.

Using the experimental data, four average effective heat transfer coefficients were obtained at four air velocities for each test case. The effective heat transfer coefficients were correlated using the following forms:

$$
h_{a, c}=c_{c} V^{d_{c}} \text { or } h_{a, f}=c_{f} V^{d_{f}}
$$

where $h_{a, c}$ is the coil air-side effective heat transfer coefficient at clean conditions and $h_{a, f}$ is the coil air-side effective heat transfer coefficient at fouled conditions. The coefficients $c_{c}$, $d_{c}, c_{f}, d_{f}$ were determined using regression. (See Appendix 1, Table 2)

\subsubsection{Effective heat transfer coefficient error analysis}

The effective heat transfer coefficient is an implicit function of many variables and iteration is required to determine the error. It could be expressed as a function of eight measurement variables as:

$$
h_{a}=f\left(X_{1}, X_{2}, X_{3}, X_{4}, X_{5}, X_{6}, X_{7}, X_{8}\right)
$$

where: $X_{1}=T_{a, i} \quad X_{2}=T_{a, o}$ 


$$
\begin{array}{ll}
X_{3}=T_{w, i} & X_{4}=T_{w, o} \\
X_{5}=R H_{i} & X_{6}=R H_{o} \\
X_{7}=V & X_{8}=M_{w}
\end{array}
$$

and $h_{a}+d h_{a}=f\left(X_{1}+d X_{1}, X_{2}+d X_{2} \cdots X_{8}+d X_{8}\right)$

where $d X_{1}, d X_{2}, \ldots d X_{8}$ are independent errors. Considering these errors separately:

$$
\begin{aligned}
& h_{a}+d h_{a n}=f\left(X_{1}, X_{2} \cdots\left(X_{n}+d X_{n}\right) \cdots X_{8}\right) \quad n \text { : from } 1 \text { to } 8 \\
& \text { and } d h_{a}= \pm \sqrt{\sum_{n=1}^{8}\left(d h_{a n}\right)^{2}}
\end{aligned}
$$

A small deviation $d X_{n}$ (equal to the uncertainty of the measurement) is applied to the variables and the variation of effective heat transfer coefficient is determined numerically using Equation (2.22) and (2.23).

Table 2.5 shows the uncertainties of the eight measurements. Table 2.6 gives the sensitivity of effective heat transfer coefficient to the measurements for HX8L. Table 2.7 shows the total relative error of effective heat transfer coefficient for all coil cases at different air velocities. The errors were in the range of $3.5 \%-4.9 \%$ for all coils at baseline conditions.

Table 2.5: Uncertainties of measurements used to determine effective heat transfer coefficients

\begin{tabular}{|c|c|}
\hline Measurement data & Uncertainty \\
\hline $\mathrm{T}_{\mathrm{a} \_} \mathrm{i}, \mathrm{T}_{\mathrm{a} \_}{ }_{\mathrm{o}} \mathrm{T}_{\mathrm{W} \_} \mathrm{i}, \mathrm{T}_{\mathrm{W} \_\mathrm{o}}$ & $\pm 0.2^{\mathrm{o}} \mathrm{C}$ \\
\hline $\mathrm{RH} H_{\mathrm{i}}$ & \pm 0.01 (below 0.9 ) \\
\hline $\mathrm{RH}_{\mathrm{O}}$ & \pm 0.02 (above 0.9$)$ \\
\hline $\mathrm{M}_{\mathrm{W}}$ & $\pm 0.5 \%$ of indicated value \\
\hline $\mathrm{V}_{\mathrm{air}}$ & $\pm 0.04,0.03,0.02,0.02 \mathrm{~m} / \mathrm{s}$ \\
& (for $1.52,2.03,2.54,3.05 \mathrm{~m} / \mathrm{s}$ respectively) \\
\hline
\end{tabular}


Table 2.6: Sensitivity of effective heat transfer coefficient to the measurements (for HX8L) (Unit: $\mathrm{W} / \mathrm{m}^{2}-\mathrm{K}$ )

\begin{tabular}{|c|c|c|c|c|c|c|c|c|}
\hline $\mathrm{V}_{\text {air }}(\mathrm{m} / \mathrm{s})$ & $d h_{a 1}$ & $d h_{a 2}$ & $d h_{a 3}$ & $d h_{a 4}$ & $d h_{a 5}$ & $d h_{a 6}$ & $d h_{a 7}$ & $d h_{a 8}$ \\
\hline 1.52 & \pm 0.44 & \pm 0.50 & \pm 0.30 & \pm 1.11 & \pm 0.4 & \pm 0.47 & \pm 0.00 & \pm 0.01 \\
\hline 2.03 & \pm 0.52 & \pm 0.49 & \pm 0.32 & \pm 1.36 & \pm 0.4 & \pm 0.44 & \pm 0.07 & \pm 0.01 \\
\hline 2.54 & \pm 0.56 & \pm 0.61 & \pm 0.40 & \pm 1.50 & \pm 0.38 & \pm 0.56 & \pm 0.04 & \pm 0.01 \\
\hline 3.05 & \pm 0.63 & \pm 0.73 & \pm 0.44 & \pm 1.81 & \pm 0.36 & \pm 0.70 & \pm 0.05 & \pm 0.01 \\
\hline
\end{tabular}

Table 2.7: Relative error in effective heat transfer coefficient for different coils at four air velocity levels for baseline tests

\begin{tabular}{|c|c|c|c|c|}
\hline Air Vel (m/s) & HX8L & HX8W & HX4L & HX2L \\
\hline 1.52 & $3.7 \%$ & $4.0 \%$ & $3.5 \%$ & $3.5 \%$ \\
\hline 2.03 & $4.0 \%$ & $4.5 \%$ & $3.7 \%$ & $4.2 \%$ \\
\hline 2.54 & $4.3 \%$ & $4.7 \%$ & $4.0 \%$ & $4.2 \%$ \\
\hline 3.05 & $4.9 \%$ & $4.8 \%$ & $4.3 \%$ & $4.2 \%$ \\
\hline
\end{tabular}

Figure 2.17 shows the error bounds and baseline data for HX8L. All the baseline data ranged within the error bounds, which indicated that after cleaning, the heat transfer performance of the coils returned to their original conditions. (See Appendix 2, Figures A5-A8 for the error bounds of all coil cases) 


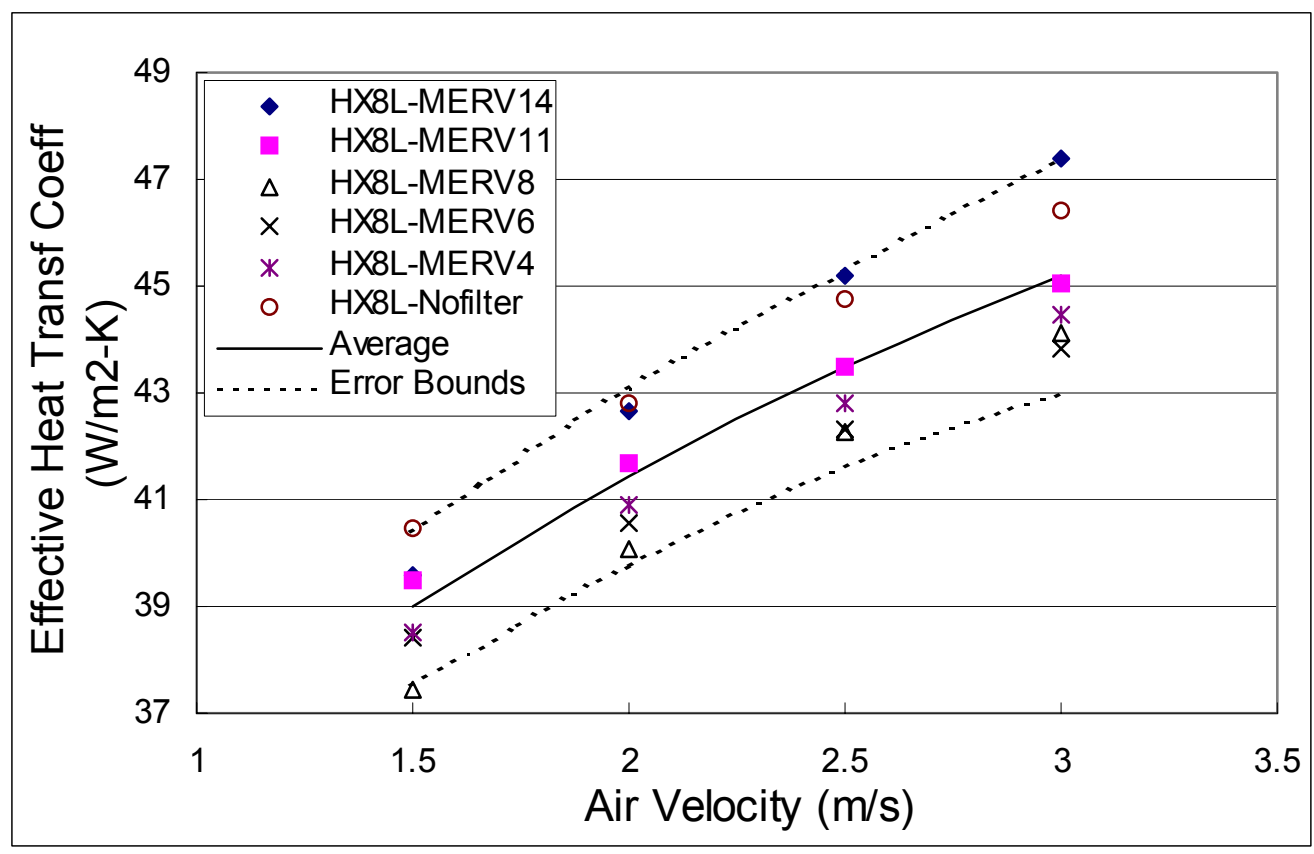

Figure 2.17: Effective heat transfer coefficient baseline and error bounds for HX8L

\subsection{Filter Evaluation and ASHRAE Standard Dust}

As described in section 2.2.4, the test filters were chosen based on MERV values, which are set forth in ASHRAE standard 52.2-1999. Compared to the older standard (ASHRAE standard 52.1-1992), the MERV rating is more complicated and synthetic and involves determining average efficiencies over a range of particle sizes. ASHRAE arrestance and ASHRAE dust-spot efficiency are two ways to evaluate filter performances in ASHRAE standard 52.1: the former way is to measure the percentage of the weight of ASHRAE dust (coarse dust) captured by the filter; and the latter is to compare the light transmission of stains on paper targets at both upstream and downstream of the filter using atmospheric dust (fine dust).

The study described here was based on ASHRAE arrestance. Thus, filter arrestances were measured through fouling tests and verified with those from manufacturers. Dust-spot efficiencies, however, were not obtained from tests and the manufacturers' values were chosen as references. 
The ASHRAE synthetic arrestance dust used in the experiment meets specifications set forth in ASHRAE 52.1. The compounded dust consists by weight of:

(1) $72 \%$ of standardized air cleaner test dust. It is predominantly silica and has a mass-mean diameter of approximately 7.7 micrometers.

(2) $23 \%$ of powdered carbon

(3) $5 \%$ of cotton linter

\subsection{Test Selection and Conditions}

Originally, six types of coils were to be tested. However, based on initial test results, tests of the four-row wavy-fin coil and the two-row wavy-fin coil were not performed and not all filters were considered for HX4L. The tests that were conducted are indicated in Table 2.8. All the cases shown in the table were performed at wet conditions. Another two tests (HX8L-No-filter-C-D and HX8L-MERV11-F-D) were carried out at dry conditions to understand the impact of moisture condensation on fouling.

Table 2.8: Test Matrix

\begin{tabular}{|c|c|c|c|c|c|c|}
\hline \multirow[t]{2}{*}{ Clean } & \multirow{2}{*}{\multicolumn{2}{|c|}{ No Filter }} & HX8L & HX8W & HX4L & HX2L \\
\hline & & & $X$ & X & $X$ & $X$ \\
\hline \multirow[t]{6}{*}{ Fouling } & \multirow[t]{5}{*}{ Filter } & MERV4 & $X$ & $X$ & $\mathrm{X}$ & $\mathrm{X}$ \\
\hline & & MERV6 & $\mathrm{X}$ & $\mathrm{X}$ & -- & $\mathrm{X}$ \\
\hline & & MERV8 & $\mathrm{X}$ & $\mathrm{X}$ & $\mathrm{X}$ & $\mathrm{X}$ \\
\hline & & MERV11 & $\mathrm{X}$ & $\mathrm{X}$ & -- & $\mathrm{X}$ \\
\hline & & MERV14 & $X$ & $\mathrm{X}$ & -- & $\mathrm{X}$ \\
\hline & \multicolumn{2}{|c|}{ No Filter } & $\mathrm{X}$ & $X$ & $\mathrm{X}$ & $X$ \\
\hline
\end{tabular}

The experimental conditions were set as:

(1) Air velocity: $1.52,2.03,2.54,3.05 \mathrm{~m} / \mathrm{s}(300,400,500,600 \mathrm{ft} / \mathrm{min})$

(2) Air inlet dry-bulb temperature: $T_{a, i}=26.7^{\circ} \mathrm{C}\left(80^{\circ} \mathrm{F}\right)$

(3) Air inlet relative humidity: $R H_{i}=61 \%$ (for wet condition) and $<20 \%$ (for dry condition)

(4) Water inlet temperature: $T_{w, i}=3{ }^{\circ} \mathrm{C}\left(37.4^{\circ} \mathrm{F}\right)$

(5) Water flow rate: $0.5 \mathrm{~kg} / \mathrm{s}$ ( $8 \mathrm{gal} / \mathrm{min}$, for 8 -row coil test), $0.35 \mathrm{~kg} / \mathrm{s}(5.5 \mathrm{gal} / \mathrm{min}$, for 
4-row coil test), $0.25 \mathrm{~kg} / \mathrm{s}$ (4 gal/min, for 2-row coil test)

\subsection{Test Procedure}

In general, each coil was tested at three conditions: (1) clean condition; (2) fouled condition, i.e., after dust loading with 600 grams of dust; (3) after cleaning condition, i.e., after cleaning the fouled coil with a detergent. The specific test procedure for each coil is presented below (see Appendix 3 for the more detailed operating procedure):

STEP 1: Baseline test

Each coil was tested without any upstream filter at clean conditions and the basic performance was obtained at four airflow rates.

The original test coil as received from the manufacturer or after it was used in a previous fouling test was cleaned using the detergent "Evap Pow'r-C" (a concentrated biodegradable detergent specifically formulated for "no-rinse" application on evaporator coils). Then, the coil was installed in the wind tunnel using a hoist. A new pocket filter (MERV14) was weighted and installed downstream of the coil. In the next step, the air system and water system was started.

After the whole system was running, it usually took $0.5-1$ hour to reach a stable operating condition, i.e., steady air inlet temperature, relative humidity and steady water inlet temperature. The air velocity was adjusted to four levels: $3.05 \mathrm{~m} / \mathrm{s}(600 \mathrm{ft} / \mathrm{min}), 2.54 \mathrm{~m} / \mathrm{s}$ $(500 \mathrm{ft} / \mathrm{min}), 2.03 \mathrm{~m} / \mathrm{s}(400 \mathrm{ft} / \mathrm{min})$ and $1.52 \mathrm{~m} / \mathrm{s}(300 \mathrm{ft} / \mathrm{min})$. It took approximately 20 minutes to reach steady state after each variation and another 20 minutes to collect the test data.

STEP 2: Dust injection

After the baseline test was completed, the coil was loaded with dust during 6 hours for each filter case. When injecting the dust, the air velocity was held constant at $2.54 \mathrm{~m} / \mathrm{s}(500$ $\mathrm{ft} / \mathrm{min}$ ) with the test conditions specified in Section 2.7.

A new upstream filter (one of the five different types of test filters) was weighed and inserted in the wind tunnel. During feeding of the dust, a careful watch was kept on the data. When the upstream filter or downstream filter reached its maximum acceptable 
pressure drop, it was replaced with a new one. To replace a filter, the whole air system was shut down.

Approximately 4 to 7 upstream filters and 2 to 3 downstream filters were used to load 600 grams of dust in each fouling test. All the filters were weighed before and after each fouling test to determine the dust quantity captured by the filter. During dust feeding, approximately 40 to 80 liters (10 to 20 gallons) of condensation from each coil was collected by buckets. The condensation was filtered and the filtered dust was dried and weighed.

STEP 3: Performance tests after fouling

After injecting 600 grams of dust, the upstream filter and downstream filter were removed and the coil was tested with all the settings and conditions the same as for STEP 1.

STEP 4: Cleaning process

After completion of the fouling tests, the drain pan of the test coil was dismounted from the coil and washed using pure water. The dust deposited in the drained pan was obtained by filtering the dirty water. Then, the test coils were cleaned.

Since the eight-row coils could not be cleaned very easily inside the wind tunnel, they were taken out of the wind tunnel and cleaned using Evap Pow'r-C. The cleaner was diluted with 3 parts of water according to the instruction listed on the cleaner and sprayed onto the contaminated coil. For the next test, the coil was installed in the wind tunnel. It was operated at a high humidity inlet air stream with cooling water passed through the tubes, so that condensation occurred on the coil. The condensation cleaned the coil further and when the condensation was clear, a new baseline was performed.

It was not necessary to remove the four-row and two-row coils and they were cleaned inside the wind tunnel. Two doors on the duct were designed at the front side and back side of the test coil so that it was easy to wash the coil from two directions in the wind tunnel. The condensation process also was performed to further clean the coil before the next test. The duct inside of the test section was cleaned with pure water and brushed at the end of each test. The amount of dust was determined by filtering the water, drying and weighing the dust. The dust weight data for the duct, filters, condensation, injected dust and dust in 
the drain pan were all used to obtain filter arrestances and the amount of dust deposited on the coil. The specific computation and results are presented in section 3.3.

After Step 4, the coil was cleaned to return to the original performance. Then, another type of filter was inserted and Steps 2-4 were repeated until all five filter cases and one no-filter case were tested. 


\section{TEST RESULTS}

The coil air-side pressure drops, effective heat transfer coefficients and filter pressure drop were obtained from measurements. The coil fouling factors were then determined from the clean and fouling tests and dust distributions were obtained from the mass of dust deposited on each test section.

\subsection{Air-side Pressure Drops and Fouling Factors for Wet Conditions}

Figure 3.1 shows the four average pressure drop baselines for the four test coils. For each coil, separate baselines were determined (obtained when the coil was clean) for the different filter cases. However, since the coils were cleaned very well and the baselines had very small differences, an average baseline was presented. The coil pressure drops are presented as a function of air velocity. The pressure drop increases nonlinearly with air velocity for a given coil and is higher for coils having greater depths.

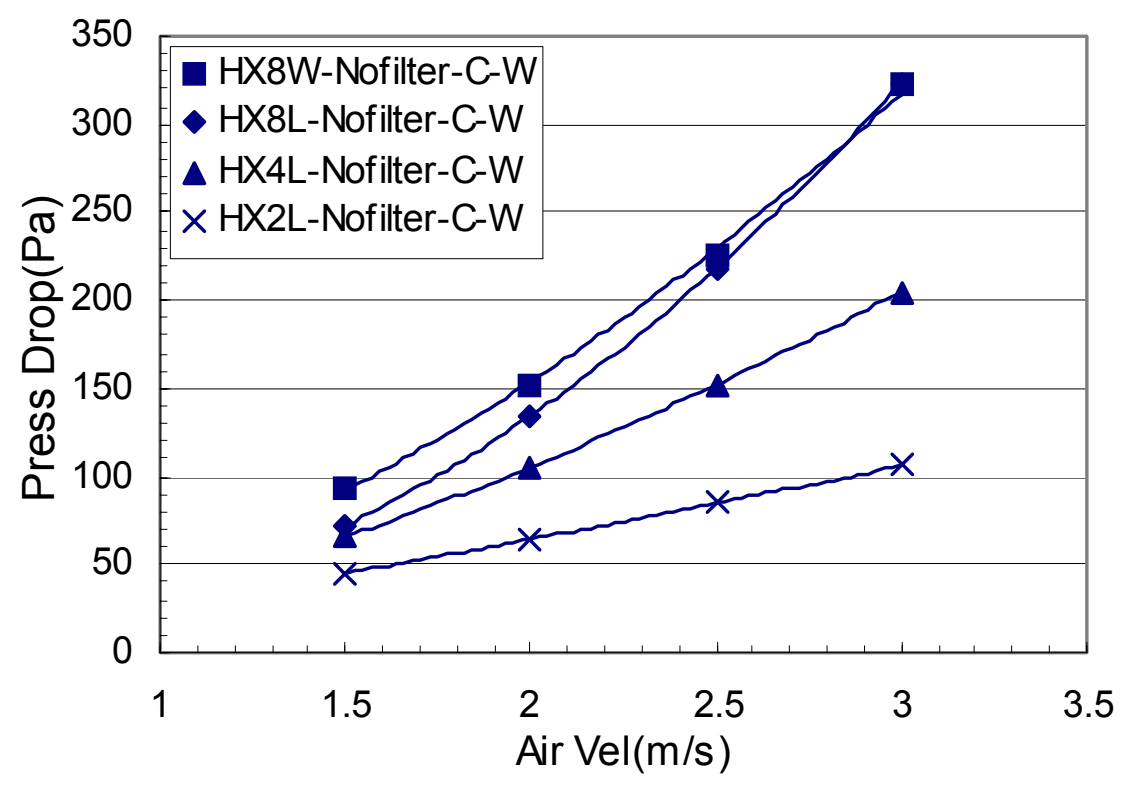

Figure 3.1: Baseline pressure drop vs air velocity for four test coils

Each coil was tested with different filter levels. For higher MERV filters, less dust passed the filter and deposited on the coil and lower coil air pressure drop was observed. This trend appears in Figure 3.2-3.5.

Figures 3.2-3.5 show the air-side pressure drops of HX8W, HX8L, HX4L and HX2L at the 
test air velocities. One average baseline and six curves (or four curves) of six fouling cases (or four fouling cases) were presented in each figure.

Figure 3.2 shows the air pressure drop of HX8W. It increased from approximately $93 \mathrm{~Pa}$ $\left(0.36 \mathrm{inH}_{2} \mathrm{O}\right)$ to $323 \mathrm{~Pa}\left(1.28 \mathrm{inH}_{2} \mathrm{O}\right)$ when the air velocity changed from $1.52 \mathrm{~m} / \mathrm{s}(300$ $\mathrm{ft} / \mathrm{min})$ to $3.05 \mathrm{~m} / \mathrm{s}(600 \mathrm{ft} / \mathrm{min})$ for the baseline test. The coil pressure drop increased with dust loading. The pressure drops of case HX8W-MERV14 and HX8W-MERV11 were similar: approximately a 7\% increase was found at an air velocity of $2.54 \mathrm{~m} / \mathrm{s}(500 \mathrm{ft} / \mathrm{min})$. Cases HX8W-MERV8, HX8W-MERV6 and HX8W-MERV4 had similar results: approximately a $30 \%$ increase was found at an air velocity of $2.54 \mathrm{~m} / \mathrm{s}(500 \mathrm{ft} / \mathrm{min})$. For the no-filter case, a $44 \%$ increase was found at the same air velocity.

From Figure 3.3 it can be seen that the pressure drop data for the HX8L cases were similar to those for HX8W cases. The baseline pressure drop was from $72 \mathrm{~Pa}\left(0.29 \mathrm{inH}_{2} \mathrm{O}\right)$ to 324 $\mathrm{Pa}\left(1.30 \mathrm{inH}_{2} \mathrm{O}\right)$ in the test air velocity range. The data almost overlapped for cases HX8L-MERV14 and HX8L-MERV11. For these two cases, the pressure drop increased by approximately $6 \%$ at an air velocity of $2.54 \mathrm{~m} / \mathrm{s}(500 \mathrm{ft} / \mathrm{min})$. For case HX8L-MERV8, the increase was approximately 14\%. For case HX8L-MERV6 and HX8L-MERV4, the increases were approximately $25 \%$. For the no-filter case, the increase was $43 \%$.

Figure 3.4 shows results for HX4L. The baseline pressure drop was from $66 \mathrm{~Pa}(0.27$ $\left.\mathrm{inH}_{2} \mathrm{O}\right)$ to $205 \mathrm{~Pa}\left(0.82 \mathrm{inH}_{2} \mathrm{O}\right)$. Compared to the results of $\mathrm{HX} 8 \mathrm{~L}$, the baseline of $\mathrm{HX} 4 \mathrm{~L}$ was approximately 40\% lower. However, at fouled conditions, the increases in pressure drop of HX4L were 18\%, 31\%, 108\% for cases MERV8, MERV4 and no-filter, respectively. Clearly, the impact of fouling is greater for four-row than eight-row coils.

Figure 3.5 shows results for HX2L. The baseline pressure drop was from $45 \mathrm{~Pa}(0.18$ $\left.\mathrm{inH}_{2} \mathrm{O}\right)$ to $106 \mathrm{~Pa}\left(0.43 \mathrm{inH}_{2} \mathrm{O}\right)$. The pressure drop of $\mathrm{HX} 2 \mathrm{~L}$ increased uniformly from case HX2L-MERV14 to case HX2L-MERV4. At an air velocity of $2.54 \mathrm{~m} / \mathrm{s}(500 \mathrm{ft} / \mathrm{min})$, the increases were $7 \%, 12 \%, 19 \%, 28 \%, 35 \%$ and $200 \%$ for the six cases compared to the baseline, respectively.

Thus, it is concluded that the impact of fouling on pressure drop is much more significant for coils with fewer rows. 


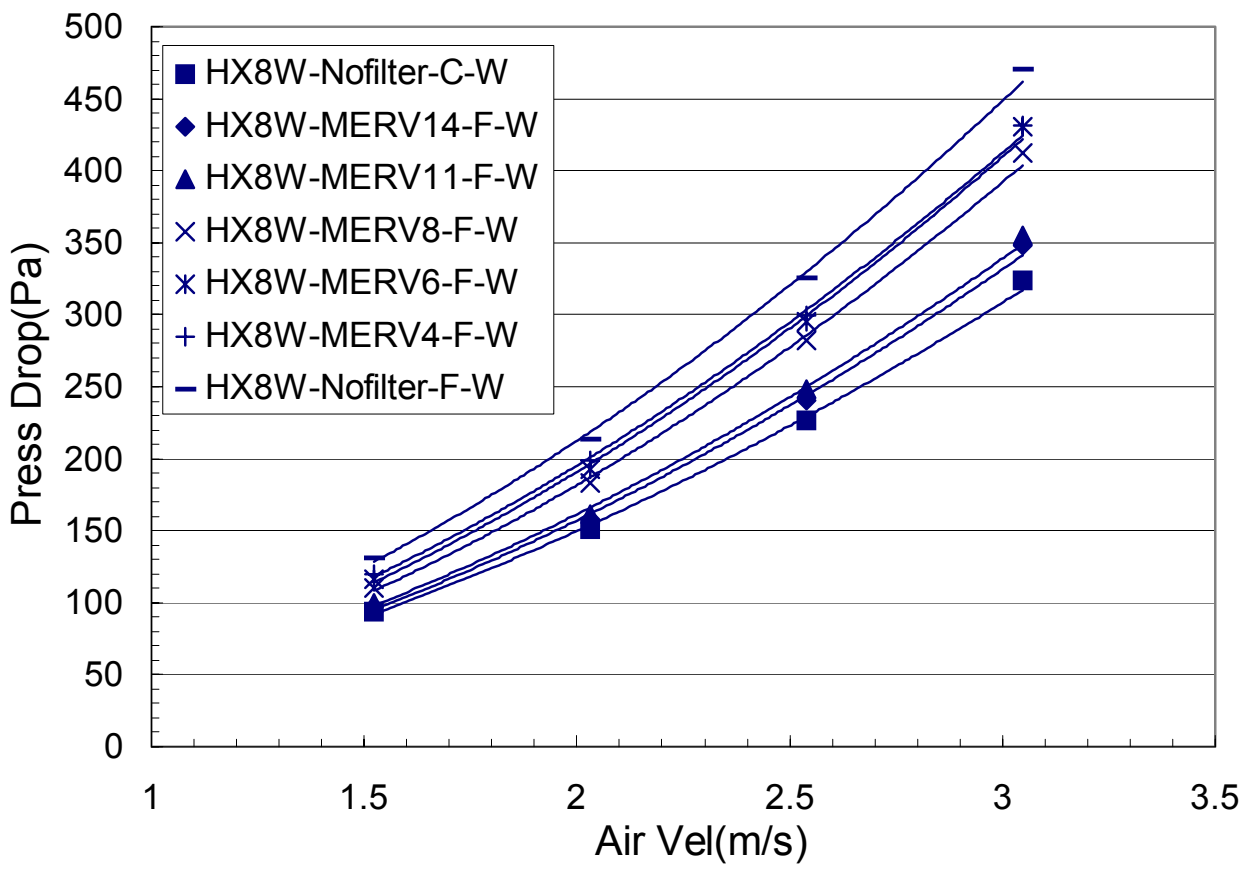

Figure 3.2: Air-side pressure drop vs air velocity of HX8W

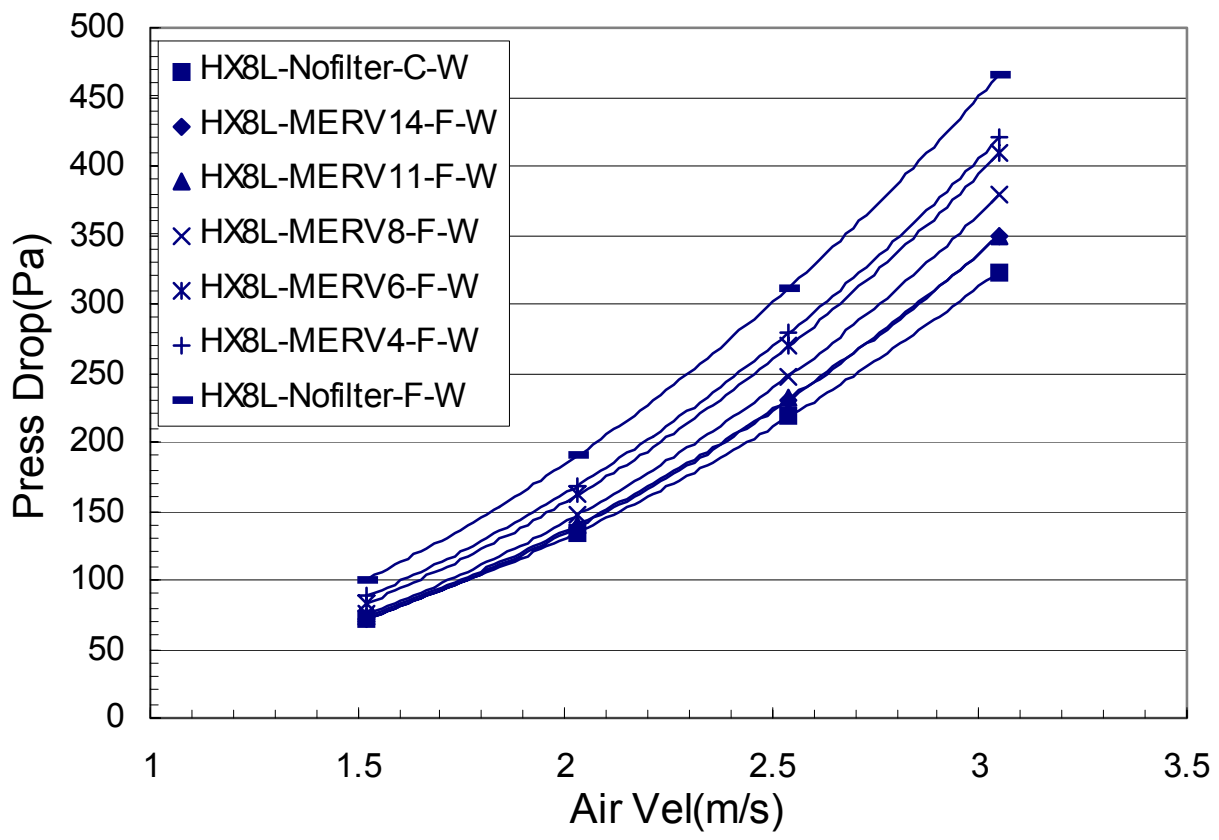

Figure 3.3: Air-side pressure drop vs air velocity of HX8L 


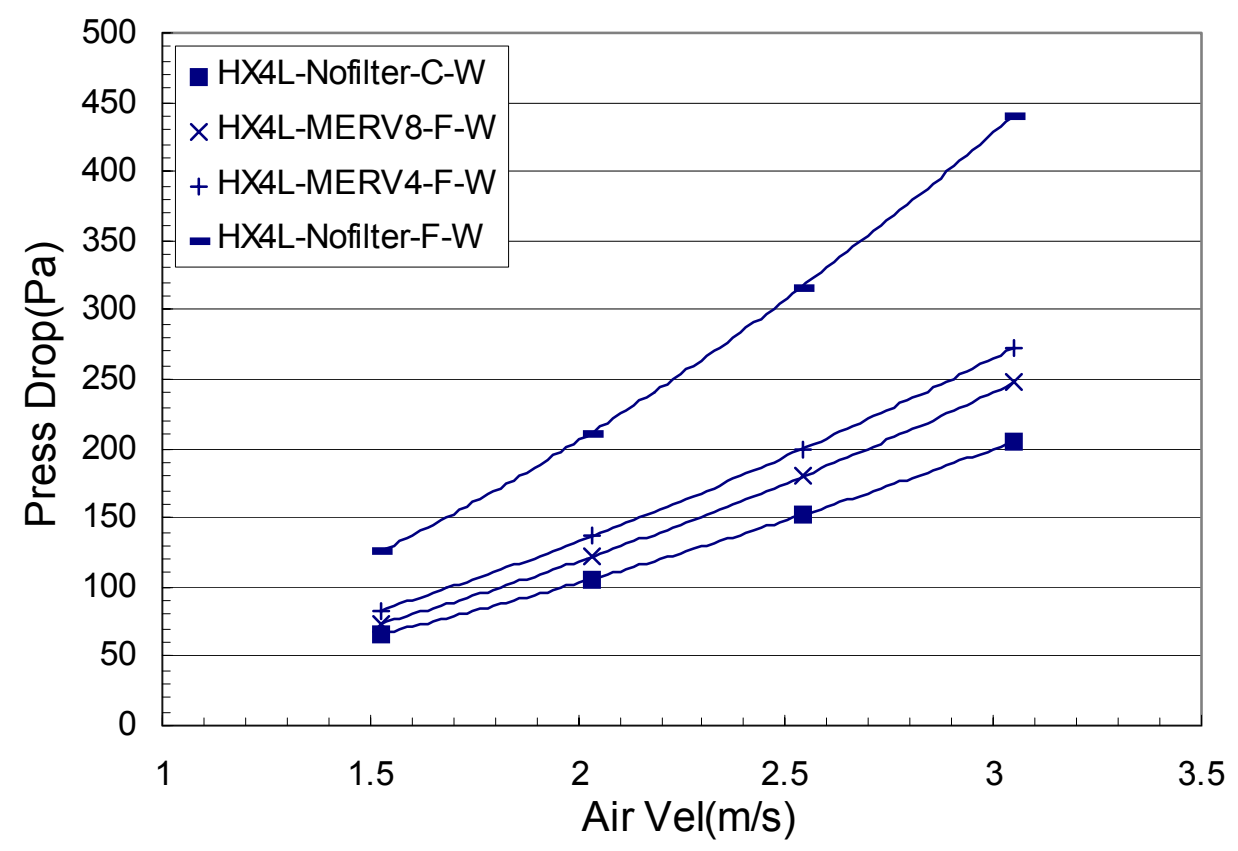

Figure 3.4: Air-side pressure drop vs air velocity of HX4L

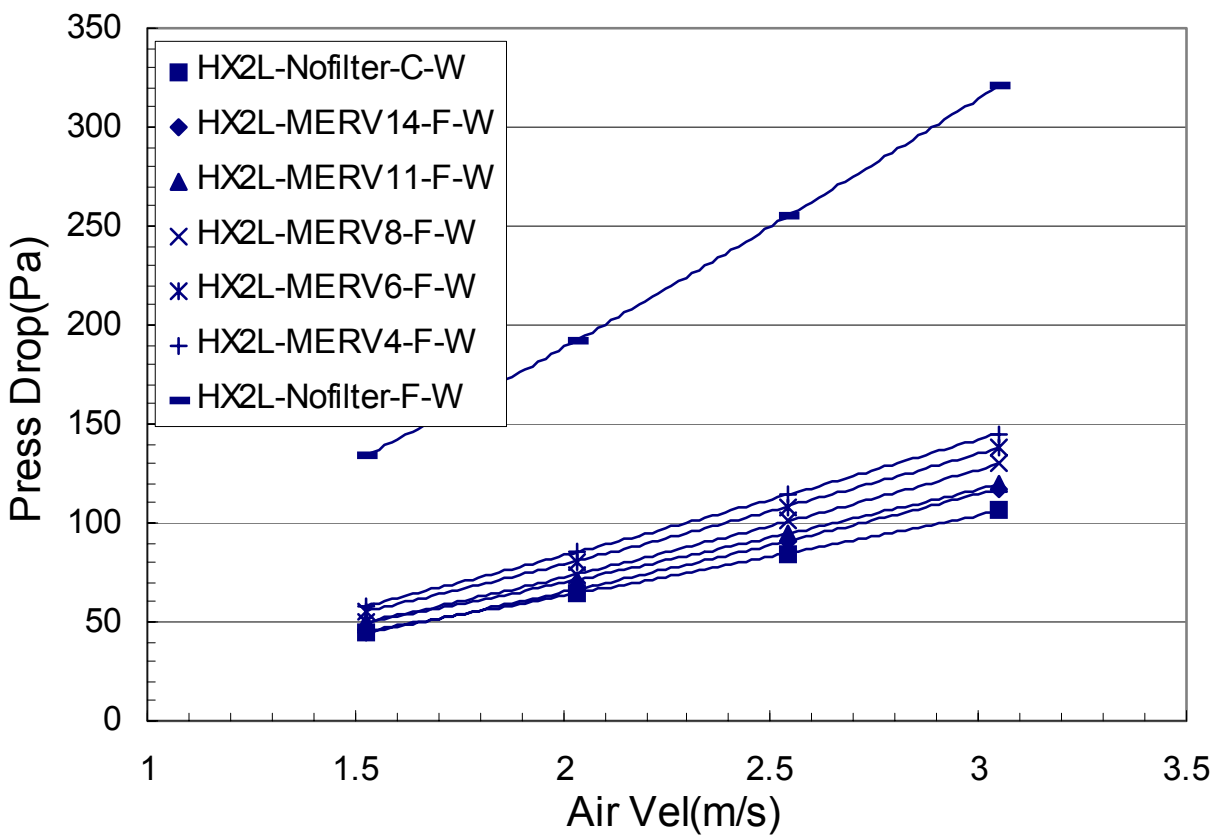

Figure 3.5: Air-side pressure drop vs air velocity of HX2L

Fouling factors were used to represent the percentage increase or decrease of coil air-side pressure drop and effective heat transfer coefficient after fouling. 
The pressure drop fouling factor $f_{d p}$ was defined as: $f_{d p}=\frac{100\left(\Delta P_{c, f}-\Delta P_{c, c}\right)}{\Delta P_{c, c}} \%$

where $\Delta P_{c, c}$ is the coil air-side pressure drop at clean conditions and $\Delta P_{c, f}$ is the coil air-side pressure drop at fouled conditions.

Table 3.1 shows pressure drop fouling factors for all cases. For each coil, from MERV14 to no-filter cases, the quantity of dust deposited on the coil increased, and thus, the value of fouling factor increased. Figure 3.6 shows $f_{d p}$ of the four coils for the different filter cases with an air velocity of $2.54 \mathrm{~m} / \mathrm{s}(500 \mathrm{ft} / \mathrm{min})$. The differences of $f_{d p}$ among the four coils were small for different filters. However, for the no-filter case, the $f_{d p}$ for HX4L (equal to $108 \%$ ) was more than two times the $f_{d p}$ for HX8L and HX8W, and the $f_{d p}$ for HX2L (equal to $201 \%$ ) was two times the $f_{d p}$ for HX4L.

In general, coils with fewer rows are more affected by fouling. This is due to the following two reasons:

(1) Dust is mainly deposited on the front of coil. This situation was clearly observed for the test coils; especially the eight-row coils. For deep coils, the pressure drop at the frontal face is a smaller percentage of the total coil pressure drop than for a shallow coil.

(2) Coils with fewer rows generally have greater fin density. The fin densities were 3.15 fin/cm, $4.72 \mathrm{fin} / \mathrm{cm}$, and $5.51 \mathrm{fin} / \mathrm{cm}$ (8 fin/inch, $12 \mathrm{fin} /$ inch and $14 \mathrm{fin} / \mathrm{inch}$ ) for 8-row, 4-row and 2-row coils, respectively. Greater fin density leads to greater dust capture on the coil surfaces. 
Table 3.1: Pressure drop fouling factor of all test cases.

\begin{tabular}{|c|c|c|c|c|c|c|}
\hline \multicolumn{7}{|c|}{ HX8W } \\
\hline Air Vel (m/s) & MERV14 & MERV11 & MERV8 & MERV6 & MERV4 & no-filter \\
\hline 1.52 & $3.2 \%$ & $6.6 \%$ & $17.6 \%$ & $23.9 \%$ & $27.6 \%$ & $39.5 \%$ \\
\hline 2.03 & $5.0 \%$ & $7.1 \%$ & $21.6 \%$ & $27.6 \%$ & $31.7 \%$ & $42.0 \%$ \\
\hline 2.54 & $6.4 \%$ & $7.4 \%$ & $24.7 \%$ & $30.6 \%$ & $32.5 \%$ & $43.9 \%$ \\
\hline 3.05 & $7.6 \%$ & $7.7 \%$ & $27.4 \%$ & $33.1 \%$ & $33.3 \%$ & $45.6 \%$ \\
\hline \multicolumn{7}{|c|}{ HX8L } \\
\hline Air Vel $(\mathrm{m} / \mathrm{s})$ & MERV14 & MERV11 & MERV8 & MERV6 & MERV4 & no-filter \\
\hline 1.52 & $-0.6 \%$ & $1.6 \%$ & $4.1 \%$ & $15.6 \%$ & $22.1 \%$ & $39.2 \%$ \\
\hline 2.03 & $2.8 \%$ & $4.1 \%$ & $9.3 \%$ & $20.0 \%$ & $25.3 \%$ & $41.5 \%$ \\
\hline 2.54 & $5.6 \%$ & $6.2 \%$ & $13.5 \%$ & $23.5 \%$ & $27.8 \%$ & $42.8 \%$ \\
\hline 3.05 & $7.9 \%$ & $7.9 \%$ & $17.0 \%$ & $26.4 \%$ & $29.9 \%$ & $44.1 \%$ \\
\hline \multicolumn{7}{|c|}{ HX4L } \\
\hline $\operatorname{Air} \operatorname{Vel}(\mathrm{m} / \mathrm{s})$ & MERV14 & MERV11 & MERV8 & MERV6 & MERV4 & no-filter \\
\hline 1.52 & -- & -- & $11.7 \%$ & -- & $26.5 \%$ & $90.4 \%$ \\
\hline 2.03 & -- & -- & $15.4 \%$ & -- & $29.1 \%$ & $100.2 \%$ \\
\hline 2.54 & -- & -- & $18.3 \%$ & -- & $31.2 \%$ & $108.2 \%$ \\
\hline 3.05 & -- & -- & $20.7 \%$ & -- & $33.0 \%$ & $115.0 \%$ \\
\hline \multicolumn{7}{|c|}{ HX2L } \\
\hline Air Vel $(\mathrm{m} / \mathrm{s})$ & MERV14 & MERV11 & MERV8 & MERV6 & MERV4 & no-filter \\
\hline 1.52 & $-1.8 \%$ & $9.3 \%$ & $10.1 \%$ & $22.1 \%$ & $28.8 \%$ & $195.4 \%$ \\
\hline 2.03 & $3.2 \%$ & $10.6 \%$ & $15.0 \%$ & $25.4 \%$ & $32.1 \%$ & $198.4 \%$ \\
\hline 2.54 & $7.2 \%$ & $11.7 \%$ & $19.0 \%$ & $28.0 \%$ & $34.8 \%$ & $200.8 \%$ \\
\hline 3.05 & $10.6 \%$ & $12.6 \%$ & $22.3 \%$ & $30.1 \%$ & $37.1 \%$ & $202.7 \%$ \\
\hline
\end{tabular}




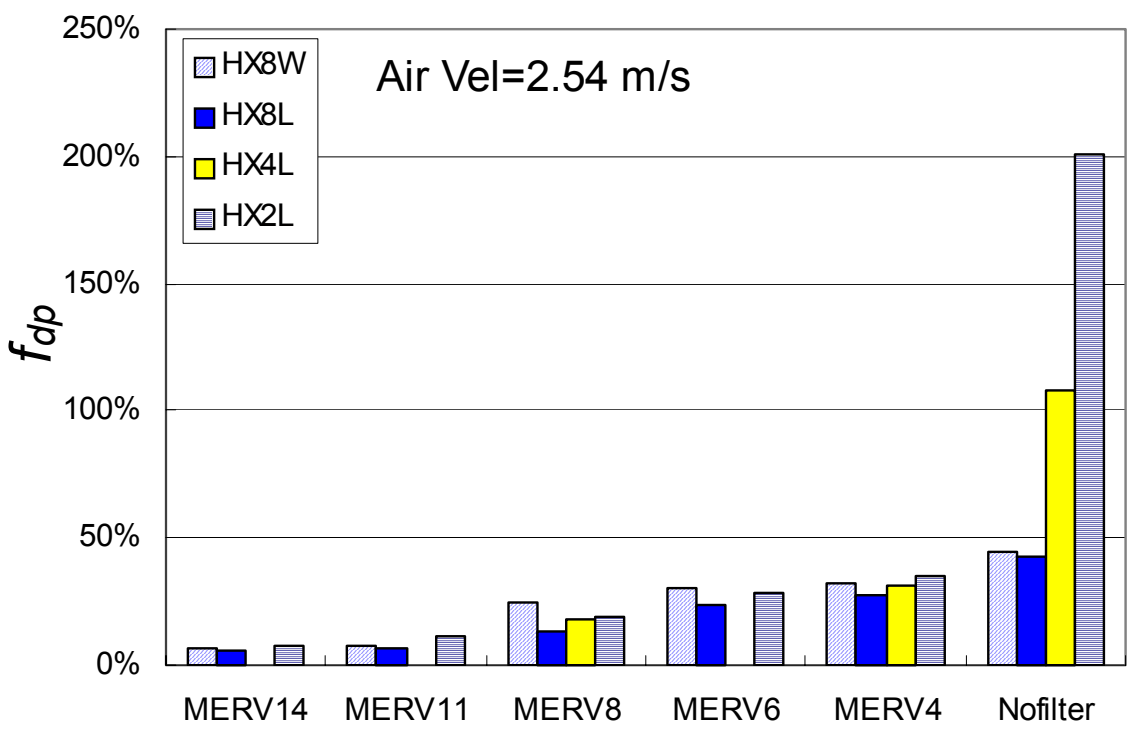

Figure 3.6: Comparison of pressure drop fouling factors of four coils at air velocity of $2.54 \mathrm{~m} / \mathrm{s}(500 \mathrm{ft} / \mathrm{min})$

Figure 3.7 shows the photos of HX8L: the front side before fouling, the front side after fouling and the back side after fouling. It can be seen that after fouling, the face of the coil captured a thick layer of dust while its back side was clean. 

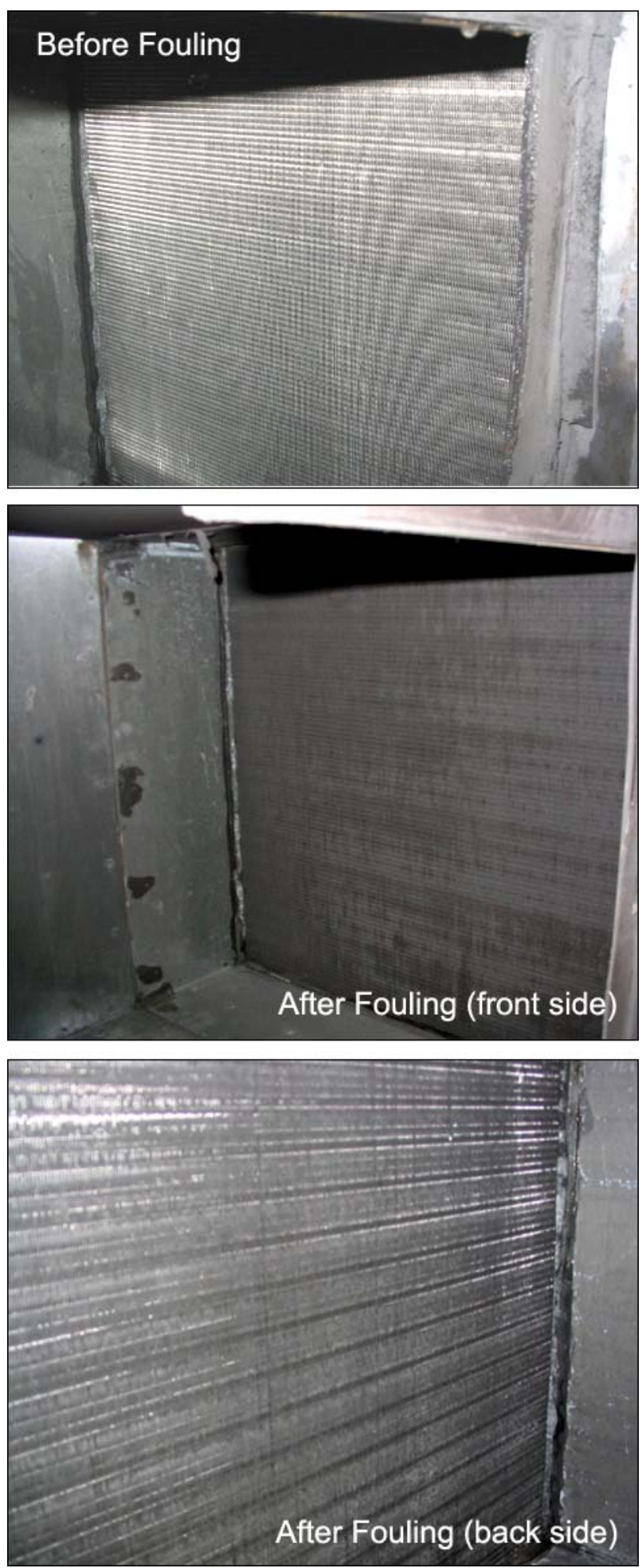

Figure 3.7: Photos of HX8L before and after fouling 


\subsection{Heat Transfer Coefficients and Fouling Factors for Wet Conditions}

The coil air-side effective heat transfer coefficient was defined in section 2.5 .2 as the product of the fin efficiency and airside heat transfer coefficient, $\eta h_{a w}$. For studying the overall impact of fouling on heat transfer capacity of an air conditioning unit, it was important to know the effective heat transfer coefficient.

Figures 3.8 shows the average effective heat transfer baselines for the four test coils. The effective heat transfer coefficient increases with air velocity. Differences between different coils are relatively small compared to the differences in pressure drop. Generally, greater fin density and greater coil depth can increase the effective heat transfer coefficient, but the effect of fin density is relatively small compared to the effect of coil depth when the number of rows is larger than four (C. C. Wang, K. Y. Chi (1999)). Therefore, the effective heat transfer coefficient for HX4L is a little lower than that for HX8L. The highest effective heat transfer coefficient occurred for HX2L, possibly because of the tighter fin spacing and a somewhat different fin and tube geometry. The manufacturer for HX2L was different than the manufacturer for HX8L, HX8W and HX4L, so that there might be greater difference between the performance of HX2L and other coils.

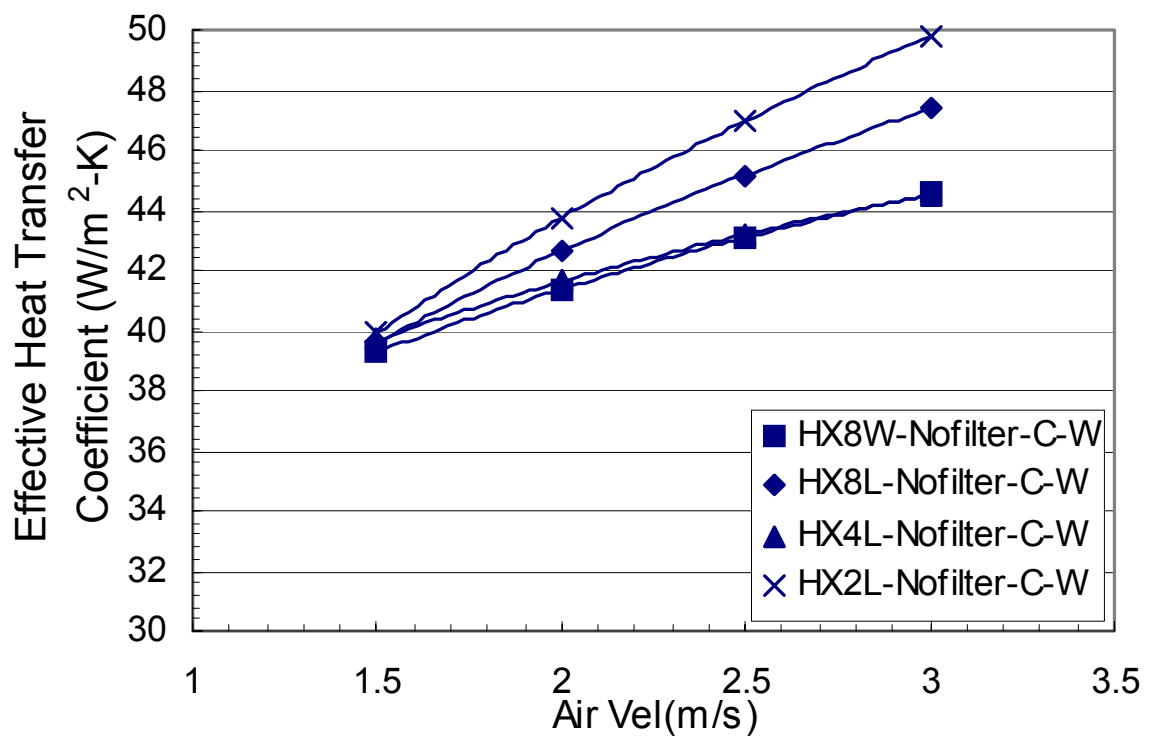

Figure 3.8: Baseline effective heat transfer coefficient vs air velocity for four test coils 
Figures 3.9-3.12 show the effective heat transfer coefficient for all the test cases of HX8W, HX8L, HX4L and HX2L at the test air velocities. One average baseline and six curves (or four curves) of six fouling cases (or four fouling cases) were presented in each figure.

Figure 3.9 shows the data for HX8W. The air-side effective heat transfer coefficient at the

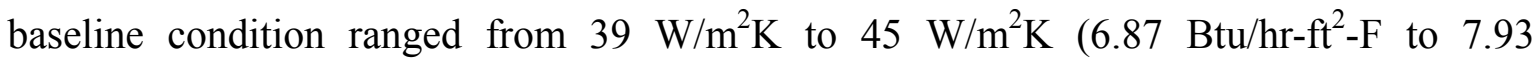
$\mathrm{Btu} / \mathrm{hr}-\mathrm{ft}^{2}-\mathrm{F}$ ). Comparing the effective heat transfer coefficients of fouling cases to the baseline at an air velocity of $2.54 \mathrm{~m} / \mathrm{s}(500 \mathrm{ft} / \mathrm{min})$, a slight increase (a maximum of $4 \%$ ) was found for each filter case and a decrease of $8 \%$ was found for the no-filter case. It shows that dust slightly enhanced the coil air-side heat transfer for HX8W for the filter cases.

Figure 3.10 shows the data for HX8L. The baseline data ranged from $40 \mathrm{~W} / \mathrm{m}^{2} \mathrm{~K}$ to 47 $\mathrm{W} / \mathrm{m}^{2} \mathrm{~K}\left(7.04 \mathrm{Btu} / \mathrm{hr}-\mathrm{ft}^{2}-\mathrm{F}\right.$ to $\left.8.28 \mathrm{Btu} / \mathrm{hr}-\mathrm{ft}^{2}-\mathrm{F}\right)$. However, only one fouling case (HX8L-MERV4) had an increase $(2 \%)$ in heat transfer at the air velocity of $2.54 \mathrm{~m} / \mathrm{s}$ compared to the baseline. The other cases had deceases of $2 \%$ to $7 \%$.

The baseline data for HX4L ranged from $40 \mathrm{~W} / \mathrm{m}^{2} \mathrm{~K}$ to $45 \mathrm{~W} / \mathrm{m}^{2} \mathrm{~K}\left(7.04 \mathrm{Btu} / \mathrm{hr}-\mathrm{ft}^{2}-\mathrm{F}\right.$ to

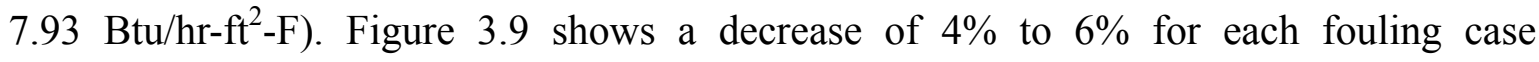
compared to the baseline.

Figure 3.12 shows data for HX2L. The baseline data for HX2L ranged from $40 \mathrm{~W} / \mathrm{m}^{2} \mathrm{~K}$ to $50 \mathrm{~W} / \mathrm{m}^{2} \mathrm{~K}\left(7.04 \mathrm{Btu} / \mathrm{hr}-\mathrm{ft}^{2}-\mathrm{F}\right.$ to $\left.8.81 \mathrm{Btu} / \mathrm{hr}-\mathrm{ft}^{2}-\mathrm{F}\right)$. The effective heat transfer coefficients dropped for all fouling cases. The maximum decrease of $14 \%$ occurred for the no-filter case.

Contrary to the coil air-side pressure drop results, the heat transfer coefficient did not monotonically increase or decrease with dust quantity and the fouling impact was small compared to the pressure drop impact.

To further investigate this result, an extra step-by-step dust injection test was carried out using HX8L and without an upstream filter installed. 600 grams of dust was injected for HX8L in 15 steps at wet conditions. At each step, HX8L was tested so that 15 measurements were obtained under four air velocities. Figure 3.13 shows the effective heat transfer coefficient as a function of mass of injected dust. The dust had very little effect 
until 300 grams of dust had been injected. After that, it dropped somewhat with dust loading. However, the overall effect of dust load on heat transfer performance was relatively small for the 8-row coil.

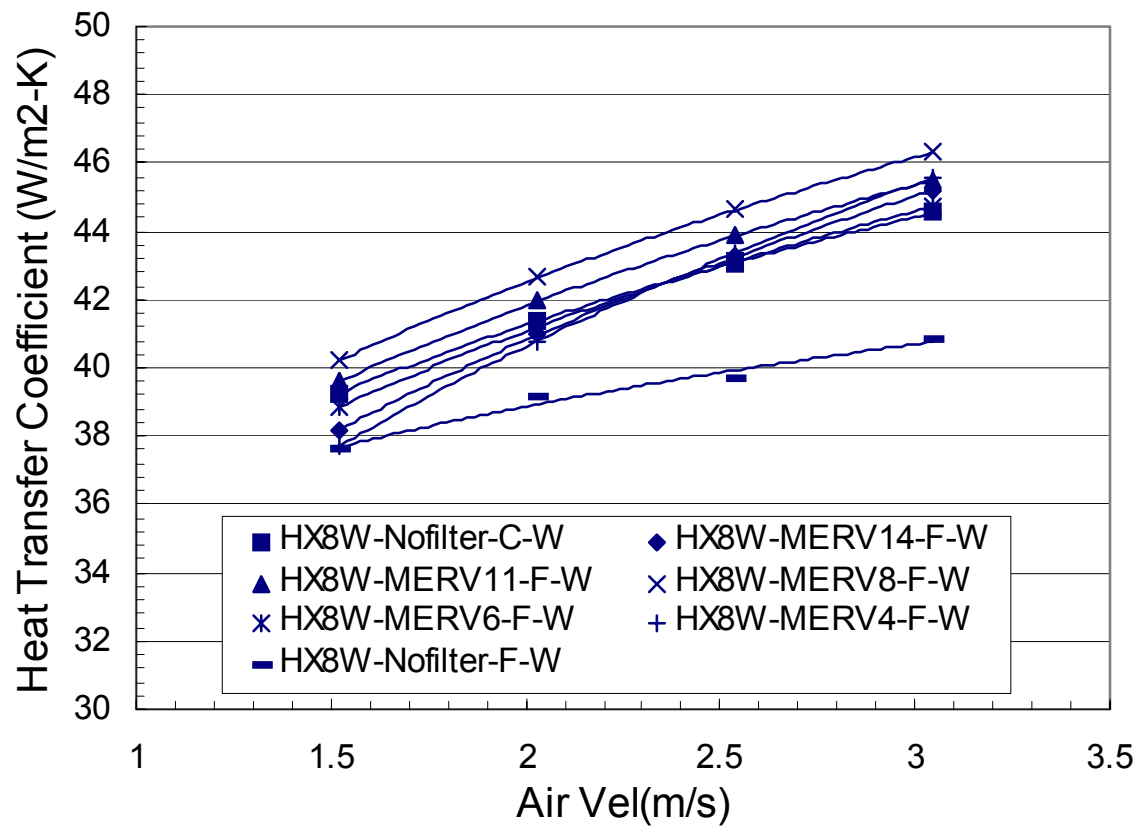

Figure 3.9: Effective heat transfer coefficient vs air velocity of HX8W 


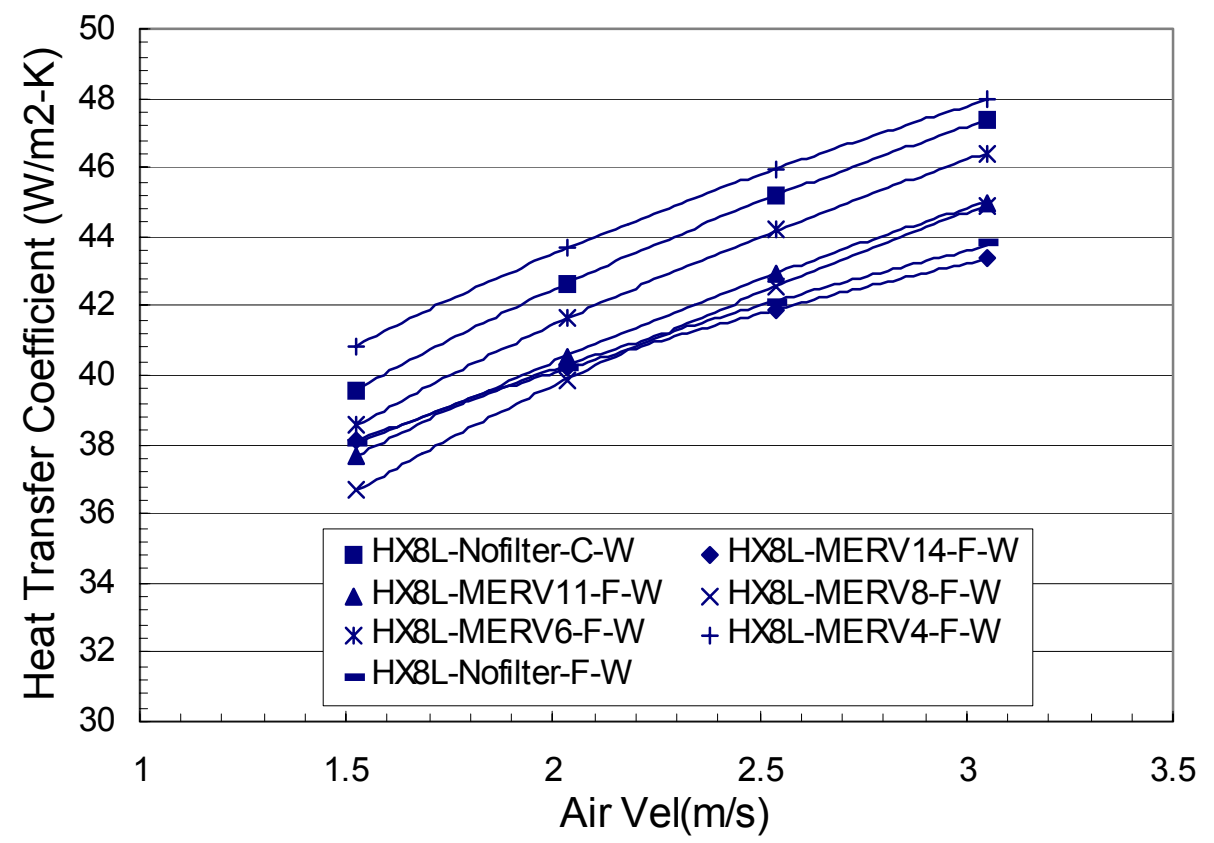

Figure 3.10: Effective heat transfer coefficient vs air velocity of HX8L

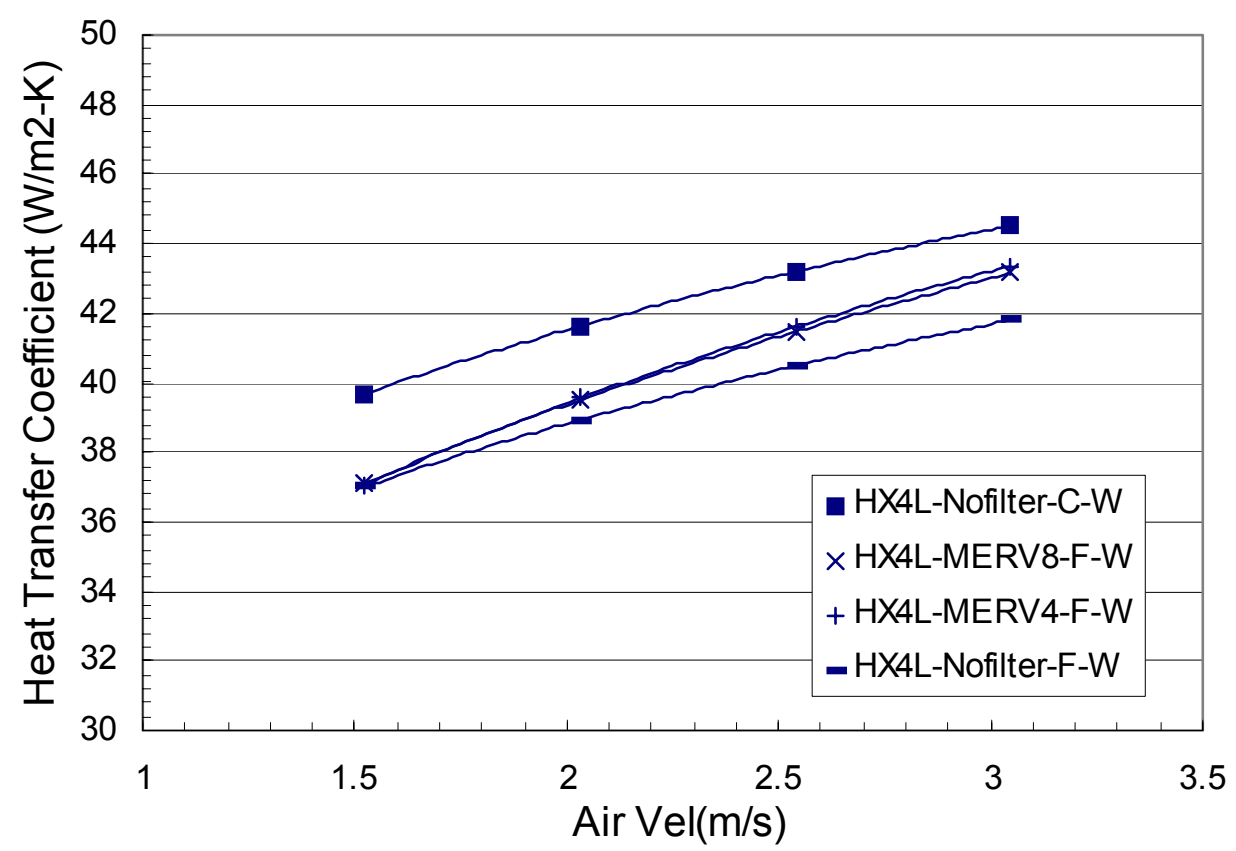

Figure 3.11: Effective heat transfer coefficient vs air velocity of HX4L 


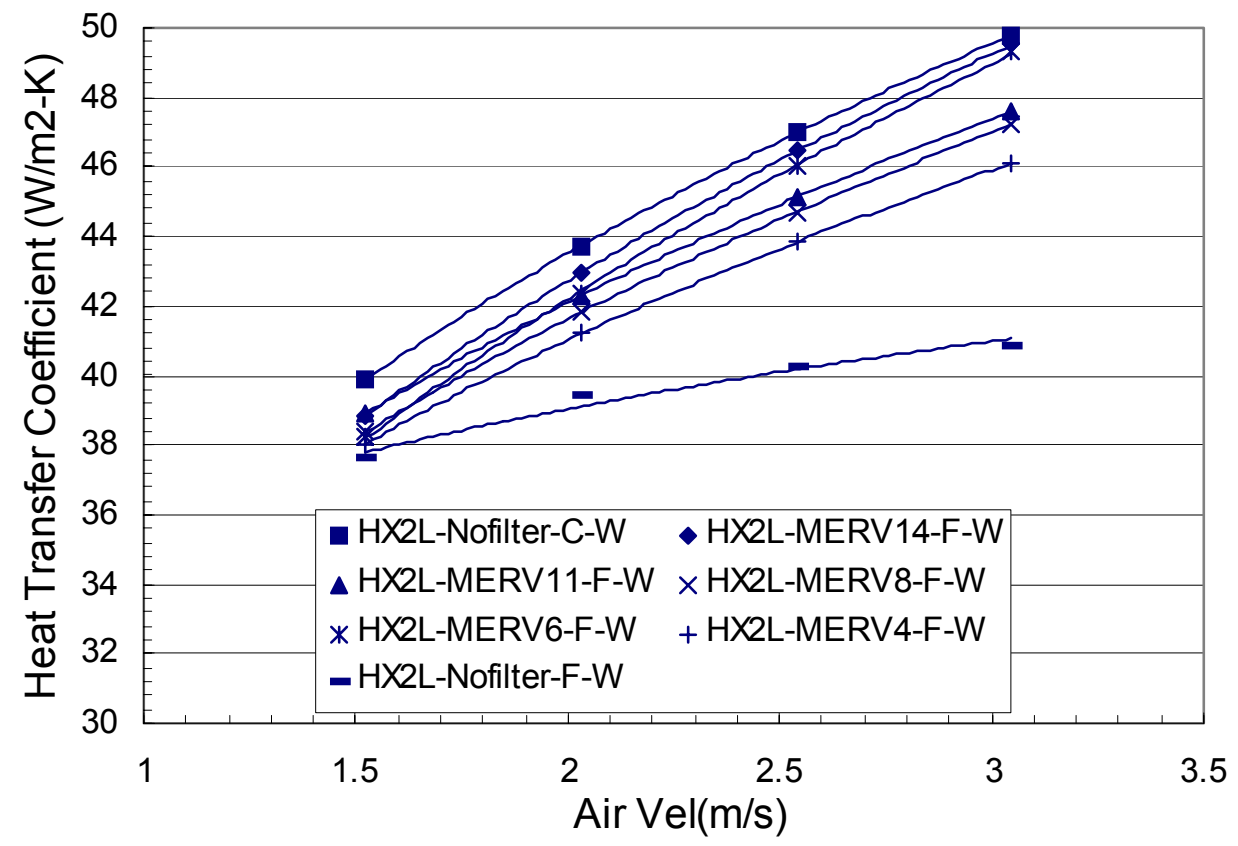

Figure 3.12: Effective heat transfer coefficient vs air velocity of HX2L

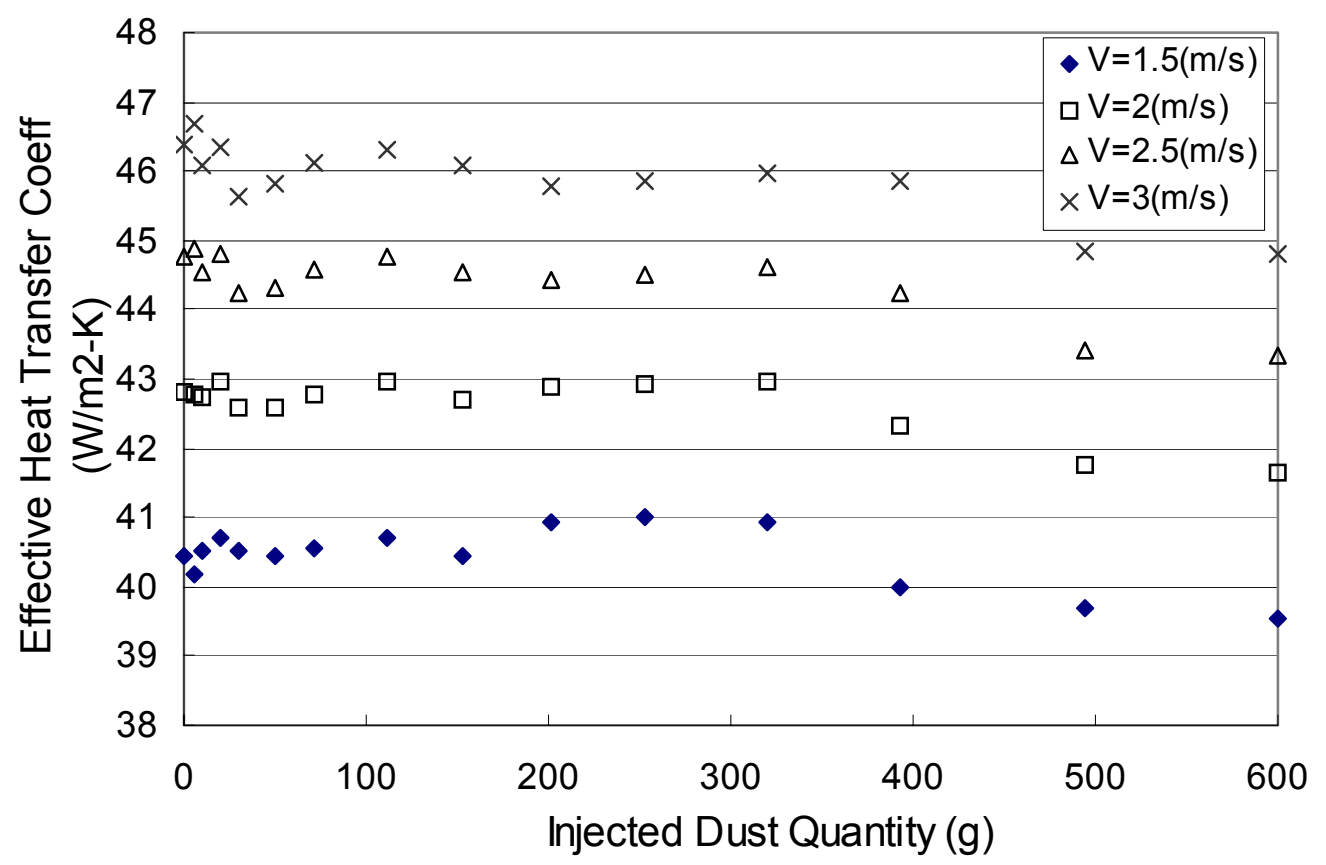

Figure 3.13: Effective heat transfer coefficient vs. injected dust quantity of HX8L 
The effective heat transfer coefficient fouling factor is defined as: $f_{h}=\frac{100\left(h_{f}-h_{c}\right)}{h_{c}} \%$

Table 3.2 shows effective heat transfer coefficient fouling factors for all cases and Figure 3.14 shows $f_{h}$ for all coil-filter combination cases at an air velocity of $2.54 \mathrm{~m} / \mathrm{s}(500 \mathrm{ft} / \mathrm{min})$. For most fouling cases, heat transfer was decreased but for a few cases it was enhanced.

Overall, the fouling impact on pressure drop was much greater than the impact on heat transfer coefficient. $f_{d p}$ ranged from $10 \%$ to $200 \%$ while $f_{h}$ ranged from $-14 \%$ to $4 \%$. In many cases with filters, the heat transfer impact was less than the uncertainty in the measurements and the trends were inconsistent. However, it appears that a moderate amount of dust could actually enhance heat transfer for HX8W. The enhancement could be due to additional turbulence caused by the dust. This was apparent for the HX8W which uses a wavy fin and has less turbulence than the lanced fin. However, the dust also acts as insulation and creates an uneven air velocity distribution, which decreases the heat transfer. Therefore, with large dust deposits, heat transfer is degraded.

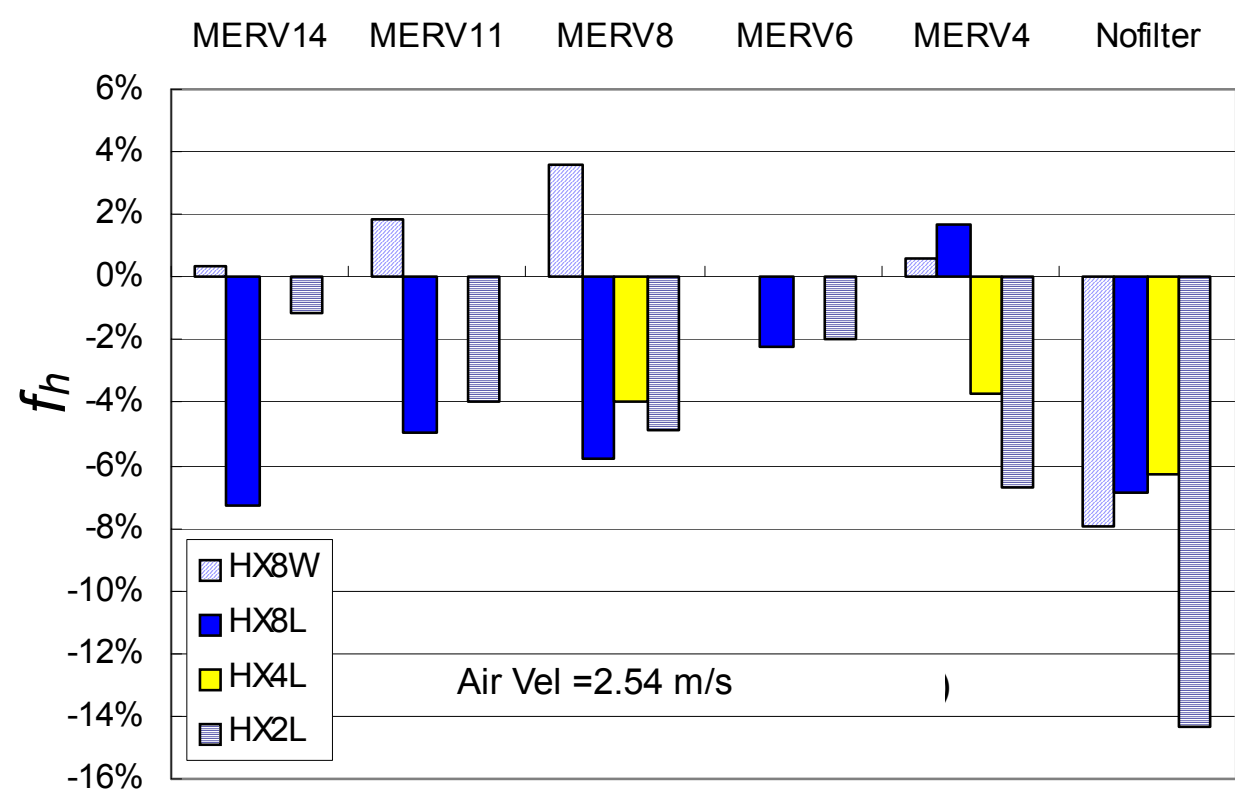

Figure 3.14: Comparison of pressure drop fouling factors of four coils at a same air velocity 
Table 3.2: Effective heat transfer coefficient fouling factor of all test cases

\begin{tabular}{|c|c|c|c|c|c|c|}
\hline \multicolumn{7}{|c|}{ HX8W } \\
\hline Air Vel $(\mathrm{m} / \mathrm{s})$ & MERV14 & MERV11 & MERV8 & MERV6 & MERV4 & No-filter \\
\hline 1.5 & $-2.7 \%$ & $0.9 \%$ & $2.4 \%$ & $-1.0 \%$ & $-4.0 \%$ & $-4.2 \%$ \\
\hline 2.0 & $-1.0 \%$ & $1.4 \%$ & $3.1 \%$ & $-0.4 \%$ & $-1.4 \%$ & $-5.3 \%$ \\
\hline 2.5 & $0.4 \%$ & $1.8 \%$ & $3.6 \%$ & $0.1 \%$ & $0.6 \%$ & $-7.9 \%$ \\
\hline 3.0 & $1.5 \%$ & $2.1 \%$ & $4.0 \%$ & $0.4 \%$ & $2.3 \%$ & $-8.3 \%$ \\
\hline \multicolumn{7}{|c|}{ HX8L } \\
\hline Air Vel $(\mathrm{m} / \mathrm{s})$ & MERV14 & MERV11 & MERV8 & MERV6 & MERV4 & No-filter \\
\hline 1.5 & $-3.8 \%$ & $-4.8 \%$ & $-7.4 \%$ & $-2.6 \%$ & $3.2 \%$ & $-3.8 \%$ \\
\hline 2.0 & $-5.8 \%$ & $-4.9 \%$ & $-6.5 \%$ & $-2.4 \%$ & $2.4 \%$ & $-5.7 \%$ \\
\hline 2.5 & $-7.3 \%$ & $-5.0 \%$ & $-5.8 \%$ & $-2.2 \%$ & $1.7 \%$ & $-6.9 \%$ \\
\hline 3.0 & $-8.5 \%$ & $-5.0 \%$ & $-5.2 \%$ & $-2.0 \%$ & $1.2 \%$ & $-7.5 \%$ \\
\hline \multicolumn{7}{|c|}{ HX4L } \\
\hline Air Vel $(\mathrm{m} / \mathrm{s})$ & MERV14 & MERV11 & MERV8 & MERV6 & 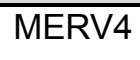 & No-filter \\
\hline 1.5 & $\overline{--}$ & $\overline{--}$ & $-6.5 \%$ & -- & $-6.6 \%$ & $-6.7 \%$ \\
\hline 2.0 & -- & -- & $-5.1 \%$ & -- & $-5.0 \%$ & $-6.5 \%$ \\
\hline 2.5 & -- & $\overline{--}$ & $-4.0 \%$ & $\overline{--}$ & $-3.7 \%$ & $-6.3 \%$ \\
\hline 3.0 & -- & -- & $-3.1 \%$ & -- & $-2.6 \%$ & $-6.1 \%$ \\
\hline \multicolumn{7}{|c|}{$\mathrm{HX2L}$} \\
\hline Air Vel $(\mathrm{m} / \mathrm{s})$ & MERV14 & MERV11 & MERV8 & MERV6 & MERV4 & No-filter \\
\hline 1.5 & $-2.6 \%$ & $-2.5 \%$ & $-3.8 \%$ & $-4.1 \%$ & $-4.6 \%$ & $-5.7 \%$ \\
\hline 2.0 & $-1.8 \%$ & $-3.3 \%$ & $-4.4 \%$ & $-3.2 \%$ & $-5.8 \%$ & $-9.9 \%$ \\
\hline 2.5 & $-1.1 \%$ & $-3.9 \%$ & $-4.8 \%$ & $-2.0 \%$ & $-6.7 \%$ & $-14.4 \%$ \\
\hline 3.0 & $-0.6 \%$ & $-4.4 \%$ & $-5.2 \%$ & $-1.0 \%$ & $-7.4 \%$ & $-17.9 \%$ \\
\hline
\end{tabular}




\subsection{Dust Distributions}

A total of 600 grams of ASHRAE standard dust was injected into the air stream during the fouling tests. Most of dust was captured by the upstream filter (when installed) and the rest was deposited on the coil, downstream filter, inside of the duct, drain pan and some flowed away with condensation. Figure 3.15 depicts these different locations for the dust. The dust weight on the coil was obtained using a mass balance:

$$
M_{6}=M-M_{1}-M_{2}-M_{3}-M_{4}-M_{5}
$$

where:

M: weight of total injected dust (600 grams); weighted.

$\mathrm{M}_{1}$ : weight of dust captured by upstream filter; obtained by weighing the upstream filter before and after each test.

$\mathrm{M}_{2}$ : weight of dust inside of the air duct; obtained by cleaning the inside of duct with water and filtering the dust from the water.

$\mathrm{M}_{3}$ : weight of dust in the drain pan; obtained by cleaning the drain pan with water and filtering the dust.

$\mathrm{M}_{4}$ : weight of dust in condensation; obtained by filtering the condensation and drying the dust.

$\mathrm{M}_{5}$ : weight of dust captured by the downstream filter; obtained by weighing the downstream filter before and after each test.

$\mathrm{M}_{6}$ : weight of dust captured by the coil; determined from the other masses.

All of the weighing was done using a high precision scale (Viper MB 6 SM), whose capacity was 6100 grams and accuracy was 0.1 gram. 


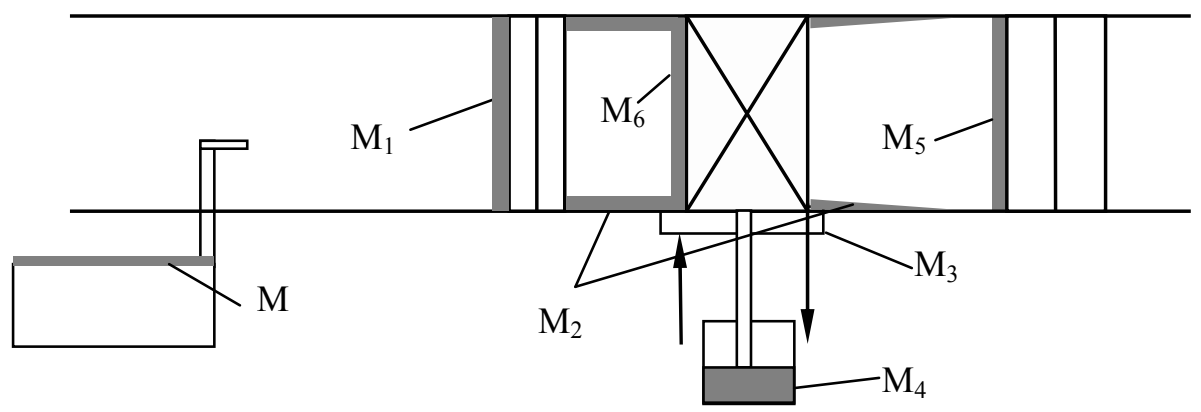

Figure 3.15: Dust distribution diagram

Table 3.3 shows the dust distributions for six cases of HX8L. For the cases with upstream filters, most of dust was captured by the upstream filter and little dust appeared in the wind tunnel, drain pan and condensation. Only approximately 3.5 grams of dust was captured by the coil and approximately 2.9 grams of dust was captured by the downstream filter for case MERV14. For cases MERV14 and MERV11, almost no dust appeared in the condensation because the amount was quite small and most of the dust in the condensation was deposited in the drain pan or attached to the hose when flowing out. For the no-filter case, approximately 286.8 grams of dust was deposited on the coil and approximately 188.2 grams of dust was deposited on the downstream filter. The masses of dust deposited in the wind tunnel, drain pan and condensation increased significantly. Using the mass balances, the actual arrestance of each filter was obtained by dividing M1 by M. The calculated arrestances were a little lower than the manufacturer's values. Appendix 1 gives detailed dust distribution for all coils in Table 5.

Table 3.4 shows the weight of dust on the coil for all test cases with the four test coils. The mass of dust captured by the coil ranged from approximately 4 grams to 50 grams for all the cases with filters and it was approximately 300 grams for no-filter cases. There appears to be little correlation between the depth of the coil and the amount of dust deposited on the coil. In fact, the two-row coil had slightly greater dust deposits than the deeper coils in many cases. This may be due to the higher fin density used for the shallower coils. 
Table 3.3: Dust distribution of the six test cases of HX8L

\begin{tabular}{|c|c|c|c|c|c|c|}
\hline Heat Exchanger & \multicolumn{5}{|c|}{ HX8L } \\
\hline Filter & MERV14 & MERV11 & MERV8 & MERV6 & MERV4 & no-filter \\
\hline M & 600.1 & 600.3 & 600.2 & 600.5 & 600.4 & 600.2 \\
\hline M1 & 590.4 & 574.1 & 536.5 & 526.9 & 451 & -- \\
\hline M2 & 3.1 & 4.1 & 3.7 & 4.3 & 5.2 & 31.6 \\
\hline M3 & 0.2 & 2.1 & 0.4 & 0.3 & 1.2 & 25.2 \\
\hline M4 & 0 & 0 & 0.9 & 1.1 & 3.4 & 68.4 \\
\hline M5 & 2.9 & 8.2 & 43.2 & 30.1 & 92.7 & 188.2 \\
\hline M6 & 3.5 & 11.8 & 15.5 & 37.8 & 46.9 & 286.8 \\
\hline Arrestance measured & $98.4 \%$ & $95.6 \%$ & $89.4 \%$ & $87.7 \%$ & $75.1 \%$ & -- \\
\hline Manufactures arrestance & $99 \%$ & $99 \%$ & $95 \%$ & $90-95 \%$ & $75-80 \%$ & - \\
\hline
\end{tabular}

Table 3.4: Weight of dust captured by the coil for all test cases

\begin{tabular}{|c|c|c|c|c|c|c|}
\hline Filter & MERV14 & MERV11 & MERV8 & MERV6 & MERV4 & No-filter \\
\hline HX8W & 3 & 7.8 & 13.4 & 27.2 & 51.1 & 341.8 \\
\hline HX8L & 3.5 & 11.8 & 15.5 & 37.8 & 51.1 & 286.8 \\
\hline HX4L & -- & -- & 19.2 & -- & 54.4 & 350.6 \\
\hline HX2L & 4.4 & 10.8 & 24.6 & 33.2 & 47.9 & 379.6 \\
\hline
\end{tabular}

\subsection{Comparison between Dry and Wet Conditions}

Limited tests were performed at dry and wet conditions to understand the impact of condensation on fouling.

\subsubsection{Coil Pressure Drops at Dry and Wet Conditions}

For the dry condition tests, HX8L-No-filter-C-D and HX8L-MERV11-F-D, the air inlet relative humidity was set at $20 \%$ and the outlet relative humidity was measured to be approximately $70 \%$. No condensation was found under this condition. The results of these two tests were then compared with tests HX8L-No-filter-C-W and HX8L-MERV11-F-W, respectively.

Figure 3.16 shows the pressure drops for the two clean cases. It can be seen that the coil 
air-side pressure drop at wet conditions was $24 \%$ to $59 \%$ higher than the pressure drop at dry conditions, because the condensation on the coil surface reduced the air flow area and increased the turbulence. Figure 3.17 shows the pressure drop fouling factors for the two fouled cases. It was found that when the coil was fouled, the pressure drop increased $2 \%$ to $8 \%$ after fouling for wet conditions while it increased $17 \%$ to $25 \%$ for dry conditions. Fouling had a greater impact on the pressure drop of the dry coil than the pressure drop of the wet coil. Possibly, the condensation helps to wash some of the dust of the coil and reduce the amount of dust deposited. Unfortunately, the coil dust deposits were not determined for the dry tests. More tests are needed to understand the differences between fouling at wet and dry conditions.

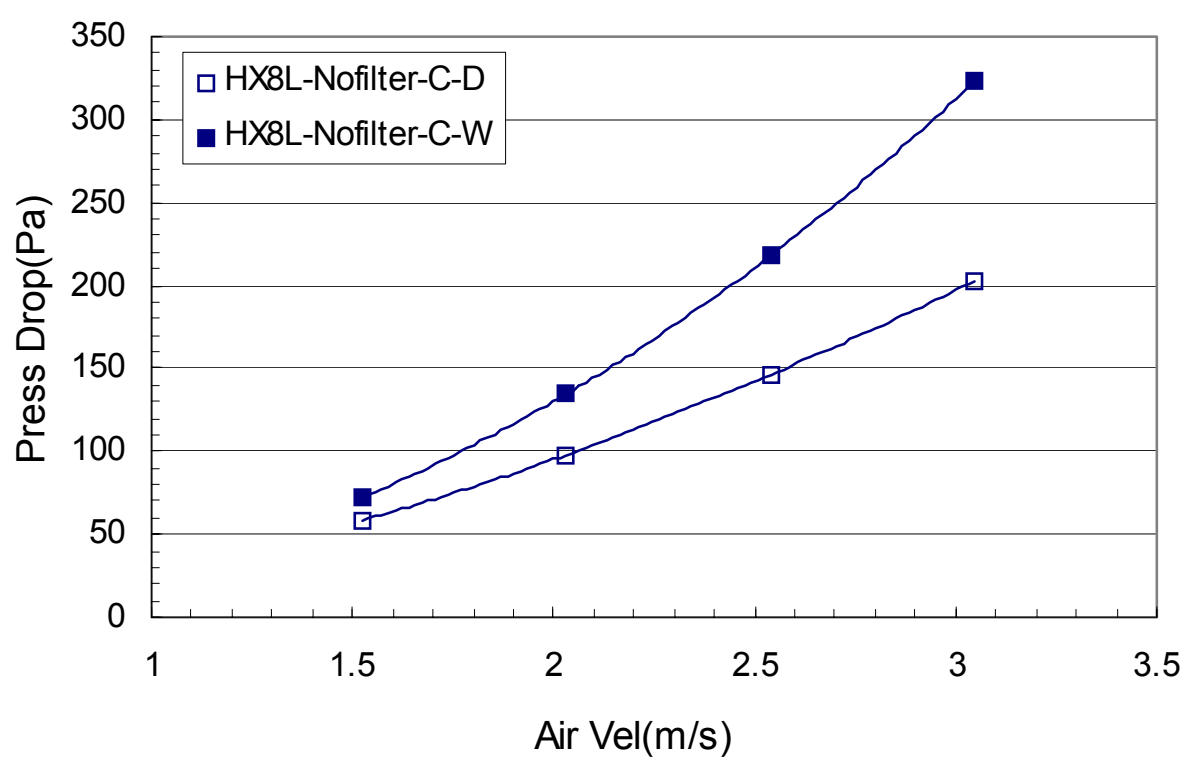

Figure 3.16: Baseline pressure drop vs air velocity of HX8L-No-filter-C at dry and wet conditions 


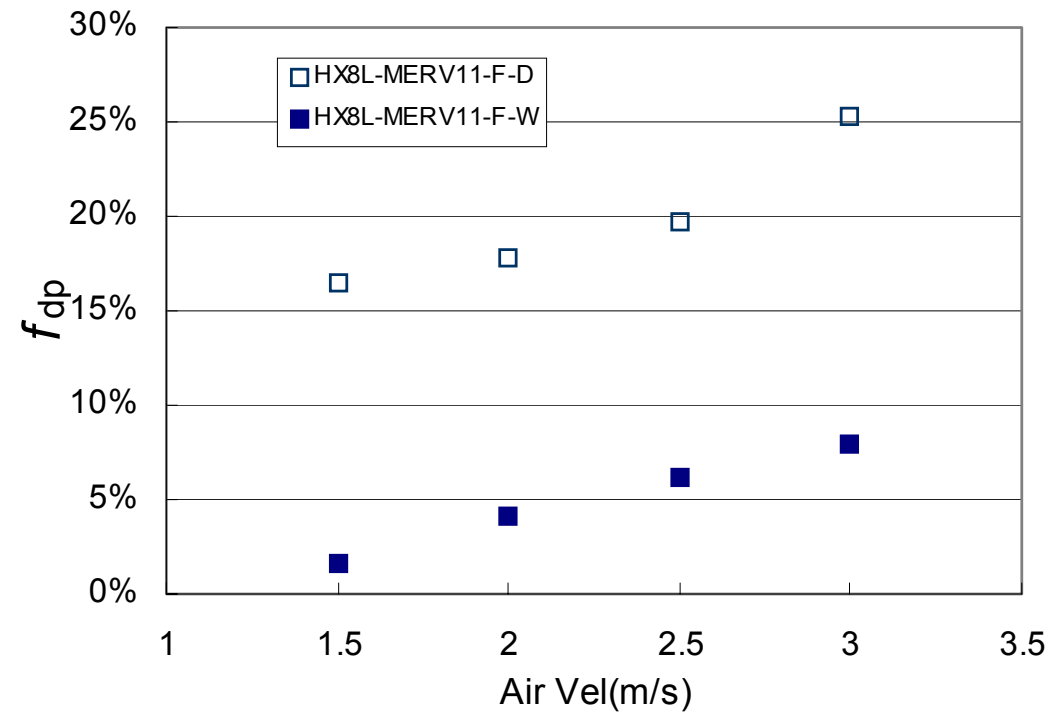

Figure 3.17: Pressure drop fouling factor vs. air velocity of HX8L-MERV11-F at dry and wet conditions

\subsubsection{Coil Effective Heat Transfer Coefficients at Dry and Wet Conditions}

Comparisons of fouling impacts on coil air-side effective heat transfer coefficients between dry and wet conditions were performed for HX8L with a MERV11 filter and no filter. For the dry tests, the air inlet relative humidity was set at $20 \%$ and no condensation was found during the tests.

From Figure 3.18, at clean test conditions, it can be seen that the coil air-side effective heat transfer coefficient for wet conditions was $9 \%$ higher than the effective heat transfer coefficient for dry conditions at an air velocity of $1.52 \mathrm{~m} / \mathrm{s}(300 \mathrm{ft} / \mathrm{min})$. When the air velocity increased, the difference became smaller. At an air velocity of $3.05 \mathrm{~m} / \mathrm{s}(600$ $\mathrm{ft} / \mathrm{min}$ ), the effective heat transfer coefficient at a wet condition was slightly smaller than the one at dry condition. This may be due to experimental error.

Figure 3.19 shows the effective heat transfer coefficient fouling factors for dry and wet conditions. At both conditions, the heat transfer was reduced after fouling. However, fouling made the effective heat transfer coefficient for wet conditions decrease within a range of $5 \%$, but it had a less effect on the dry condition results. Those effects may be due to experimental error. The overall effect is so small that it is difficult to identity reasons for these trends. 


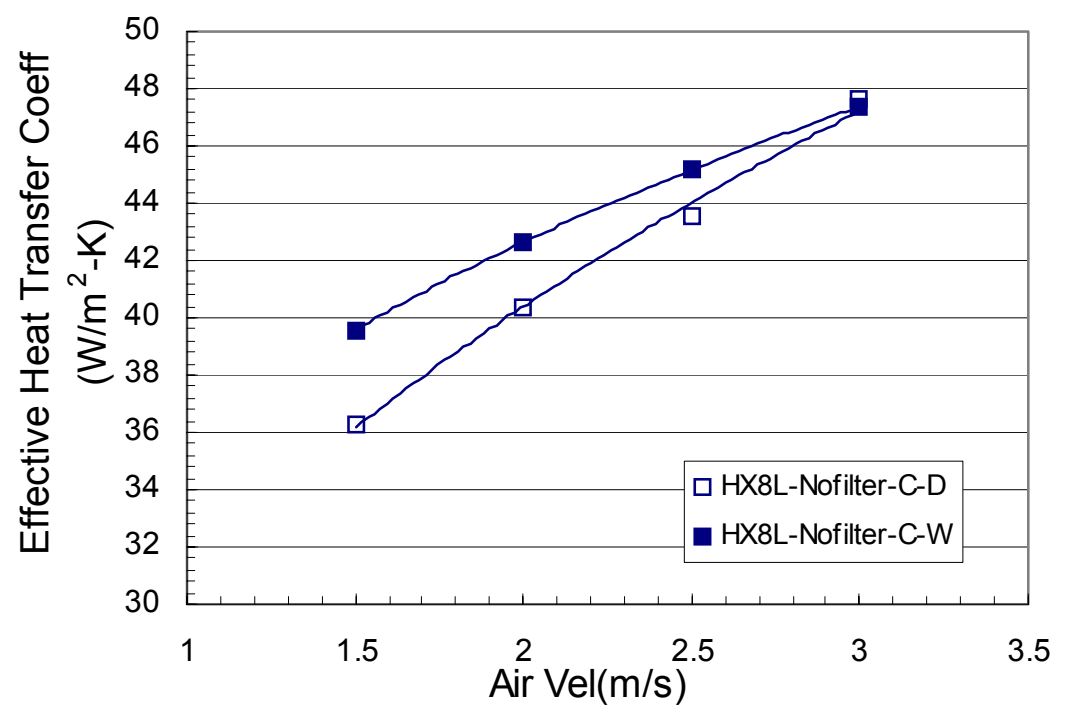

Figure 3.18: Effective heat transfer coefficient vs air velocity of HX8L-No-filter-C at dry and wet conditions.

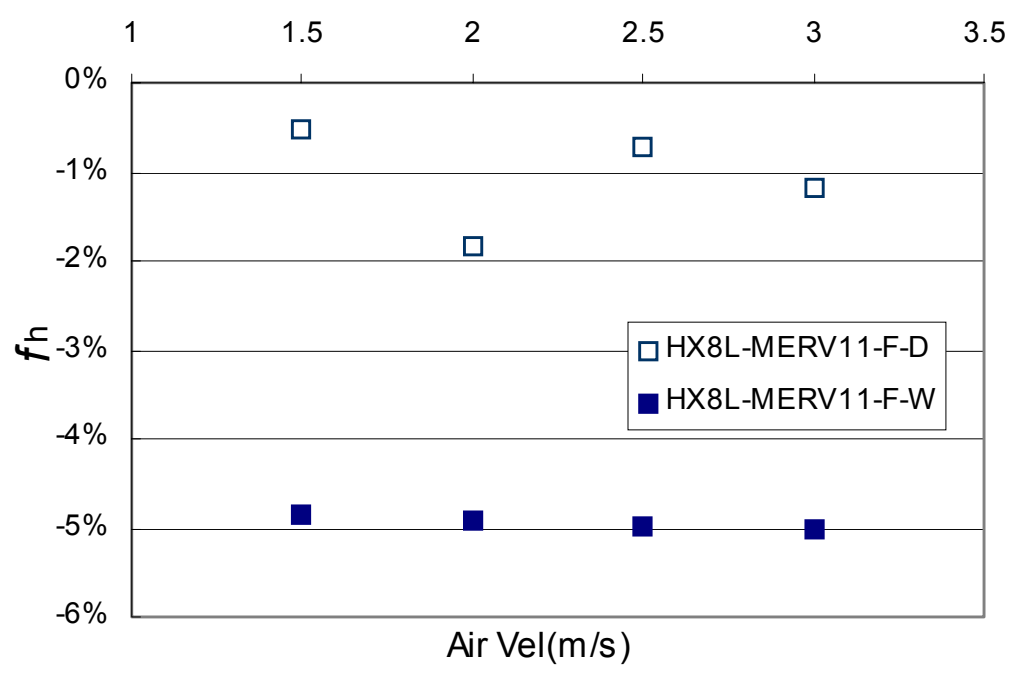

Figure 3.19: Effective heat transfer coefficient fouling factor vs. air velocity of HX8L-MERV11-F at dry and wet conditions. 


\section{IAQ EFFECTS}

Filtration impacts IAQ (Indoor Air Quality) and overall equipment performance. IAQ effects were quantified from the tests by obtaining the dust quantites passing the upstream filter and coil, which would be supplied to the indoor area. The quantity $M_{5}$ defined in Equation (3.1) was regarded as the amount of dust passing the upstream filter and coil.

Figures 4.1-4.4 show the percentage of $\mathrm{M}_{5}$ relative to the total 600 grams of injected dust for all cases. Approximately $0.5 \%-1.8 \%$ of dust passed through the coil with an upstream filter of MERV14 or MERV11; 4.8\%-7.3\% of dust passed through the coil with a MERV8 or MERV6 filter; $15.5 \%-18.8 \%$ of dust passed coil for MERV4 cases and approximately $30 \%$ of dust passed coil without any upstream filter. The mass of dust that would enter the indoor space for no-filter cases was nearly 60 times of the mass of dust for MERV14 cases. The difference is extremely large compared to the equipment system impact, which will be discussed in next section. 


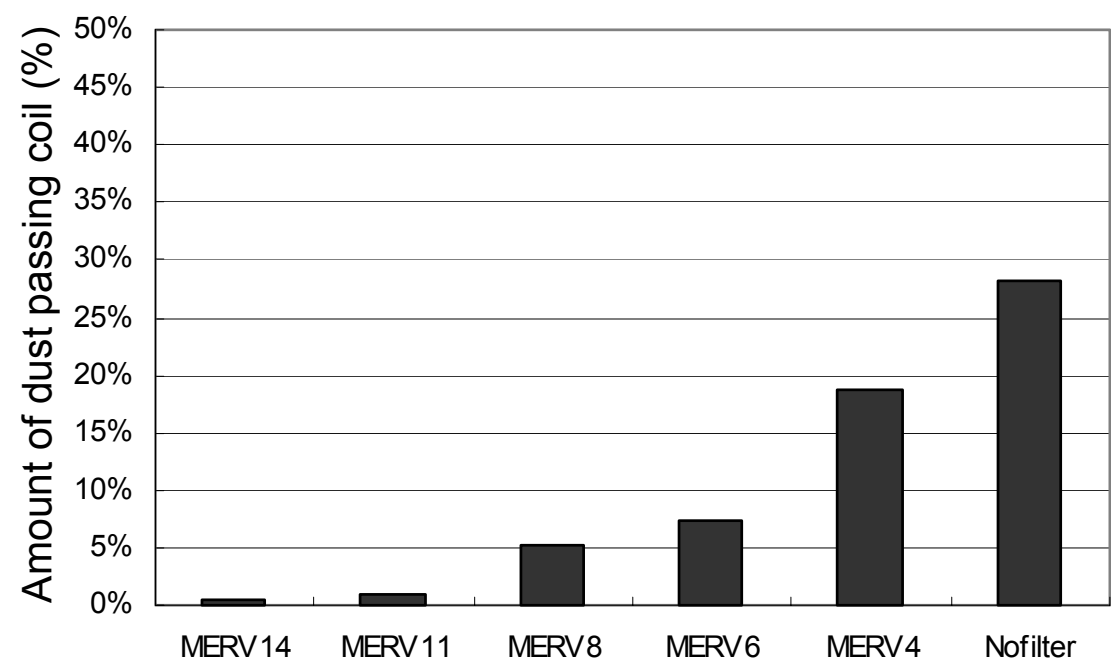

Figure 4.1: Dust quantities passing coil and filter for HX8W cases

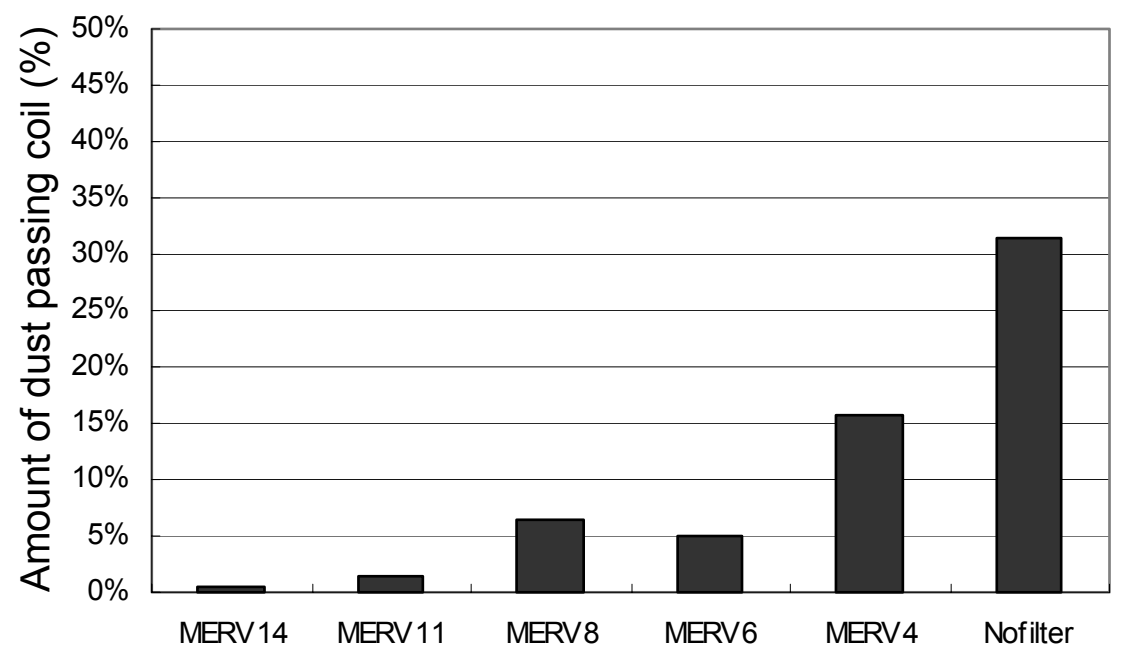

Figure 4.2: Dust quantities passing coil and filter for HX8L cases 


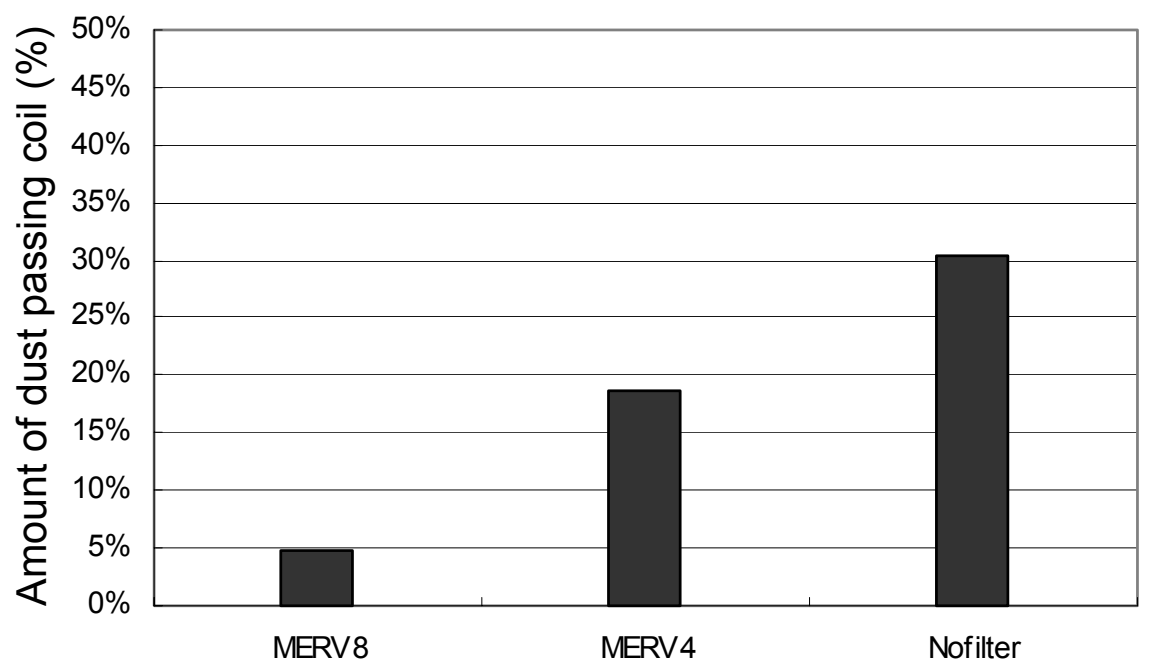

Figure 4.3: Dust quantities passing coil and filter for HX4L cases

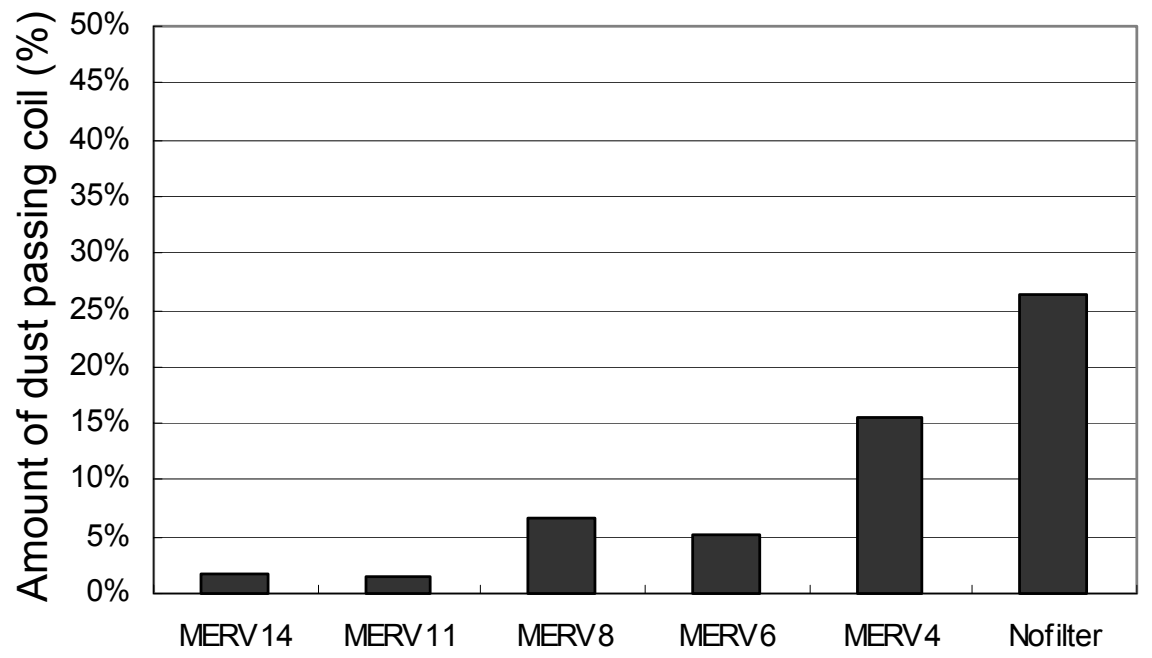

Figure 4.4: Dust quantities passing coil and filter for HX2L cases 


\section{EQUIPMENT PERFORMANCE EFFECTS}

This section addresses the overall fouling impact on equipment performance. Fouling affects the coil air-side heat transfer coefficient which influences the cooling capacity and efficiency. Fouling also increases the coil and filter pressure drop which reduces the air flow rate and increases fan power, which in turn reduces cooling capacity and increases compressor power. As shown in Section 3, the impact of fouling on pressure drop is more significant than the impact on heat transfer coefficient. In order to study the overall impact of fouling on equipment performance, a computer model was employed. Fouling factors from the laboratory tests were used along with baseline simulations for small, medium, and large direct expansion packaged air conditioners. The following sections describe the model, equipment selections, process of equipment modeling and results of the study.

\subsection{ACMODEL}

ACMODEL is a public-domain computer model developed at Purdue, which can predict the system performance of unitary air conditioners and heat pumps. It was used to obtain cooling capacity and compressor power of equipment that would employ the different test coils considered in this project. ACMODEL is extremely modular and uses separate subroutines to model each of the components of a packaged air conditioner or heat pump.

ACOMODEL accepts two kinds of compressor empirical equations for both the mass flow and power consumption. The first is based on a compressor map from the manufacturer, and the second is an ARI polynomial equation. ACMODEL can model multiple row condensing and evaporating coils. It separates each tube in the heat exchanger into smaller segments. The heat transfer for each segment is calculated with an effectiveness-NTU method. Because of its modular structure, it is simple to add new modules into ACMODEL. A modified Newton's method algorithm works as the equation solver. With respect to the iteration of the equation solver, it starts with three initial guesses, suction and discharge pressure, and the suction enthalpy.

So far, ACMODEL has been validated with data from six R-22 units. The normal capacities of these units ranged from 2 tons to 7.5 tons. They were tested at five conditions with the ambient temperature ranging from $27.8{ }^{\circ} \mathrm{C}$ to $51.7{ }^{\circ} \mathrm{C}\left(82{ }^{\circ} \mathrm{F}\right.$ to $\left.125^{\circ} \mathrm{F}\right)$, the 
relative humidity ranging from $20 \%$ to $50 \%$ and the indoor temperature of $26.7^{\circ} \mathrm{C}\left(80{ }^{\circ} \mathrm{F}\right)$. For this project, the experimental correlations and fouling factors of different filter-coil combinations were incorporated into the program to replace the original built-in correlations.

\subsection{Equipment Descriptions}

The coils tested in this project, i.e., the eight-row (HX8W, HX8L), four-row (HX4L) and two-row (HX2L) coils, would be employed in medium commercial, small commercial and residential packaged units. Table 5.1 provides information on the units considered in the simulations.

The 35-ton unit that was employed in this study was a typical commercial rooftop unit. All physical data including the compressor equations, condenser and evaporator configurations and fan performances were provided from the manufacturer. The 3-ton and 5-ton units were manufactured by a different manufacturer and they have been used in previous studies by Rossi (1995) and LeRoy (1997) for validating predictions from ACMODEL. The physical data were collected and integrated into the model. The fan curves for actual fans employed in the 3-ton and 5-ton units were not available. Thus, performance curves for similar fans were employed. 
Table 5.1: Descriptions of simulated equipment

\begin{tabular}{|l|c|c|c|}
\hline & 3-ton rooftop & 5-ton rooftop & 35-ton rooftop \\
\hline Refrigerant & \multicolumn{3}{|c|}{ R-22 } \\
\hline Compressor & Reciprocating*1 & Scroll*1 & Scroll*2 \\
\hline Exp. Device & \multicolumn{3}{|c|}{ Thermal Exp. Valve } \\
\hline Condensor rows & 1 & 2 & 4 \\
\hline Evaporator rows & 2 & 4 & 8 \\
\hline Evap: tube diameter $(\mathrm{mm})$ & $9.53(0.38 ”)$ & $12.7(0.50 ”)$ & $12.7(0.50 ”)$ \\
\hline Evap: tube thickness $(\mathrm{mm})$ & $0.65(0.0256 ”)$ & $0.65(0.0256 ”)$ & $0.55(0.0217 ”)$ \\
\hline Evap: fin density $(\mathrm{fin} / \mathrm{cm})$ & $5.51(14 \mathrm{fin} / \mathrm{inch})$ & $4.72\left(12 \mathrm{fin}^{\prime} / \mathrm{inch}\right)$ & $3.15(8 \mathrm{fin} / \mathrm{inch})$ \\
\hline Evap: fin thickness $(\mathrm{mm})$ & $0.19\left(0.0075^{\prime \prime}\right)$ & $0.114\left(0.0045^{\prime \prime}\right)$ & $0.15(0.0059 ”)$ \\
\hline Evap: face area $\left(\mathrm{m}^{2}\right)$ & $0.372\left(4 \mathrm{ft}^{2}\right)$ & $0.372\left(4 \mathrm{ft}^{2}\right)$ & $1.858\left(20 \mathrm{ft}{ }^{2}\right)$ \\
\hline Evap: nominal airflow $\left(\mathrm{m}^{3} / \mathrm{s}\right)$ & $0.57\left(1200 \mathrm{ft}^{3} / \mathrm{min}\right)$ & $0.94\left(2000 \mathrm{ft}^{3} / \mathrm{min}\right)$ & $4.72\left(10000 \mathrm{ft}^{3} / \mathrm{min}\right)$ \\
\hline
\end{tabular}

\subsection{Modeling Process}

Cooling capacity $\left(Q_{c}\right)$, compressor power $\left(W_{c}\right)$, evaporator-side fan power $\left(W_{f e}\right)$ and condenser-side fan power $\left(W_{f_{c}}\right)$ were four critical performance factors obtained in the modeling process. $Q_{c}$ and $W_{c}$ were determined by ACMODEL and $W_{f e}$ and $W_{f c}$ were determined using fan characteristics and system pressure drop. EER (Energy Efficiency Ratio) was obtained from the capacity and total power consumption for clean and fouling cases.

For each coil, the clean case was simulated within an ambient temperature range $\left(27^{\circ} \mathrm{C}\right.$ $\left.-45^{\circ} \mathrm{C}\left(81^{\circ} \mathrm{F}-113^{\circ} \mathrm{F}\right)\right)$ to obtain cooling capacity and compressor power at the nominal air flow rate. Then, the six fouling cases (five filter-cases and one no-filter-case) were simulated successively and the capacity and compressor power at fouled condition were predicted. In these cases, the air flow rate decreased somewhat from the nominal flow rate and was determined from the fan curve and system pressure drop.

In the next step, the evaporator-side fan power and condenser-side fan power was calculated. The condenser was assumed to be clean and the fan operated with a fixed air flow rate and thus, the condenser fan power was a constant. The condition was more complicated for the evaporator-side fan because the evaporator air-side pressure drop 
changed after fouling. The following describes the process to determine the evaporator-side air flow and fan power.

(1) System pressure drop and fan power at clean conditions

The system static pressure drop included three parts: filter pressure drop, coil air-side pressure drop and additional pressure drop in the air distribution system as:

$$
\Delta P_{s y s, c}=\Delta P_{f, c}+\Delta P_{c, c}+\Delta P_{d i s t}
$$

where:

$$
\begin{aligned}
& \Delta P_{f, c}=e_{c} V_{c}^{g_{c}} \\
& \Delta P_{c, c}=a_{c} V_{c}^{b_{c}}
\end{aligned}
$$

$V_{c}$ is the air velocity at clean conditions and the factors $e_{c}, g_{c}, a_{c}, b_{c}$ were determined from experiments and are given in Appendix 1, Table A1 and Table A3.

The additional system pressure drop includes frictional losses that occur along the entire air duct length and within fittings. This distribution pressure loss would depend on the installation, but would also depend on the square of the velocity according to:

$$
\Delta P_{\text {dist }}=K V_{c}^{2}
$$

$\Delta P_{\text {dist }}$ was assumed not to be impacted by fouling. For the modeling presented here, the value of $\Delta P_{\text {dist }}$ was set at the design air velocity so that $\Delta P_{s y s, c}$ was determined and the fan ran at the its peak efficiency $\eta_{c}$ for the highest filter tested (MERV 14 for the 2 and 8-row coils and MERV8 for the 4-row coil). $\Delta P_{\text {dist }}$ was then fixed for all other filter cases, so for those filter cases, the fan efficiency was not at the peak value. The factor $K$ was obtained from $\Delta P_{\text {dist }}$ and $V_{c}$ (see Appendix 1, Table A4).

Corresponding to the design air velocity and system pressure drop at clean conditions, the required fan speed was then determined according to the performance table provided by the manufacturer. Fan power $W_{f e, c}$ was also determined with performance table. Figure 5.1 shows a diagram of the system pressure drop and fan curve for both clean and fouled conditions. The fan operates at the intersection of the fan and system 
characteristic. As the coil and filter foul, the pressure drop increases and the air flow is reduced.

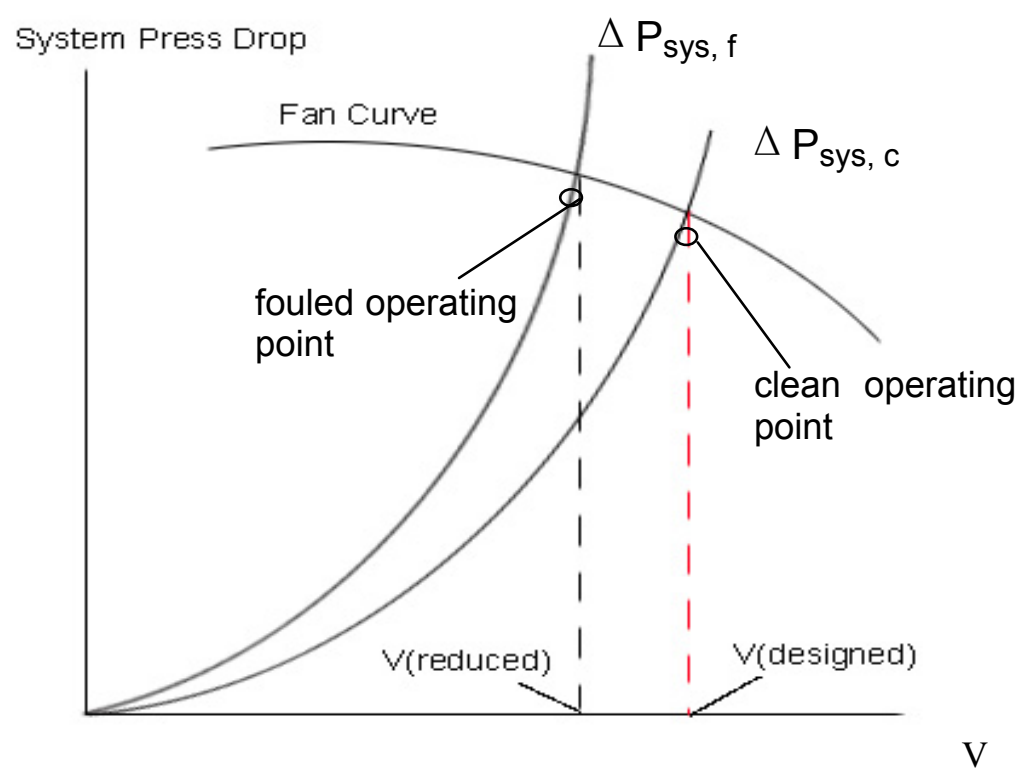

Figure 5.1: System pressure drop and fan curve

(2) System pressure drop and fan power at fouled conditions

After fouling, the system pressure drop increases while the fan speed does not change. Therefore, the new system pressure drop line intersects the original fan curve at a lower air velocity $V_{f}$ (reduced) and higher system pressure drop $\Delta P_{s y s, f}$.

The system static pressure drop at fouled condition was determined with:

$$
\Delta P_{s y s, f}=\Delta P_{f, f}+\Delta P_{c, f}+\Delta P_{d i s t}
$$

where:

$$
\begin{aligned}
& \Delta P_{f, f}=e_{f} V_{f}^{g_{f}} \\
& \Delta P_{c, f}=a_{f} V_{f}^{b_{f}} \\
& \Delta P_{\text {dist }}=K V_{f}^{2}
\end{aligned}
$$

Here, $V_{f}$ is the reduced air velocity and the factors $e_{f}, g_{f}, a_{f}, b_{f}$ were determined from the experiments and are given in Appendix1, Table A1 and Table A3. 
Fan power $\left(W_{f e, f}\right)$ was obtained from the performance data with a known $\Delta P_{s y s, f}$ and reduced air velocity. Fan efficiency changed from $\eta_{c}$ to $\eta_{f} . W_{f e, f}$ could increase or decrease compared to $W_{f e, c}$ according to the following equation:

$$
W_{f e, c(f)}=\frac{\dot{V}_{c(f)} \Delta P_{s y s, c(f)}}{\eta_{c(f)}}
$$

where $\dot{V}_{c(f)}$ is air volumetric flow rate $\left(\mathrm{m}^{3} / \mathrm{s}\right)$ at clean or fouled conditions.

$\dot{V}$ dropped after fouling while $\Delta P_{\text {sys }}$ increased. $\eta$ decreased if $\eta_{c}$ was set at the peak value but it was possible to increase if $\eta_{c}$ was not at the peak to begin with. Therefore, as a result of the tradeoffs between these factors, $W_{f e}$ could increase or decrease after fouling, but it generally increased in this study.

The final step was to compute EER of the equipment. EER is defined as a ratio calculated by dividing the difference of cooling capacity and evaporator-side fan power in Btu per hour by the power input in Watts at rating conditions, expressed in Btu/hr per Watt:

$$
E E R=\frac{Q_{c}-w_{f e}}{w_{c}+w_{f e}+w_{f c}} B .412\left(\frac{\mathrm{btu} / \mathrm{hr}}{W}\right)
$$

It was found that $W_{f e}$ had a very critical effect on EER. At a typical fan efficiency of $30 \%$ to $40 \%, W_{f e}$ was approximately $13 \%$ to $37 \%$ of the total power.

Figures 5.2 and 5.3 depicts the baseline cooling capacity and EER for all coils computed from the model. Both cooling capacity and EER decrease with the ambient temperature which ranges from $27^{\circ} \mathrm{C}$ to $45^{\circ} \mathrm{C}\left(81^{\circ} \mathrm{F}\right.$ to $\left.113^{\circ} \mathrm{F}\right)$. The cooling capacity decreases by $14 \%$ to $19 \%$ and the EER decreases by $30 \%$ to $40 \%$ with outdoor temperature. 


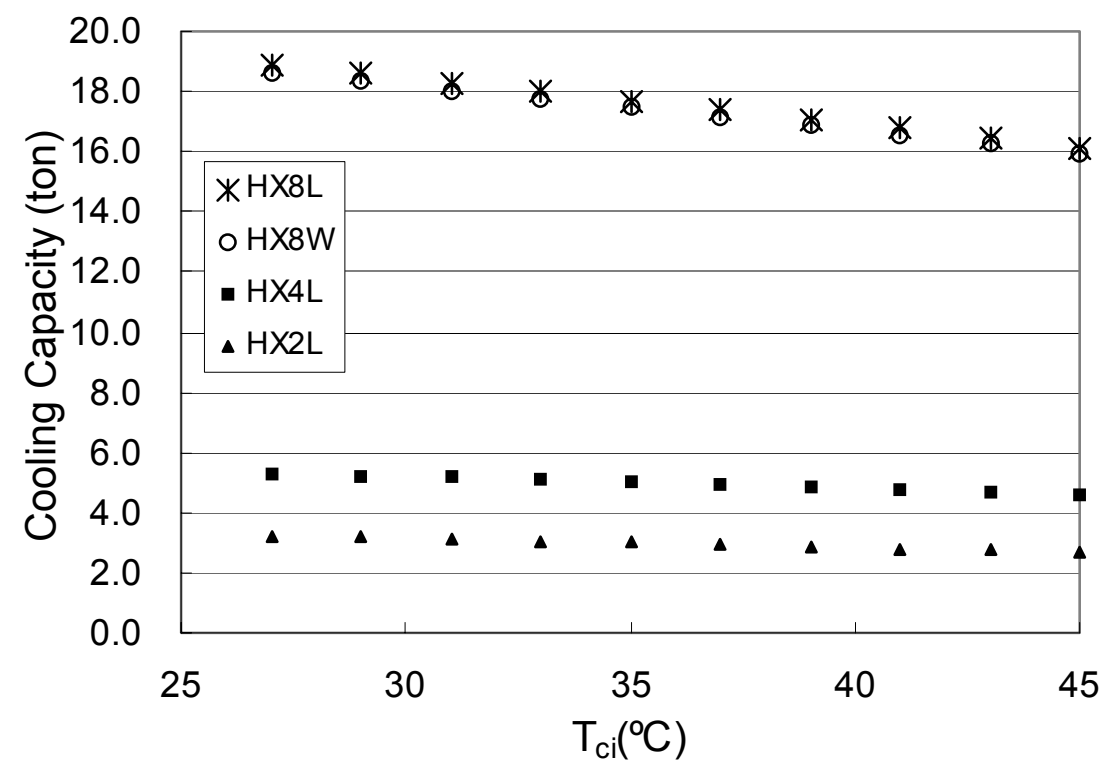

Figure 5.2: Baseline cooling capacity vs. condenser side inlet temperature for all coils

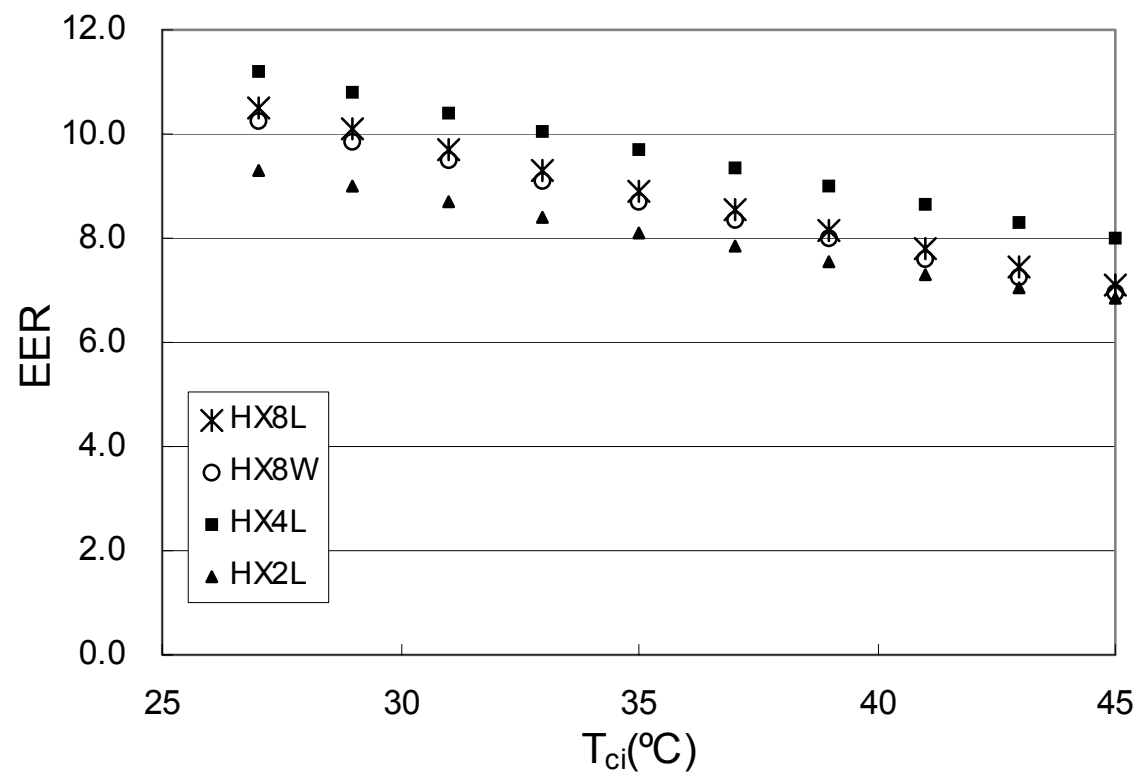

Figure 5.3: Baseline EER vs. condenser side inlet temperature for all coils 


\subsection{Fouling Impact on Equipment Capacity and EER}

\subsubsection{Capacity Impact}

Fouling affects the equipment cooling capacity through two ways: through reduction in heat transfer coefficient and through reduction in air flow. It was found from the experimental test that the heat transfer coefficient could actually increase with limited fouling. Even with significant fouling, the degradation in heat transfer coefficient was small. Furthermore, this impact was small compared to the impact on coil air-side pressure drop. As a result of the increase of coil and filter pressure drop, the air flow rate decreases so that the total cooling capacity decreases as well.

For one year's dust loading (600 grams of dust), the degradation in cooling capacity after fouling was not very significant. The decrease in cooling capacity was approximately $2 \%$ to $4 \%, 2 \%$ to $3 \%, 5 \%$ to $7 \%$, and $4 \%$ to $5 \%$ for the 35 -ton (HX8L), 35-ton (HX8W), 5-ton (HX4L) and 3-ton (HX2L) units, respectively. The effect is greater for smaller system that employs shallower coils with higher fin densities. Figure 5.4 shows the degradation for all filter cases for the 3-ton (HX2L) unit as an example. (Appendix 2, Figure A3 gives results for all coil cases). The capacity ratio (capacity divided by the capacity of the no-filter case at clean conditions) was used as the vertical axis. Since for all cases at clean conditions the air flow rate was set at the design value $(1.52 \mathrm{~m} / \mathrm{s}$ for 3 -ton unit) and the coil had the same performance, all clean cases had the same cooling capacity ratios. 


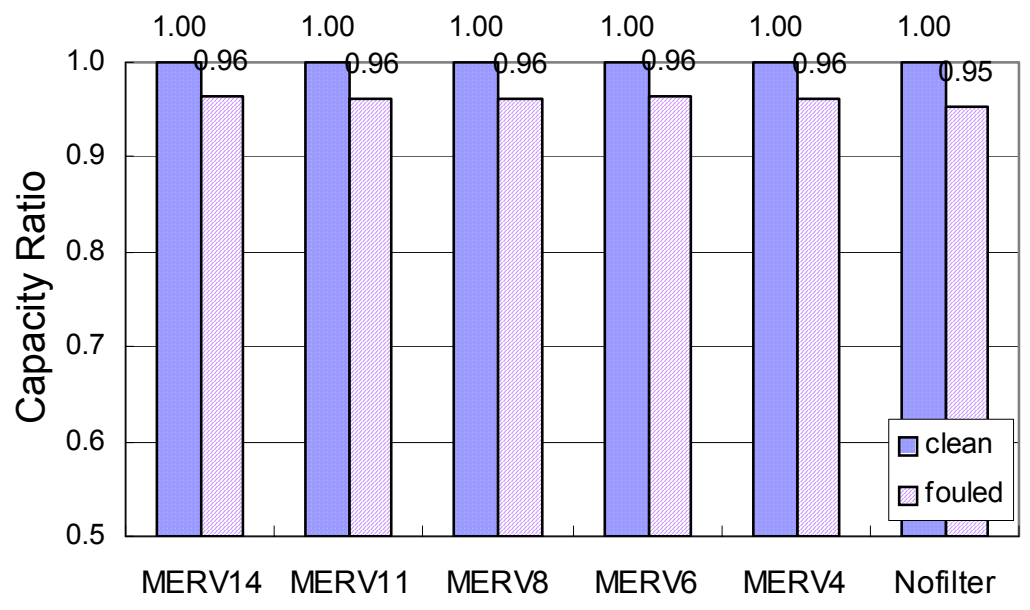

Figure 5.4: Capacity ratio of all coil-filter cases for $\mathrm{HX} 2 \mathrm{~L}\left(T_{c i}=35^{\circ} \mathrm{C}\right)$

\subsubsection{EER Impact}

EER values for all cases (for different coil-filter combinations and at clean and fouled conditions) were obtained. For each coil, all EER values were compared with EERs for no-filter clean cases so that EER ratios were obtained and are presented in Figures 5.5 through 5.8.

From the results in Figures 5.5 to 5.8, it was concluded that: (1) the clean equipment without an upstream filter worked at the highest EERs for all coil cases. (2) The equipment with the highest MERV filters got the lowest EERs for all clean coil cases. (3) The EER decreased significantly after fouling. For the 35-ton units (HX8L and HX8W), the degradations ranged from $2 \%$ to $10 \%$ ( $2 \%$ for no-filter case); for the 5 -ton unit, the degradation ranged from $3 \%$ to $8 \%$ ( $8 \%$ for no-filter case); for the 3 -ton unit, the degradation ranged from $6 \%$ to $10 \%$ (10\% for no-filter case). It was found that the 3 -ton unit had the greatest degradation and the 35-ton units had the smallest degradation with fouling. In addition, for the larger equipment, the impact of fouling was greater for the high efficiency filter, whereas the opposite was true for the smaller units. This is due to that fact that fouling has a greater impact on shallower designs. (4) The greatest impact of filter choice on EER occurred for the larger capacity equipment. This was caused by different fan performance: the 35-ton unit had a steep fan efficiency curve so that EER 
varied greatly with system pressure drop, which was influenced by both filter choice and fouling. The 3-ton unit had a more flat fan efficiency curve. The differences would be eliminated if these units had similar fan performance characteristics. The influence of fan curves will be discussed in the following section.

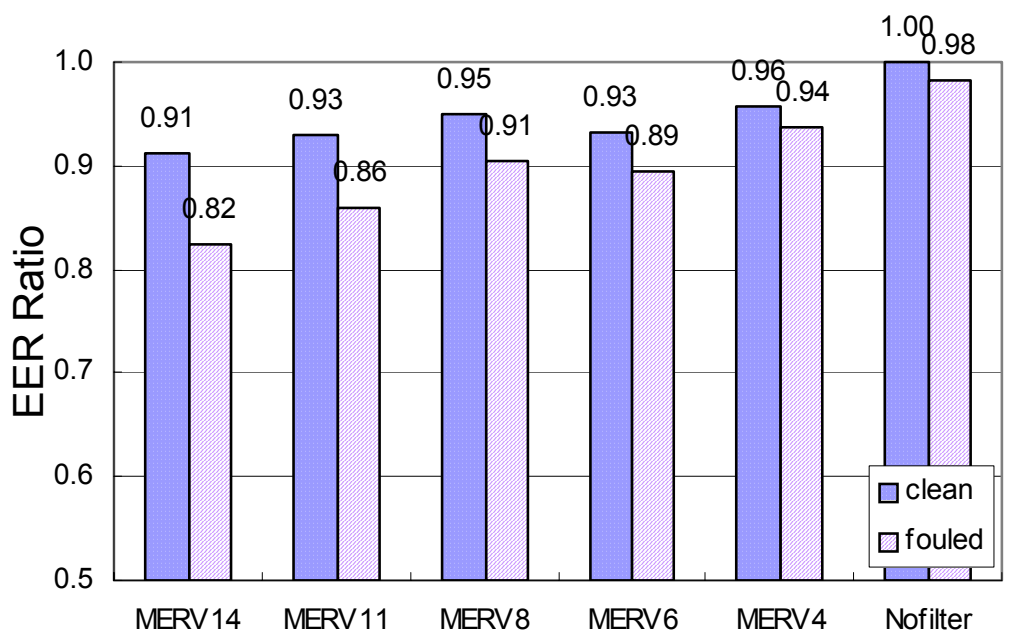

Figure 5.5: EER ratio of all coil-filter cases for $\operatorname{HX8L}\left(T_{c i}=35^{\circ} \mathrm{C}\right)$

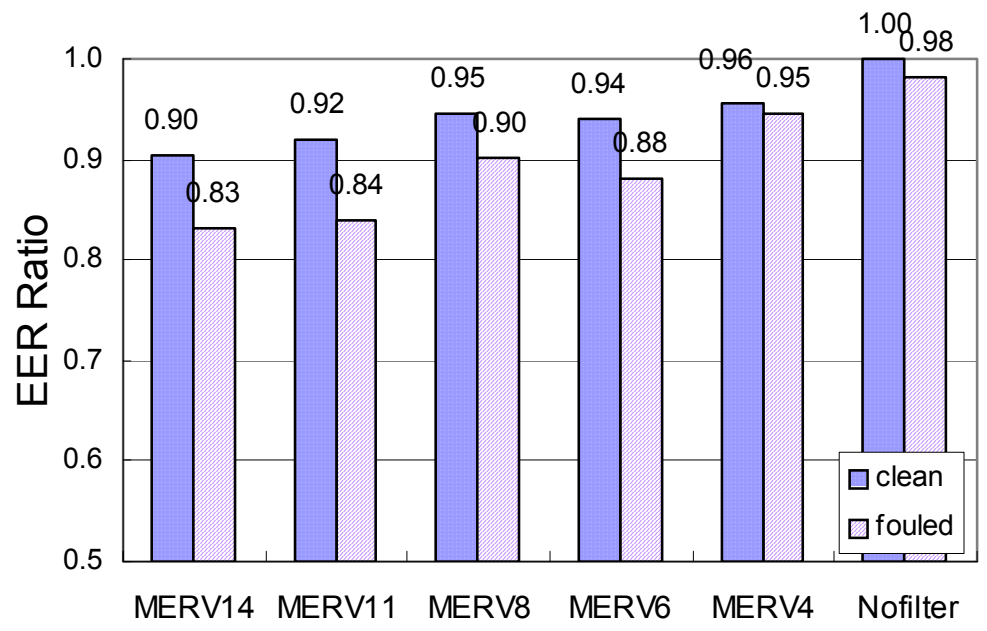

Figure 5.6: EER ratio of all coil-filter cases for $\mathrm{HX} 8 \mathrm{~W}\left(T_{c l}=35^{\circ} \mathrm{C}\right)$ 


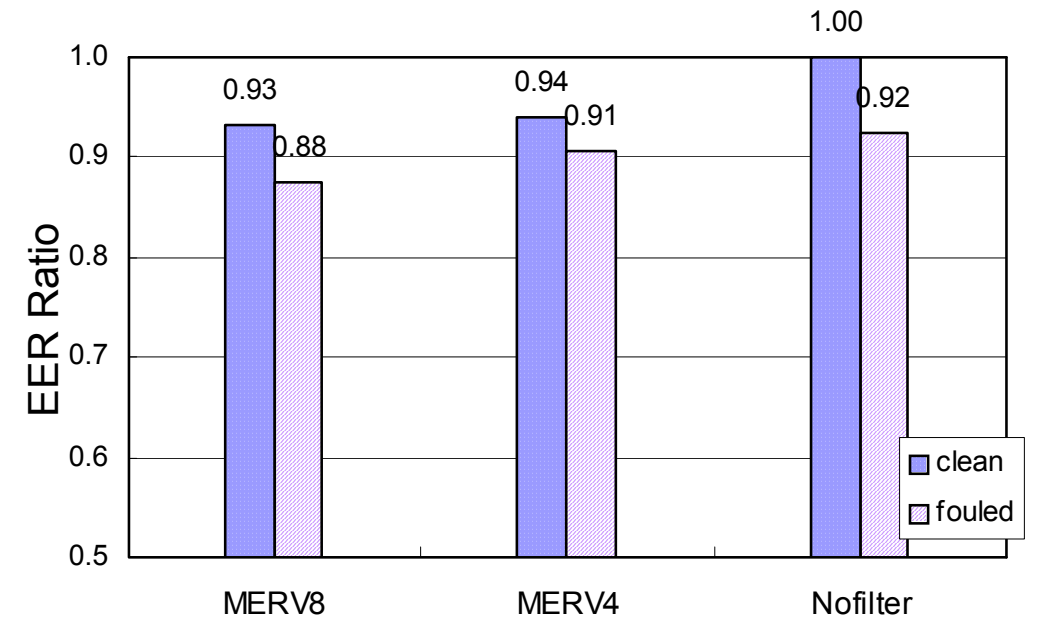

Figure 5.7: EER ratio of all coil-filter cases for $\mathrm{HX} 4 \mathrm{~L}\left(T_{c i}=35^{\circ} \mathrm{C}\right)$

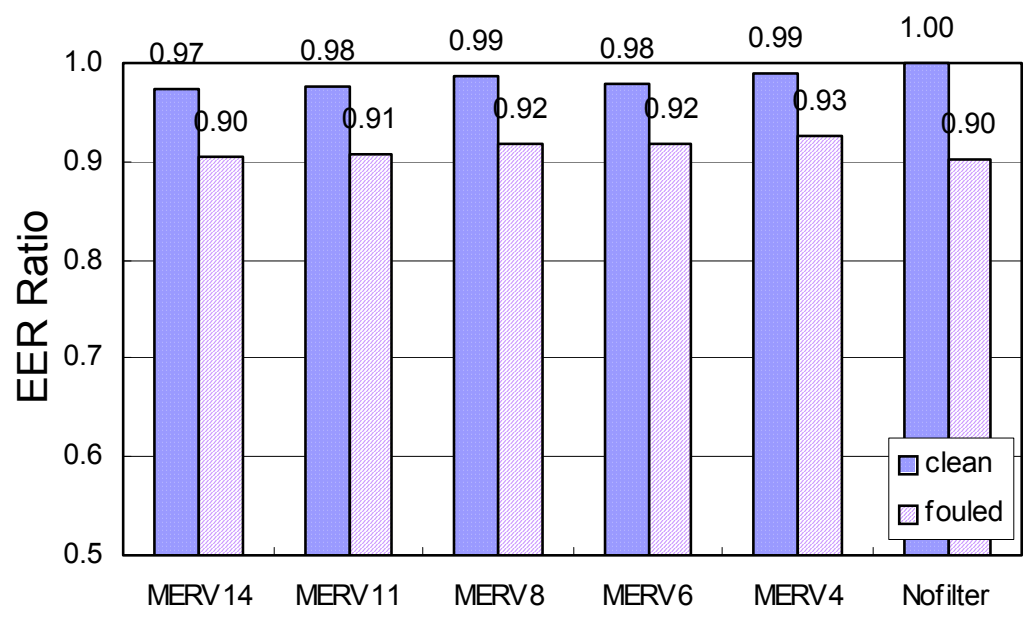

Figure 5.8: EER ratio of all coil-filter cases for $\mathrm{HX} 2 \mathrm{~L}\left(T_{c i}=35^{\circ} \mathrm{C}\right)$

\subsubsection{Influence of Fan Efficiency Curve on EER}

For the previous results, the evaporator side fan power $W_{f e}$ was approximately $13 \%$ to $37 \%$ of the total power with the fan efficiency of approximately $30 \%$ to $40 \%$. Therefore, the results are sensitive to the fan curve and fan efficiency. To study the influence of fan efficiency, two cases were considered:

(1) Assume that the fan efficiency does not change with air flow rate and pressure drop: $38 \%$ for 35 -ton (HX8L and HX8W) units, $28 \%$ for 5-ton (HX4L) unit and 29\% for 
3-ton (HX2L) unit. These efficiencies were the peak values for the actual fan curves.

(2) Assume that the fan efficiency did not change with air flow rate and was $100 \%$ for all cases.

Figures 5.9-5.12 show the EER ratios for HX8L and HX2L for these two cases. (HX8W and HX4L had similar trends. See Appendix 2, Figures A13-A16 for their behaviors).

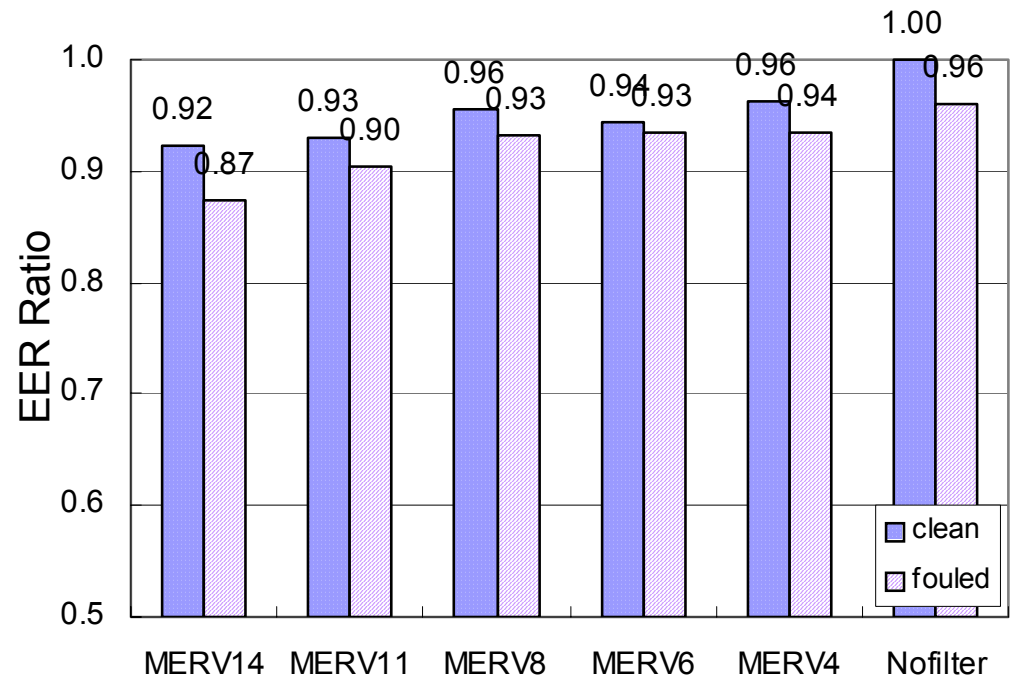

Figure 5.9: EER ratio of all coil-filter cases for HX8L when fan efficiencies at constant $38 \%\left(T_{c i}=35^{\circ} \mathrm{C}\right)$

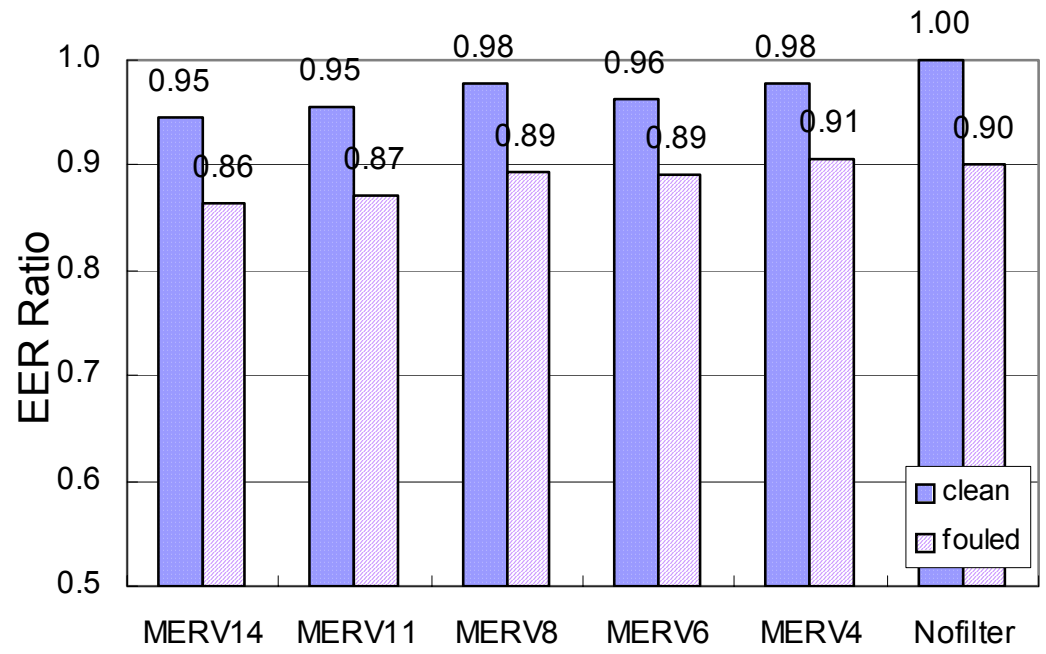

Figure 5.10: EER ratio of all coil-filter cases for HX2L when fan efficiencies at constant $29 \%\left(T_{c i}=35^{\circ} \mathrm{C}\right)$ 


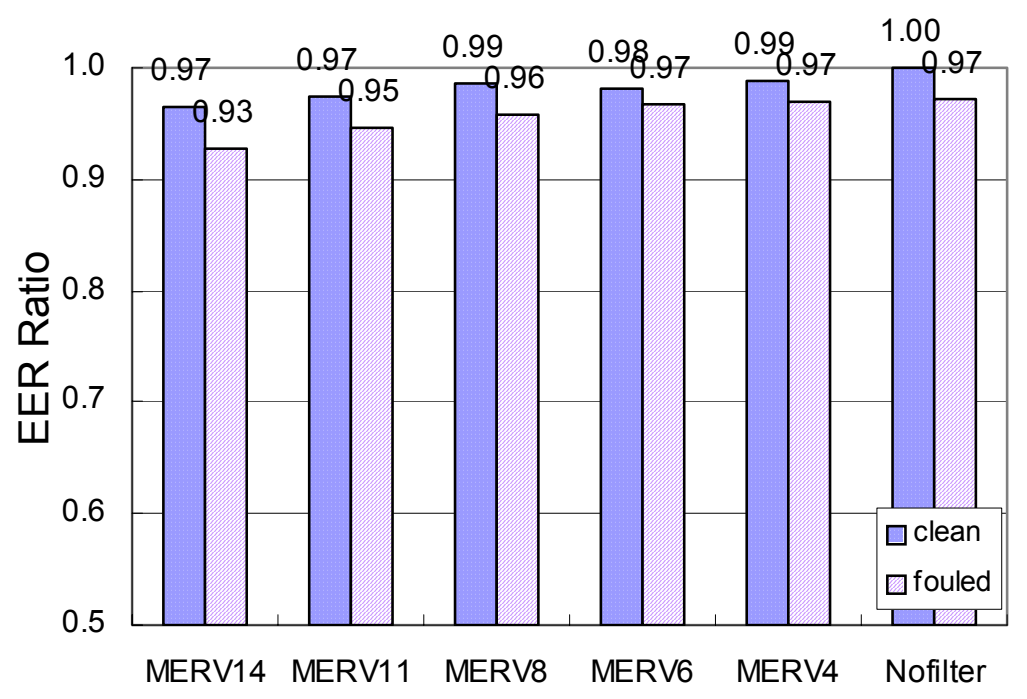

Figure 5.11: EER ratio of all coil-filter cases for HX8L when fan efficiencies at constant $100 \%\left(T_{c i}=35^{\circ} \mathrm{C}\right)$

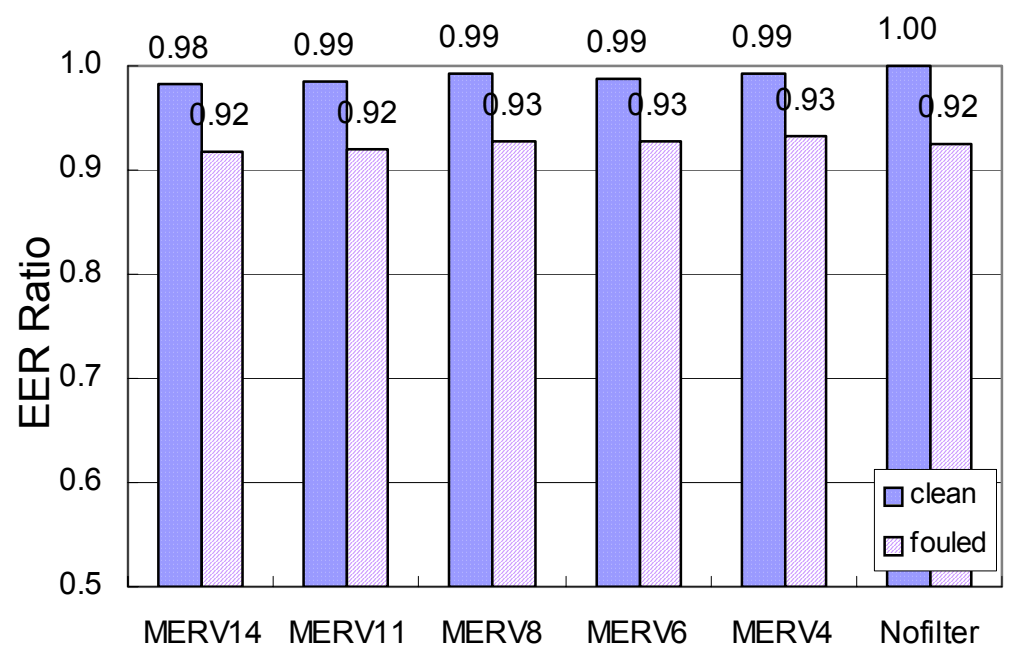

Figure 5.12: EER ratio of all coil-filter cases for HX2L when fan efficiencies at constant $100 \%\left(T_{c i}=35^{\circ} \mathrm{C}\right)$

Compared to the actual fan curves, the penalty associated with using high efficiency filters was reduced. This was particularly true for the higher capacity unit. Given a perfect fan curve ( $\eta_{f e}=100 \%$, Figures 5.11 and 5.12), the differences among all filter-cases were much smaller than for the original analysis with actual fan curves. 
The absolute value of EER increased from case1 to case3 (case1: with a fan efficiency of $100 \%$; case 2 : with a constant fan efficiency of $38 \%$ or $29 \%$; case 3 : with a constant fan efficiency of $100 \%$ ). This trend could not be represented since EER ratios were employed as the standard of comparison. Therefore, a different way to present the results was used. Figures 5.13 to 5.16 show EER of HX8L-C(F) and HX2L-C(F) for the three cases. From case 1 to case2, the EER increased slightly, but from case 2 to case3, the EER increased by approximately approximately $11 \%$ and $27 \%$ for the 3-ton and 35-ton units, respectively. It indicates that EER values increase significantly with fan efficiencies. With higher efficiency fans, the energy penalty associated with high efficiency filters was reduced more considerably than that for low efficiency filters. 


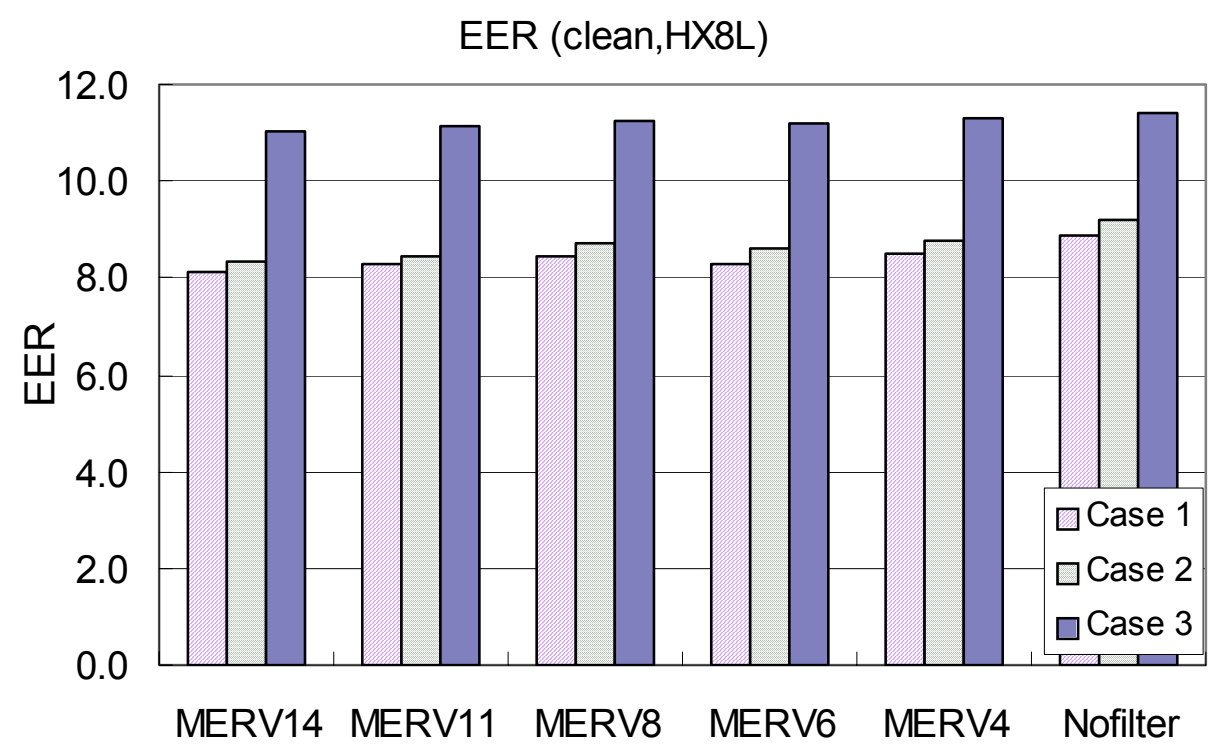

Figure 5.13: Comparison of EER values for HX8L at clean conditions for the three cases

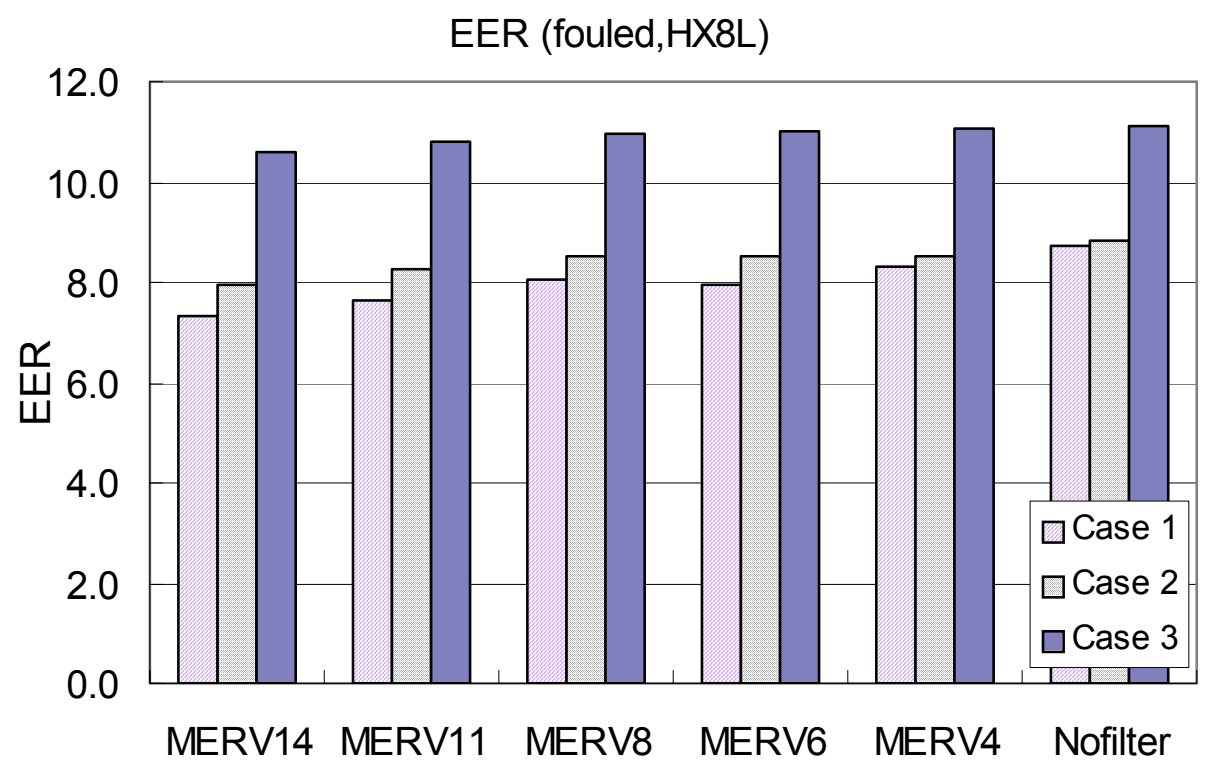

Figure 5.14: Comparison of EER values for HX8L at fouled conditions for the three cases

Case1: with actual fan curve

Case2: with a constant fan efficiency of $38 \%$ (for HX8L) or 29\% (for HX2L) Case3: with a constant fan efficiency of $100 \%$ 


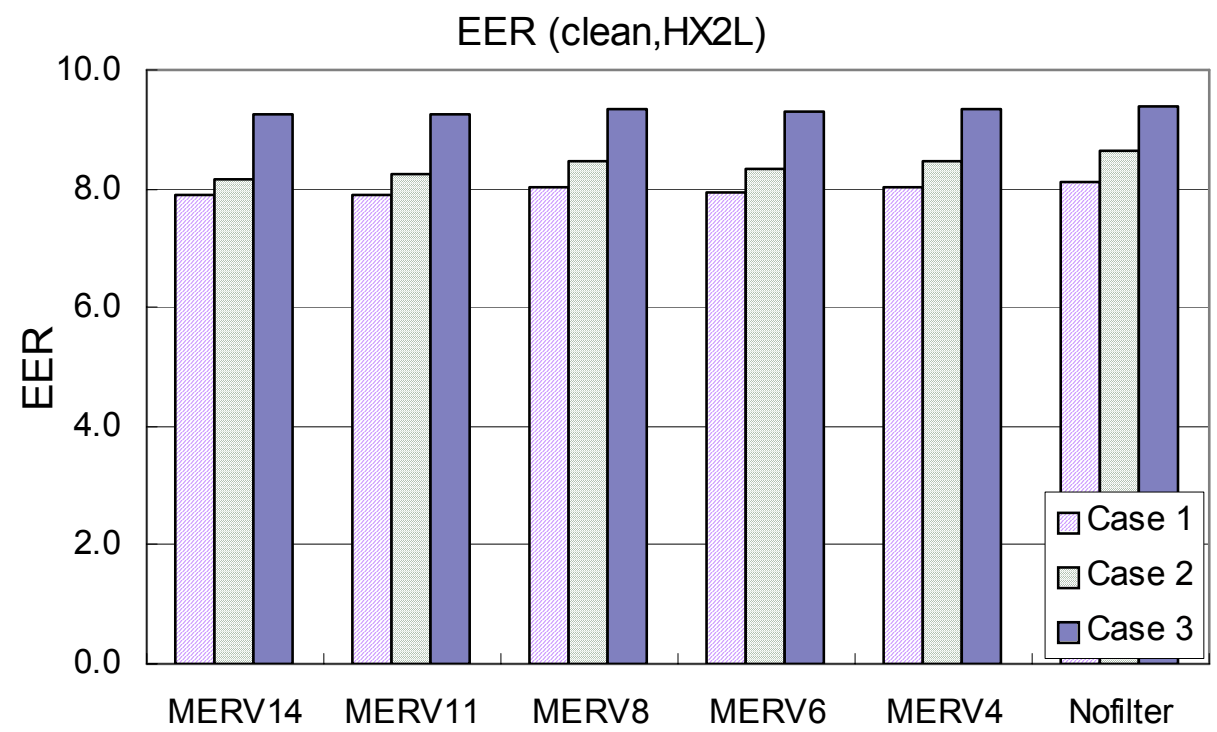

Figure 5.15: Comparison of EER values for HX2L at clean conditions for the three cases

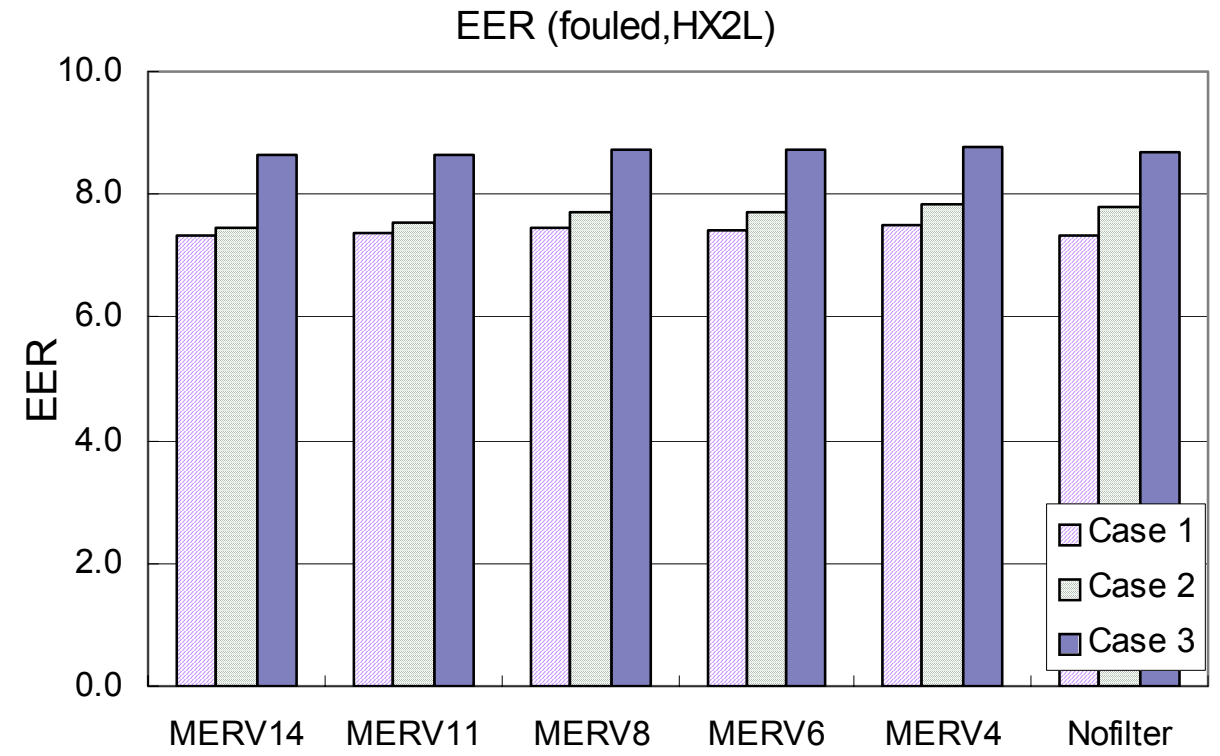

Figure 5.16: Comparison of EER values for HX2L at fouled conditions for the three cases.

Case1: with actual fan curve

Case2: with a constant fan efficiency of $38 \%$ (for HX8L) or $29 \%$ (for HX2L) Case3: with a constant fan efficiency of $100 \%$ 


\section{CONCLUSIONS AND RECOMMENDATIONS}

The collection and analysis of experimental data for four coils with different upstream filters provided useful results related to coil-filter performance. Data for coil air-side pressure drop and effective heat transfer coefficient at clean conditions and fouled conditions were then correlated and integrated in a simulation program to predict cooling capacity combining fan power computation, and total power under clean and fouled conditions. Some significant conclusions were obtained from the experimental and modeling study.

(1) Depending on the quantity of dust deposited, heat transfer coefficients can increase or decrease with fouling for a fixed air velocity. The enhancement is due to increased turbulence. The experiments showed a maximum of approximately $4 \%$ increase in effective heat transfer coefficient after fouling, whereas the maximum penalty for a year's worth of dust deposits with no filter was approximately $14 \%$ at an air velocity of $2.54 \mathrm{~m} / \mathrm{s}(500 \mathrm{ft} / \mathrm{min})$.

(2) Fouling has a greater effect on coil air-side pressure drop than heat transfer coefficient. When loading dust, the pressure drop fouling factor increases continuously. For the highest efficiency filter the pressure drop increased by approximately $6 \%$, whereas for no filter the increase was approximately $200 \%$ at an air velocity of $2.54 \mathrm{~m} / \mathrm{s}(500$ $\mathrm{ft} / \mathrm{min})$.

(3) Fouling has less effect on coil air pressure drop for deeper coils. This probably because deeper coils used in medium to large commercial applications generally have larger fin spacings than shallower coils used in residential and small commercial. Most of the dust was captured by the leading edges of coil. It was observed that the rear of the coil was very clean compared to the front for the coil. When coils were tested without an upstream filter, the pressure drop fouling factor was approximately $45 \%$ for the eight-row coil, $100 \%$ for four-row coil and 200\% for two-row coil.

(4) Large equipment seems to be affected less by fouling than small equipment.

(5) Fouling decreases equipment cooling capacity because of reduced air flow rate. For a given air velocity, the heat transfer coefficient could decrease with fouling. However 
the decrease in air flow is a more significant effect. An average decrease of $8 \%$ of the air flow rate was determined from the simulations and test results.

(6) Slight differences are found for equipment cooling capacity penalties among different filter choices. However, using high efficiency filters results in significantly higher EER penalties especially for large equipment. For 35-ton units, the EER values decreased by $8 \%-10 \%$ after fouling for MERV14 cases, but by 1\%-2\% for MERV4 and no-filter cases. This was due to an increase in pressure drop and the influence of fan efficiency.

(7) Fouling affects evaporator-side fan power which in turn affects the equipment EER significantly. Given actual fan curves with an efficiency of approximately $30 \%$, the fan power was $13 \%-37 \%$ of the total power. Comparing the fan power for fouled conditions to the fan power for clean conditions, the variation ranged from approximately $-7 \%$ to a value as high as $40 \%$ in one case (HX2L-No-filter-F). The actual fan efficiency was low (approximately 30\%) and varied with air flow rate. The effect of fan efficiency was considered through simulation. The energy penalty associated with high efficiency filters was reduced considerably with higher efficiency fans.

(8) Equipment with high efficiency upstream filters has lower EERs than equipment with low efficiency filters. This is because of increased pressure drop.

(9) Equipment with high MERV upstream filters will provide significantly better air quality. For HX8L, the quantity of dust passing through the coil with a MERV4 filter was approximately 30 times the dust passing the coil with a MERV14 filter. Without an upstream filter, the quantity of dust passing through the coil was approximately 60 times the value for a MERV14 filter.

Only one year's dust loading (600 grams) was considered in this project. At this level, the fouling impacts on coil performance are relatively low. For 35-ton units (HX8L and HX8W), the EER was highest without any upstream filter at both clean and fouled conditions compared to any filter case. Therefore, further study with more dust loading is recommended. Furthermore, in this study, ASHRAE standard dust was used which was made of coarse particles (with sizes of $6 \mu \mathrm{m}$ and up). Smaller particles can be employed in the future work so that the whole size range of ambient particles is considered. 


\section{REFERENCES}

1 J. Taborek, T. Aoki, R. B. Ritter, J. W. Palen, "Fouling: The Major Unresolved Problem in Heat Transfer", Chemical Engineering Progress, v 55. No.2, p.59-67, (1972)

2 W. J. Marner, "Progress in Gas-Side Fouling of Heat-Transfer Surfaces", Appl Mech Rev, v 43, No.3, p.35-66, (1990)

3 C. B. Mort, "Research on exhaust gas effects on heat exchangers", Technical Report SEG-TR-66-30, Wright-Patterson Air Force Base, O.H. (1966)

4 J. A. Miller, "Mechanisms of gas turbine regenerator fouling", Paper No. 67-LGT-26, ASME, New York, (1967)

5 J. T. LeRoy, "Capacity and power demand of unitary air conditioners and heat pumps under extreme temperature and humidity conditions", Master's thesis, Herrick labs, Purdue University, (1997)

6 L. Burgmeier and S. Leung, "Heat exchanger and cleaning system", test report No. 81-17932, AiReserach Manufacturing Co, Torrance, C.A. (1981)

7 S. P. Henslee, and J. L. Bogue, "Fouling of a finned-tube heat exchanger in the exhaust of a stationary diesel engine: Final report”, Report No. EGG-FM-6189, Idaho Natl Eng Lab, Idaho Falls, I.D. (1983)

8 T. T. Semler, J. L. Bogue, S. P. Henslee and L.A. Casper, "Fouling of a finned-tube diesel flue gas heat recuperator", Fouling of Heat Exchanger Surfaces, Bryers, R. W., ed., Eng Foundation, New York, p.153-167, (1983)

9 J. A. Siegel, W. W. Nazaroff, "Predicting particle deposition on HVAC heat exchangers", Atmospheric Environment, v 37, Issues 39-40, December 2003, p. $5587-5596$

10 T. R. Bott, C. R. Bemrose. "Particulate Fouling on the Gas-side of Finned Tube Heat Exchangers", ASME J of Heat Transfer, v 105, p. 178-183 (1983)

11 G. Zhang, T. R. Bott, C. R. Bemrose, "Finned Tube Heat Exchanger Fouling by 
Particles", Heat Transfer, Proceedings of the Ninth International Heat Transfer Conf., p.115-120, (1990)

12 T. Cowell, D. A. Cross. "Air-side Fouling of Internal Combustion Engine Radiators", SAE Trans., v 89, paper No. 801012, p. 3179-3188 (1981)

13 T. M. Rossi, J. E. Braun, "Minimizing Operating Costs of Vapor Compression Equipment with Optimal Service Scheduling”, HVAC\&R Research, v 2. No.1, p.3-26, (1996)

14 T. M. Rossi, "Detection, diagnosis, and evaluation of faults in vapor compression cycle equipment." Ph.D. thesis, Herrick labs, Purdue University, Ind. Report No. 1796-3 HL 95-13, (1995)

15 B. C. Krafthefer, U. Bonne, "Energy Use Implications Of Methods To Maintain Heat Exchanger Coil Cleanliness", ASHRAE Transactions. v 92 pt 1B. Pub by ASHRAE, Atlanta, GA, USA p. 420-431, (1986)

16 B. C. Krafthefer, D. R. Rask, U. Bonne, "Air-Conditioning and Heat Pump Operating Cost Savings by Maintaining Coil Cleanliness", ASHRAE Transactions. v 93 pt 1. Pub by ASHRAE, Atlanta, GA, USA, p. 1458-1473

17 D. Thornburg, "Filter Testing and IAQ Control Move Forward", Heating, Piping, Air Conditioning, v 71, n 10, Oct. 1999, p.54-56, 95.1

18 "ASHRAE STANDARD -- Gravimetric and Dust-Sport Procedures for Testing Air-Cleaning Devices Used in General Ventilation for Removing Particulate Matter”, ANSI/ASHRAE 52.1 - 1992

19 “ASHRAE STANDARD - Standard Methods for Laboratory Air-Flow Measurement", BSR/ASHRAE 41.2-1987

20 "ASHRAE STANDARD - Standard Methods for Temperature Measurement", ANSI/ASHRAE 41.1-1986

21 ASHRAE Handbook: "2000 HVAC Systems and Equipment”, Chapter 21 "Air-cooling and dehumidifying coils" 


\section{APPENDIX 1: ADDITIONAL DATA TABLES}

Table A1: Coil air-side pressure drop factors

$$
\text { (Unit of } a_{c(f):}: P a \cdot s^{b_{c(f)}} / m^{b_{c(f)}} \text { ) }
$$

HX8L

\begin{tabular}{|c|c|c|c|c|c|c|c|c|}
\hline & & & MERV 14 & MERV 11 & MERV 8 & MERV 6 & MERV 4 & No-filter \\
\hline$a_{c}$ & 30.135 & $a_{f}$ & 28.540 & 29.550 & 29.301 & 33.056 & 35.489 & 41.149 \\
\hline$b_{c}$ & 2.160 & $b_{f}$ & 2.279 & 2.247 & 2.329 & 2.290 & 2.250 & 2.210 \\
\hline
\end{tabular}

HX8W

\begin{tabular}{|c|c|c|c|c|c|c|c|c|}
\hline & & & MERV 14 & MERV 11 & MERV 8 & MERV 6 & MERV 4 & No-filter \\
\hline$a_{c}$ & 44.823 & $a_{f}$ & 45.154 & 46.727 & 50.310 & 53.269 & 56.058 & 60.970 \\
\hline$b_{c}$ & 1.781 & $b_{f}$ & 1.841 & 1.830 & 1.896 & 1.884 & 1.843 & 1.843 \\
\hline
\end{tabular}

HX4L

\begin{tabular}{|c|c|c|c|c|c|}
\hline & & & MERV 8 & MERV 4 & No-filter \\
\hline$a_{c}$ & 33.990 & $a_{f}$ & 36.290 & 41.733 & 60.271 \\
\hline$b_{c}$ & 1.636 & $b_{f}$ & 1.747 & 1.708 & 1.811 \\
\hline
\end{tabular}

HX2L

\begin{tabular}{|c|c|c|c|c|c|c|c|c|}
\hline & & & MERV 14 & MERV 11 & MERV 8 & MERV 6 & MERV 4 & No-filter \\
\hline$a_{c}$ & 27.477 & $a_{f}$ & 25.149 & 29.503 & 28.467 & 32.338 & 34.107 & 79.999 \\
\hline$b_{c}$ & 1.229 & $b_{f}$ & 1.402 & 1.272 & 1.380 & 1.320 & 1.319 & 1.265 \\
\hline
\end{tabular}

$\Delta P_{c, c}=a_{c} V^{b_{c}} \quad \Delta P_{c, f}=a_{f} V^{b_{f}}$

$\Delta P_{c, c}=$ the coil air-side pressure drop at clean conditions, $\mathrm{Pa}$

$\Delta P_{c, f}=$ the coil air-side pressure drop at fouled conditions, $\mathrm{Pa}$

$V=$ air velocity, $\mathrm{m} / \mathrm{s}$ 
Table A2: Coil air-side effective heat transfer coefficient factors

$$
\text { (Unit of } c_{c(f)}: W \cdot s^{d_{c(f)}} / m^{2+d_{c(f)}} \cdot K \text { ) }
$$

HX8L

\begin{tabular}{|c|c|c|c|c|c|c|c|c|}
\hline & & & MERV 14 & MERV 11 & MERV 8 & MERV 6 & MERV 4 & No-filter \\
\hline$c_{c}$ & 35.638 & $c_{f}$ & 35.315 & 33.948 & 32.550 & 34.570 & 37.209 & 35.036 \\
\hline$d_{c}$ & 0.259 & $d_{f}$ & 0.181 & 0.257 & 0.293 & 0.208 & 0.231 & 0.202 \\
\hline
\end{tabular}

$\mathrm{HX} 8 \mathrm{~W}$

\begin{tabular}{|c|c|c|c|c|c|c|c|c|}
\hline & & & MERV 14 & MERV 11 & MERV 8 & MERV 6 & MERV 4 & No-filter \\
\hline$c_{c}$ & 36.479 & $c_{f}$ & 34.622 & 36.542 & 37.040 & 35.802 & 33.752 & 36.011 \\
\hline$d_{c}$ & 0.182 & $d_{f}$ & 0.243 & 0.200 & 0.204 & 0.203 & 0.274 & 0.113 \\
\hline
\end{tabular}

$\mathrm{HX} 4 \mathrm{~L}$

\begin{tabular}{|c|c|c|c|c|c|}
\hline & & & MERV 8 & MERV 4 & No-filter \\
\hline$c_{c}$ & 37.095 & $c_{f}$ & 33.967 & 33.805 & 34.474 \\
\hline$d_{c}$ & 0.166 & $d_{f}$ & 0.218 & 0.227 & 0.176 \\
\hline
\end{tabular}

HX2L

\begin{tabular}{|c|c|c|c|c|c|c|c|c|}
\hline & & & MERV 14 & MERV 11 & MERV 8 & MERV 6 & MERV 4 & No-filter \\
\hline$c_{c}$ & 35.047 & $c_{f}$ & 33.712 & 34.592 & 34.005 & 32.936 & 33.993 & 36.011 \\
\hline$d_{c}$ & 0.320 & $d_{f}$ & 0.350 & 0.290 & 0.299 & 0.366 & 0.278 & 0.120 \\
\hline
\end{tabular}

$h_{a, c}=c_{c} V^{d_{c}} \quad h_{a, f}=c_{f} V^{d_{f}}$

$h_{a, c}=$ coil air-side effective heat transfer coefficient at clean conditions, $\mathrm{W} / \mathrm{m}^{2}-\mathrm{K}$

$h_{a, f}=$ coil air-side effective heat transfer coefficient at fouled conditions, $\mathrm{W} / \mathrm{m}^{2}-\mathrm{K}$

$V=$ air velocity, $\mathrm{m} / \mathrm{s}$

Table A3: Filter pressure drop factors

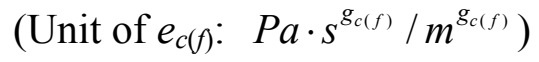

\begin{tabular}{|c|c|c|c|c|c|}
\hline & MERV 14 & MERV 11 & MERV 8 & MERV 6 & MERV 4 \\
\hline$e_{c}$ & 40.942 & 38.581 & 19.496 & 35.051 & 19.459 \\
\hline$g_{c}$ & 1.716 & 1.453 & 1.542 & 1.280 & 1.375 \\
\hline$e_{f}$ & 95.236 & 79.53 & 51.431 & 38.942 & 30.052 \\
\hline$g_{f}$ & 1.430 & 1.585 & 1.646 & 1.978 & 1.543 \\
\hline
\end{tabular}

$\Delta P_{f, c}=e_{c} V^{g_{c}} \quad \Delta P_{f, f}=e_{f} V^{g_{f}}$

$\Delta P_{f, c}=$ the filter pressure drop at clean conditions, $\mathrm{Pa}$

$\Delta P_{f, f}=$ the filter pressure drop at fouled conditions, $\mathrm{Pa}$

$V=$ air velocity, $\mathrm{m} / \mathrm{s}$ 
Table A4: Equipment system additional pressure drop $\Delta P_{\text {dist }}$ and factor $K$

\begin{tabular}{|c|c|c|c|}
\hline & 35-ton rooftop & 5-ton rooftop & 3-ton rooftop \\
\hline$\Delta P_{\text {dist }}(\mathrm{Pa})$ & 672 & 150 & 125 \\
\hline$K\left(\mathrm{~Pa}-\mathrm{s}^{2} / \mathrm{m}^{2}\right)$ & 104.2 & 23.2 & 53.9 \\
\hline
\end{tabular}

$\Delta P_{\text {dist }}=K V^{2}$

$\Delta P_{\text {dist }}=$ equipment system additional pressure drop, $\mathrm{Pa}$

$V=$ air velocity, $\mathrm{m} / \mathrm{s}$

Table A5: Dust distributions for all test cases

HX8L

\begin{tabular}{|c|c|c|c|c|c|c|}
\hline Heat Exchanger & \multicolumn{7}{|c|}{ HX8L } \\
\hline Filter & MERV14 & MERV11 & MERV8 & MERV6 & MERV4 & No-filter \\
\hline M (g) & 600.1 & 600.3 & 600.2 & 600.5 & 600.4 & 600.2 \\
\hline M1 (g) & 590.4 & 574.1 & 536.5 & 526.9 & 451 & \\
\hline M2 (g) & 3.1 & 4.1 & 3.7 & 4.3 & 5.2 & 31.6 \\
\hline M5 (g) & 0.2 & 2.1 & 0.4 & 0.3 & 1.2 & 25.2 \\
\hline M4 (g) & 0 & 0 & 0.9 & 1.1 & 3.4 & 68.4 \\
\hline M3 (g) & 2.9 & 8.2 & 43.2 & 30.1 & 92.7 & 188.2 \\
\hline M6 (g) & 3.5 & 11.8 & 15.5 & 37.8 & 46.9 & 286.8 \\
\hline Arrestance measured & $98.4 \%$ & $95.6 \%$ & $89.4 \%$ & $87.7 \%$ & $75.1 \%$ & \\
\hline Arrestance given & $99 \%$ & $99 \%$ & $95 \%$ & $90-95 \%$ & $75-80 \%$ & \\
\hline
\end{tabular}

HX8W

\begin{tabular}{|c|c|c|c|c|c|c|}
\hline Heat Exchanger & \multicolumn{7}{|c|}{ HX8W } \\
\hline Filter & MERV14 & MERV11 & MERV8 & MERV6 & MERV4 & No-filter \\
\hline M (g) & 600.2 & 600.3 & 600 & 600.2 & 600.4 & 600.6 \\
\hline M1 (g) & 593.4 & 583.2 & 550.8 & 523.3 & 425.1 & \\
\hline M2 (g) & 1 & 3.4 & 4.3 & 5.2 & 4.7 & 26.5 \\
\hline M3 (g) & 0.1 & 0.3 & 0.3 & 0.5 & 1.5 & 15.7 \\
\hline M4 (g) & 0 & 0 & 1.1 & 0.9 & 5.6 & 46.7 \\
\hline M5 (g) & 2.7 & 5.6 & 30.1 & 43.2 & 112.4 & 169.9 \\
\hline M6 (g) & 3 & 7.8 & 13.4 & 27.2 & 51.1 & 341.8 \\
\hline Arrestance measured & $98.87 \%$ & $97.15 \%$ & $91.80 \%$ & $87.19 \%$ & $70.80 \%$ & \\
\hline Arrestance given & $99 \%$ & $99 \%$ & $95 \%$ & $90-95 \%$ & $75-80 \%$ & \\
\hline
\end{tabular}


HX4L

\begin{tabular}{|c|c|c|c|}
\hline Heat Exchanger & \multicolumn{3}{|c|}{ HX4L } \\
\hline Filter & MERV8 & MERV4 & No-filter \\
\hline M (g) & 600.2 & 601.1 & 600.3 \\
\hline M1 (g) & 547.1 & 428.5 & \\
\hline M2 (g) & 4.6 & 4.9 & 26.9 \\
\hline M3 (g) & 0.4 & 0.3 & 8 \\
\hline M4 (g) & 0.5 & 2.6 & 32 \\
\hline M5 (g) & 28.4 & 110.4 & 182.8 \\
\hline M6 (g) & 19.2 & 54.4 & 350.6 \\
\hline Arrestance measured & $91.2 \%$ & $71.3 \%$ & \\
\hline Arrestance given & $95 \%$ & $75-80 \%$ & \\
\hline
\end{tabular}

HX2L

\begin{tabular}{|c|c|c|c|c|c|c|}
\hline Heat Exchanger & \multicolumn{7}{|c|}{ HX2L } \\
\hline Filter & MERV14 & MERV11 & MERV8 & MERV6 & MERV4 & No-filter \\
\hline M (g) & 600.4 & 600.3 & 600.2 & 600.2 & 600 & 600.4 \\
\hline M1 (g) & 579.6 & 574.1 & 520.9 & 528.2 & 452.4 & \\
\hline M2 (g) & 3 & 4.1 & 5.8 & 4.3 & 4.2 & 23.3 \\
\hline M3 (g) & 0.4 & 2.1 & 0.5 & 0.5 & 1 & 16 \\
\hline M4 (g) & 1.2 & 1 & 6.5 & 3.6 & 3.6 & 23.1 \\
\hline M5 (g) & 11.8 & 8.2 & 41.9 & 30.4 & 90.9 & 158.4 \\
\hline M6 (g) & 4.4 & 10.8 & 24.6 & 33.2 & 47.9 & 379.6 \\
\hline Arrestance measured & $96.5 \%$ & $95.6 \%$ & $86.8 \%$ & $88.0 \%$ & $75.4 \%$ & \\
\hline Arrestance given & $99 \%$ & $99 \%$ & $95 \%$ & $90-95 \%$ & $75-80 \%$ & \\
\hline
\end{tabular}

M: weight of total injected dust (approximately 600 grams); weighted.

$\mathrm{M}_{1}$ : weight of dust captured by upstream filter; obtained by weighing the upstream filter before and after each test.

$\mathrm{M}_{2}$ : weight of dust inside of the air duct; obtained by cleaning the inside of duct with water and filtering the dust from the water.

$\mathrm{M}_{3}$ : weight of dust in the drain pan; obtained by cleaning the drain pan with water and filtering the dust.

$\mathrm{M}_{4}$ : weight of dust in condensation; obtained by filtering the condensation and drying the dust.

$\mathrm{M}_{5}$ : weight of dust captured by the downstream filter; obtained by weighing the downstream filter before and after each test.

$\mathrm{M}_{6}$ : weight of dust captured by the coil 


\section{APPENDIX 2: ADDITIONAL DATA FIGURES}

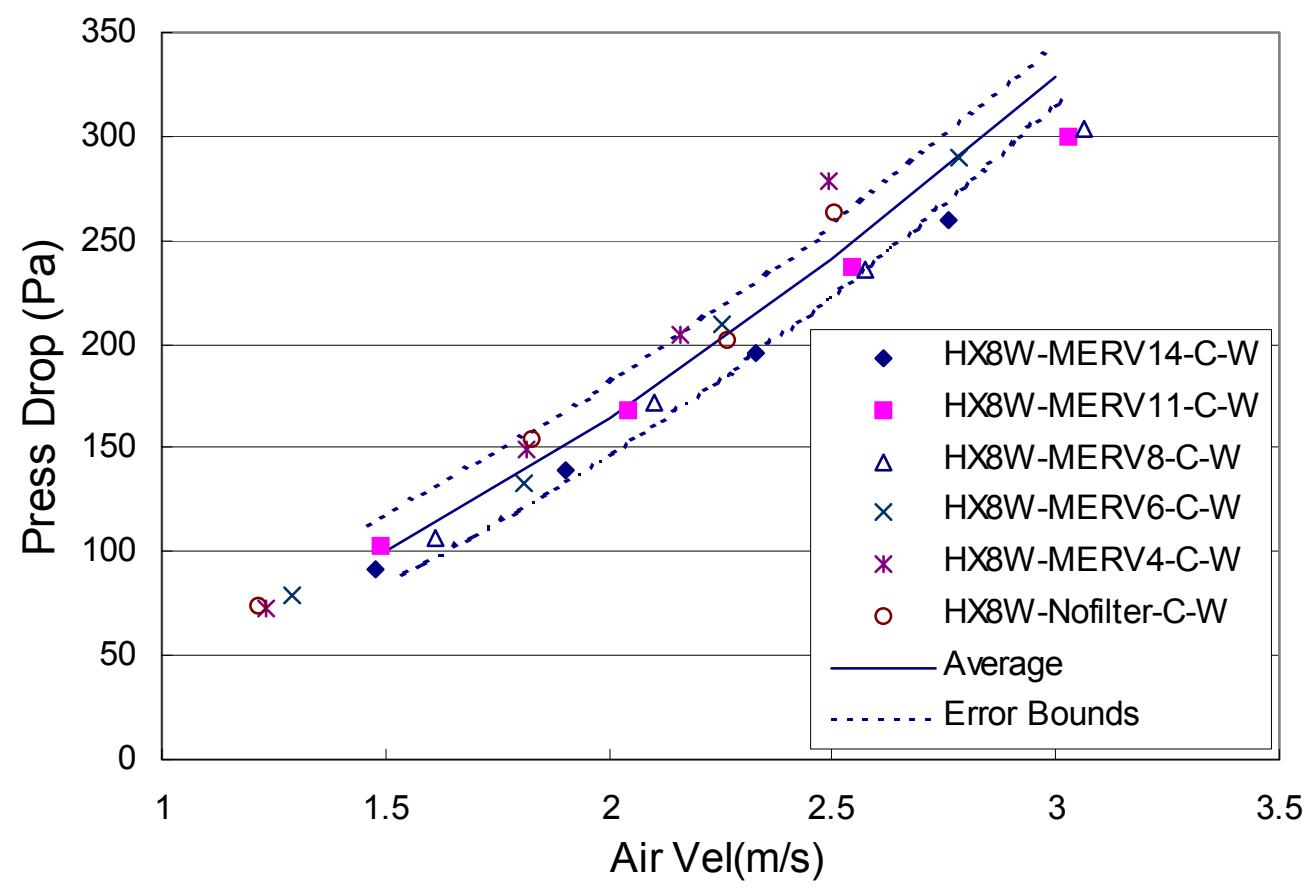

Figure A1: Pressure drop baseline and error bounds for HX8W

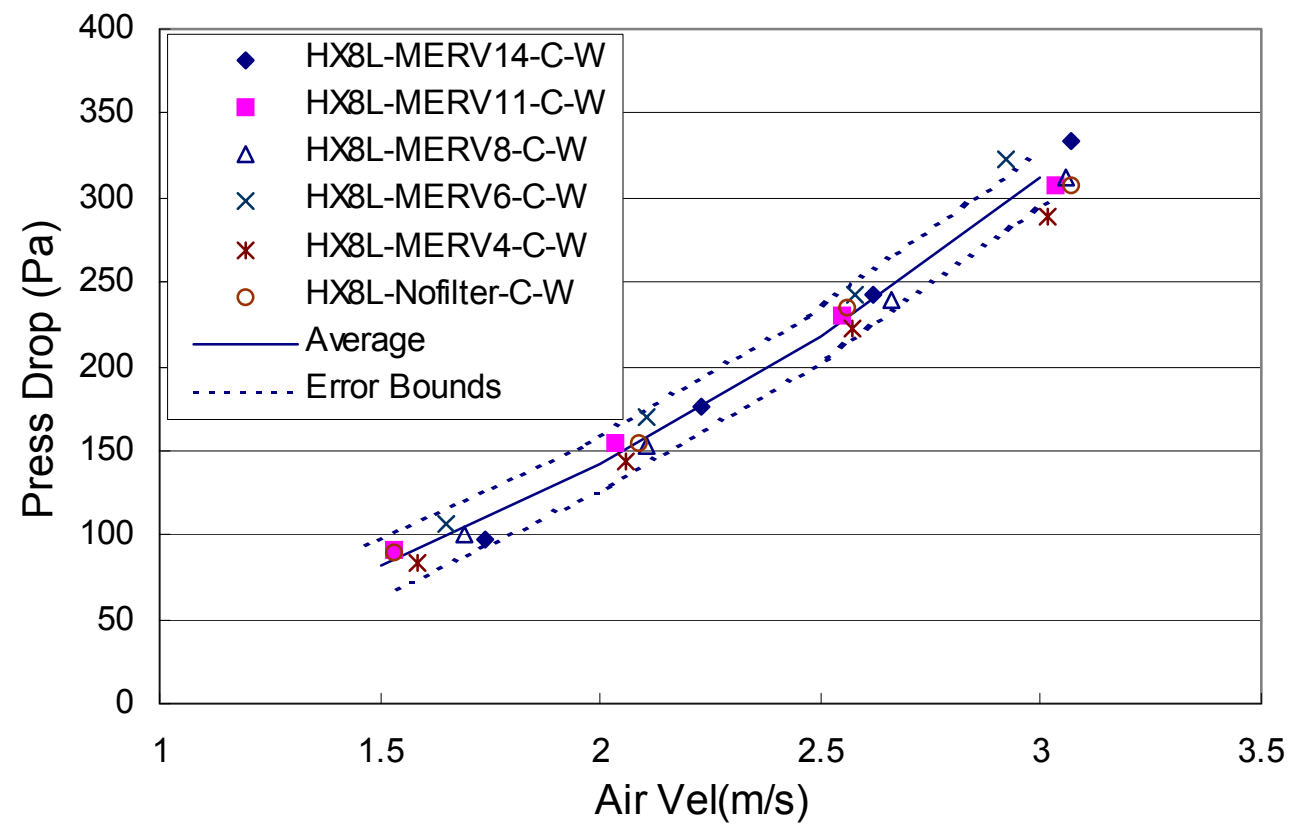

Figure A2: Pressure drop baseline and error bounds for HX8L 


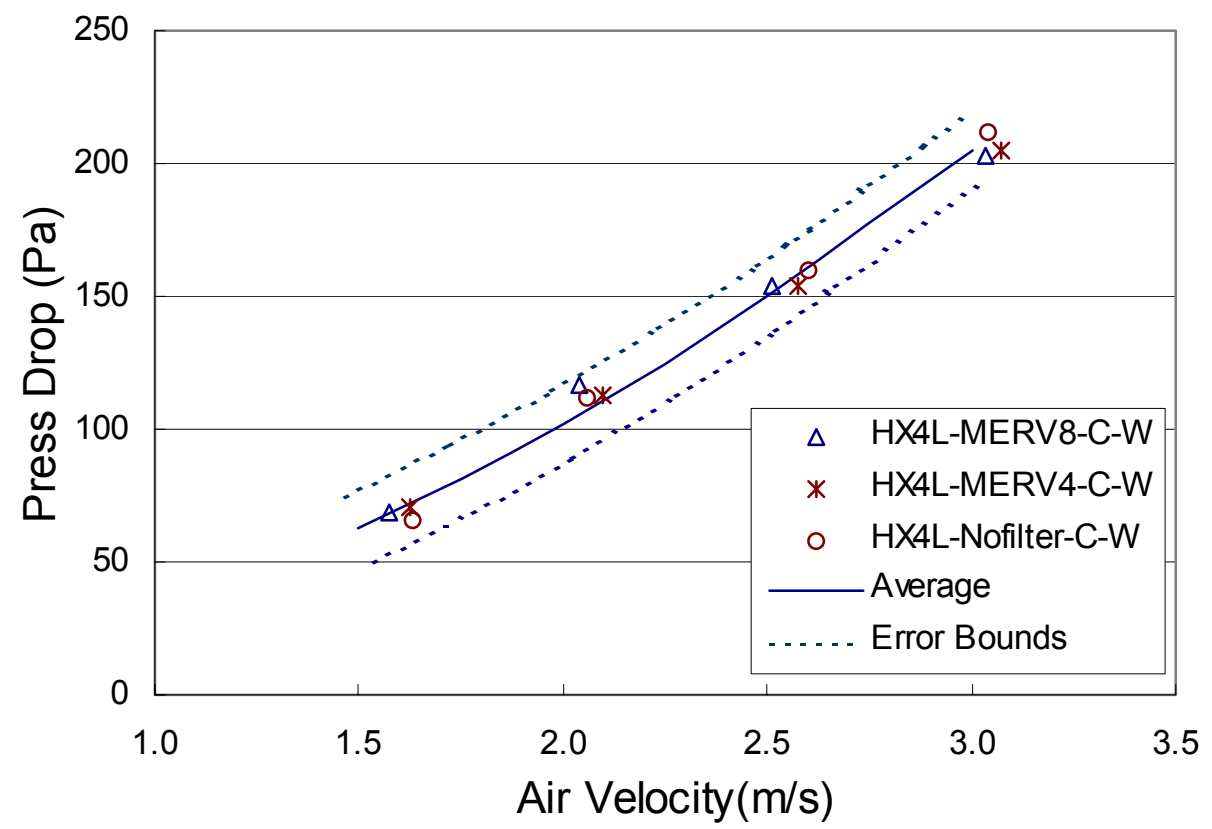

Figure A3: Pressure drop baseline and error bounds for HX4L

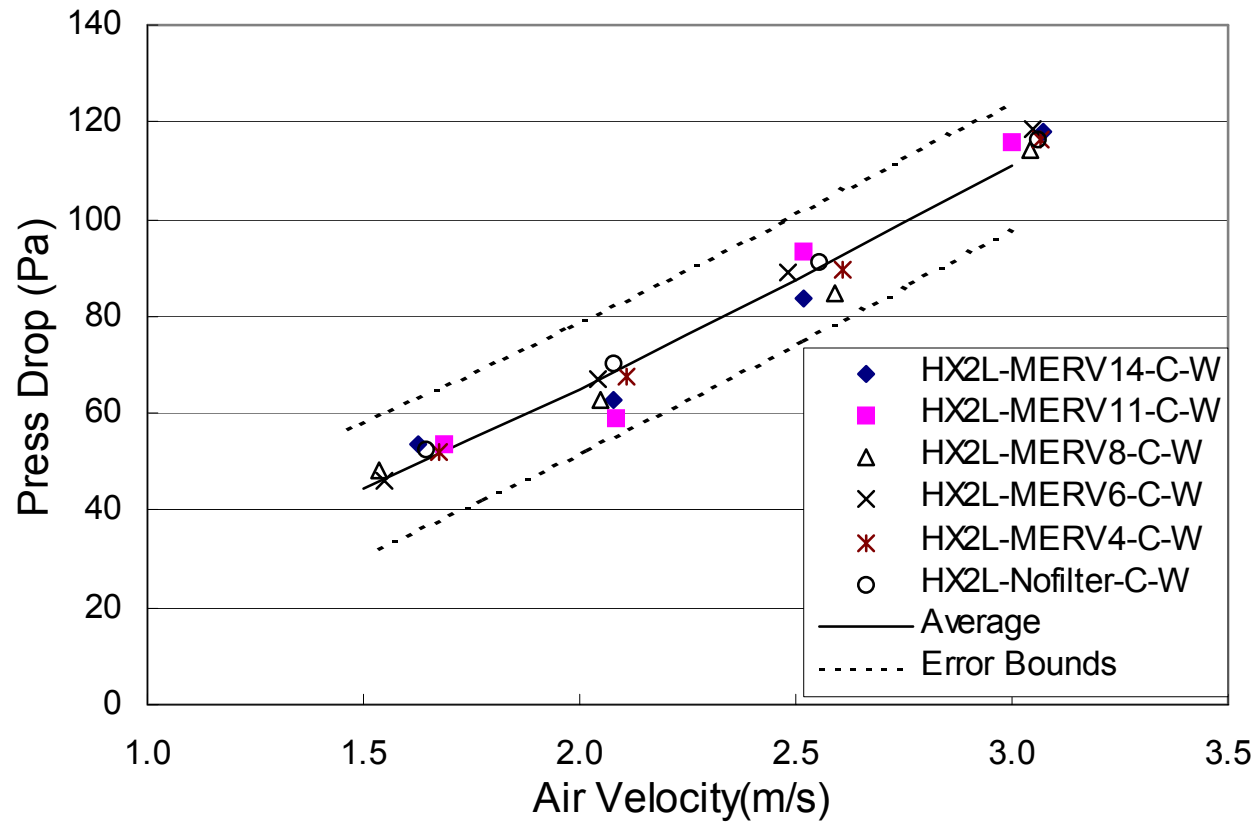

HX2L

Figure A4: Pressure drop baseline and error bounds for HX2L 


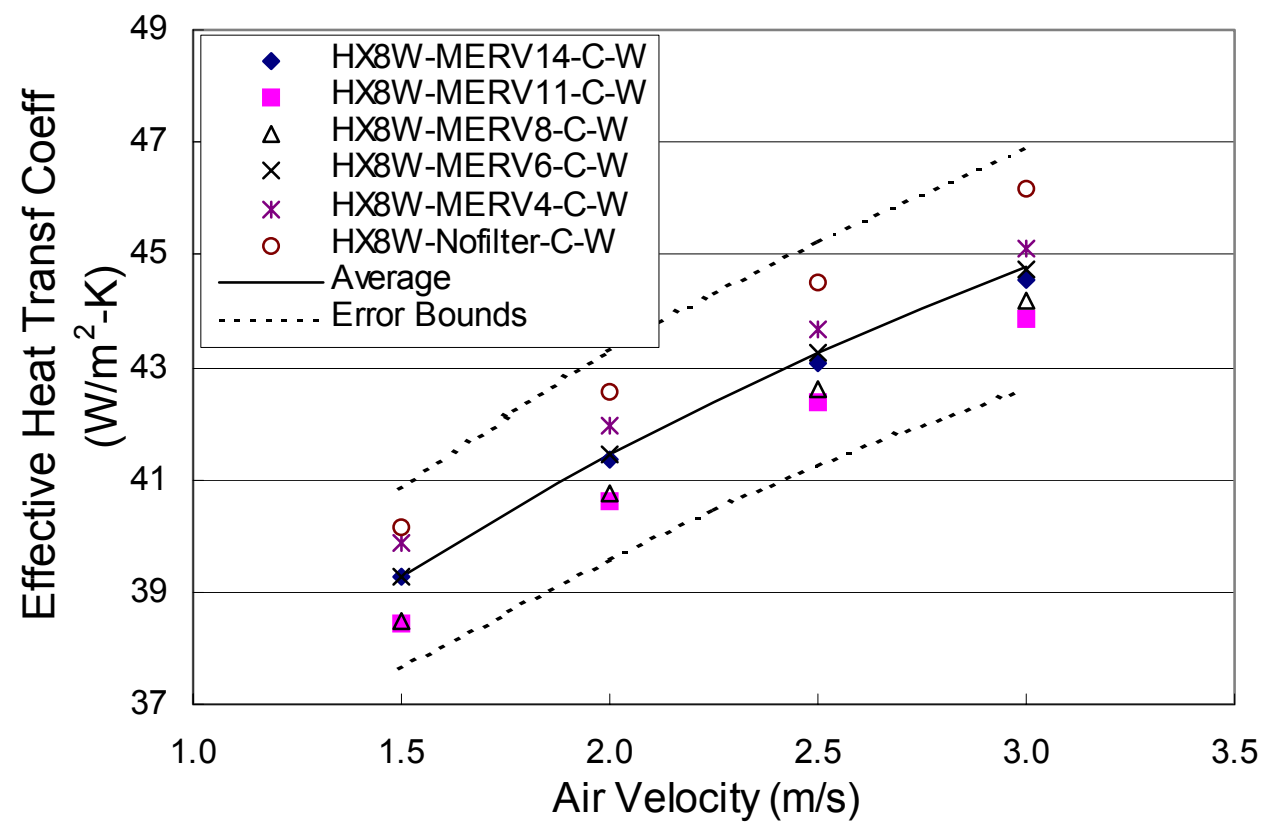

Figure A5: Effective heat transfer coefficient baseline and error bounds for HX8W

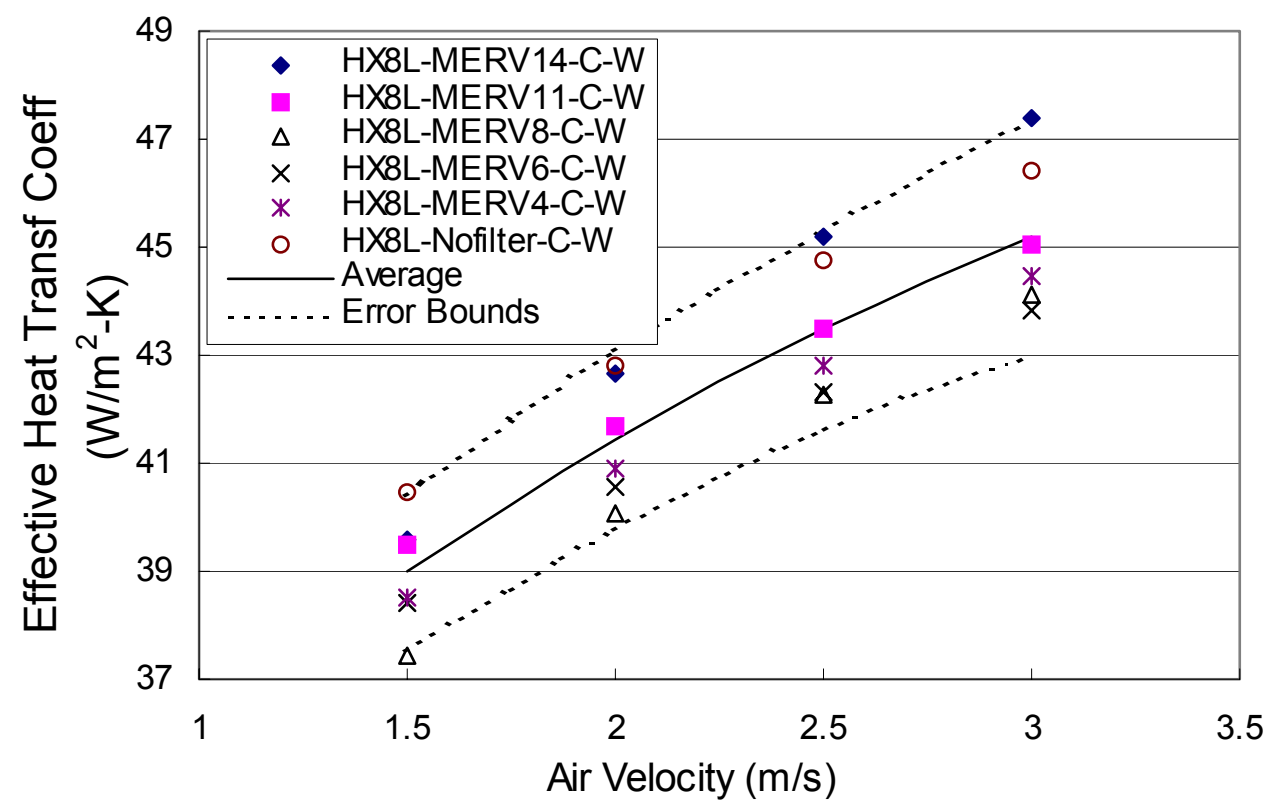

Figure A6: Effective heat transfer coefficient baseline and error bounds for HX8L 


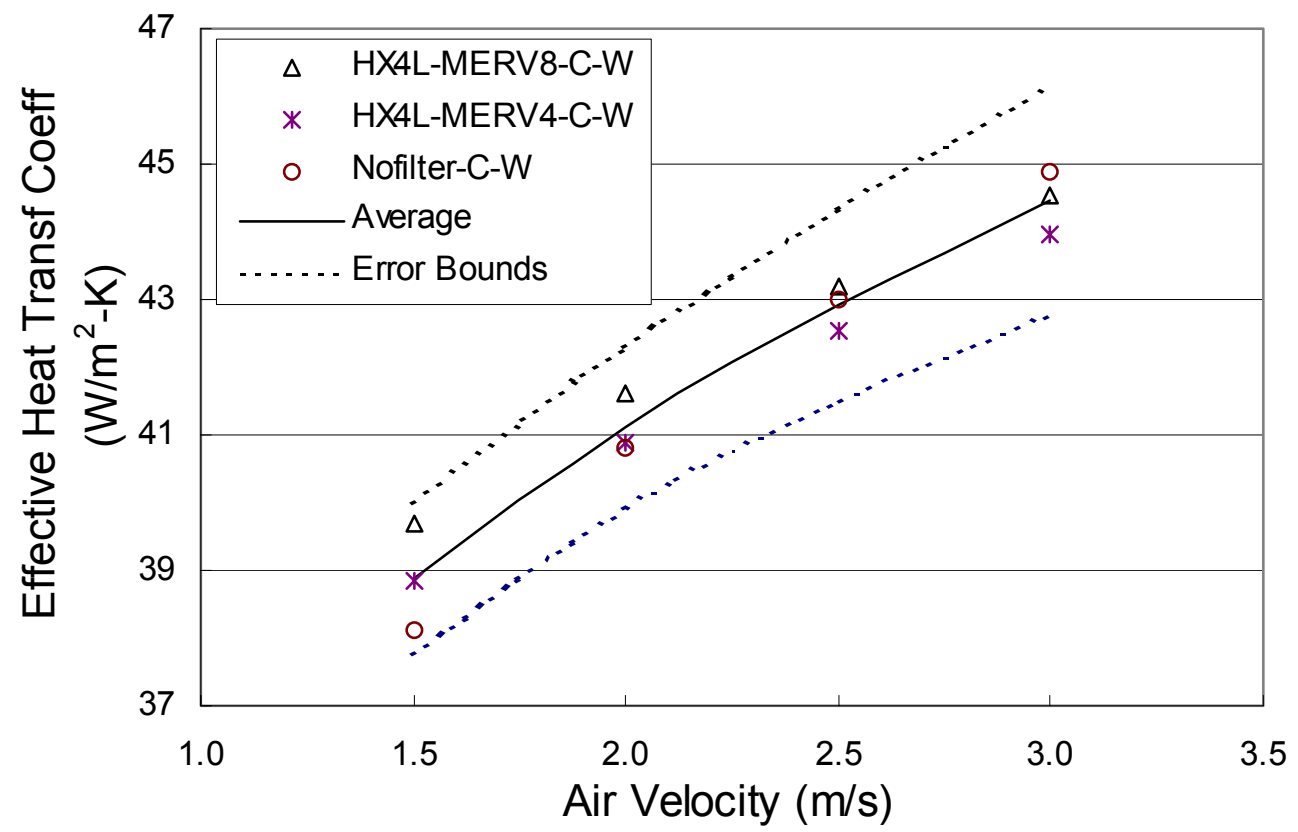

Figure A7: Effective heat transfer coefficient baseline and error bounds for HX4L

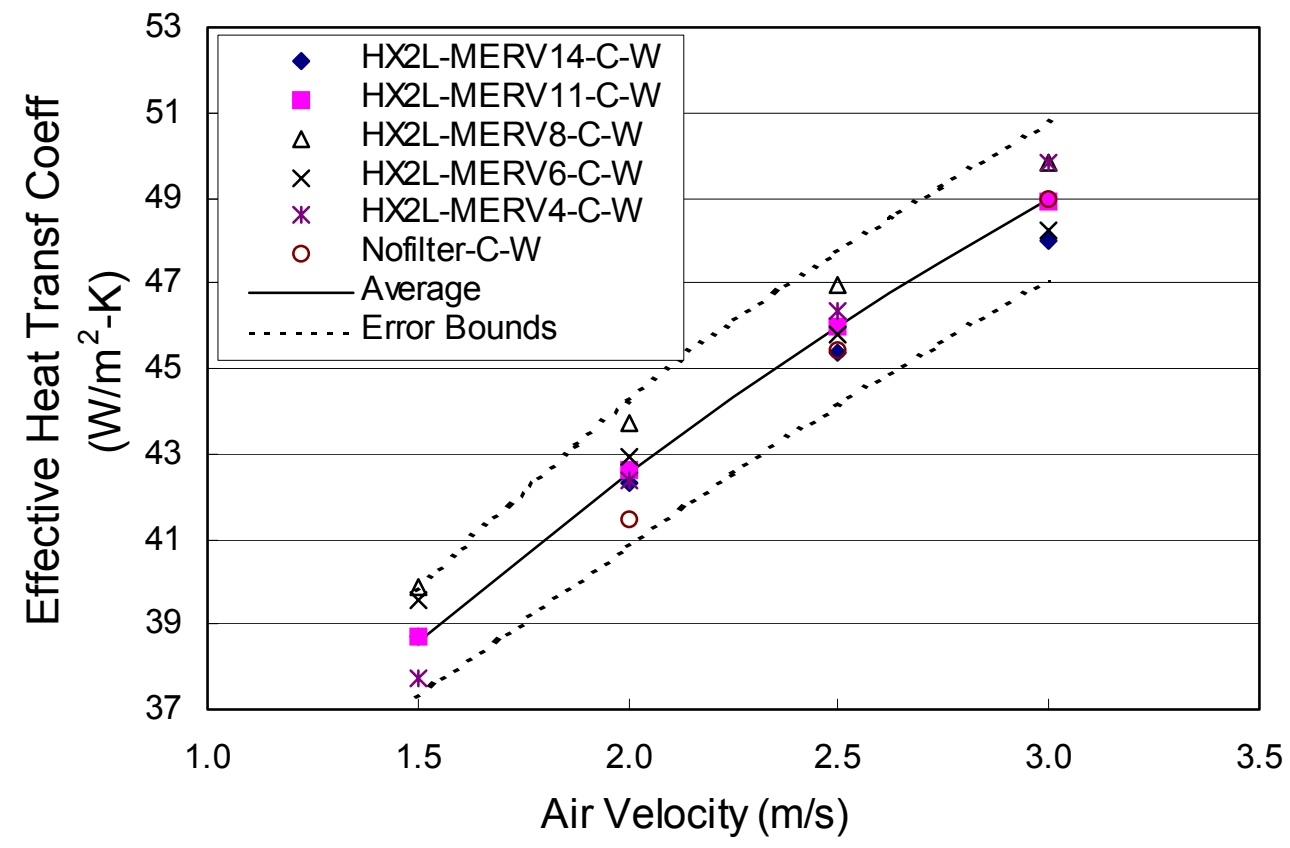

Figure A8: Effective heat transfer coefficient baseline and error bounds for HX2L 


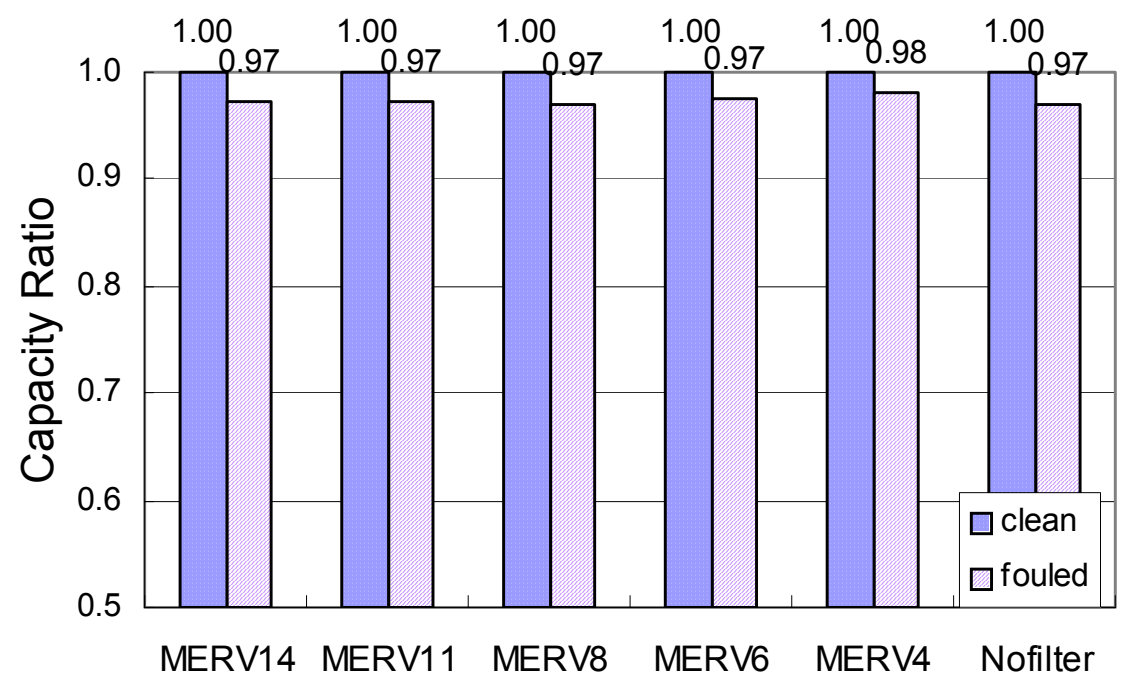

Figure A9: Capacity ratio of all filter cases for $\mathrm{HX} 8 \mathrm{~W}\left(\mathrm{~T}_{\mathrm{ci}}=35^{\circ} \mathrm{C}\right)$

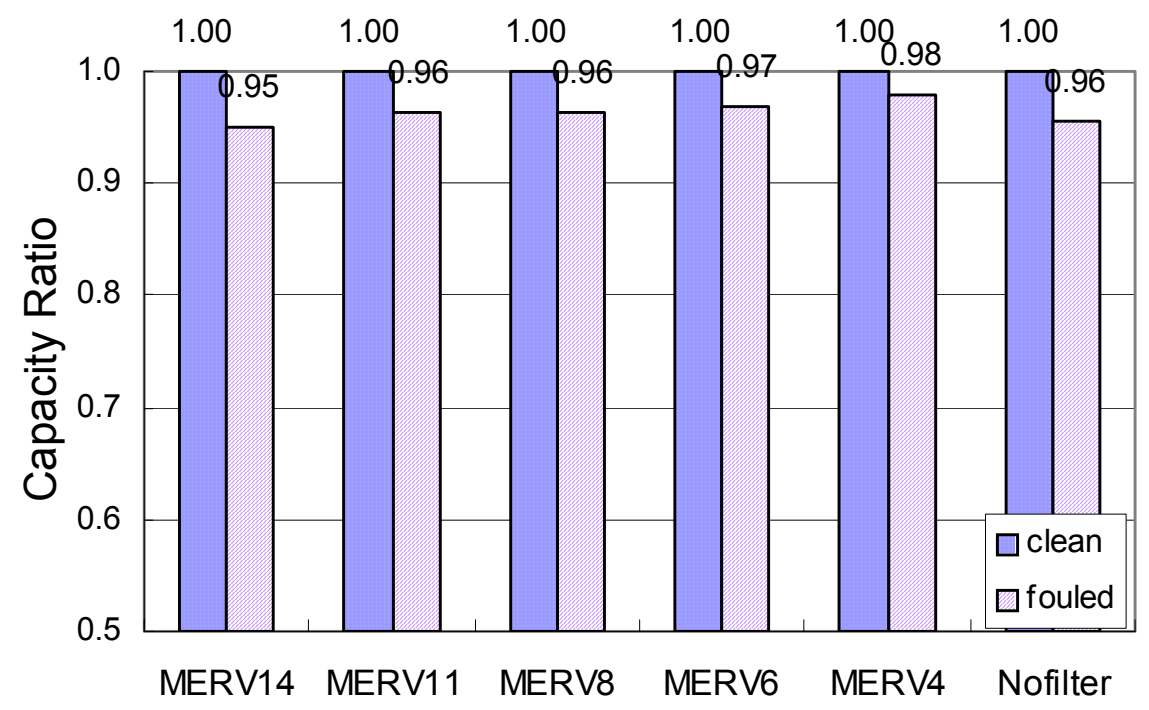

Figure A10: Capacity ratio of all filter cases for $\mathrm{HX} 8 \mathrm{~L}\left(\mathrm{~T}_{\mathrm{ci}}=35^{\circ} \mathrm{C}\right)$ 


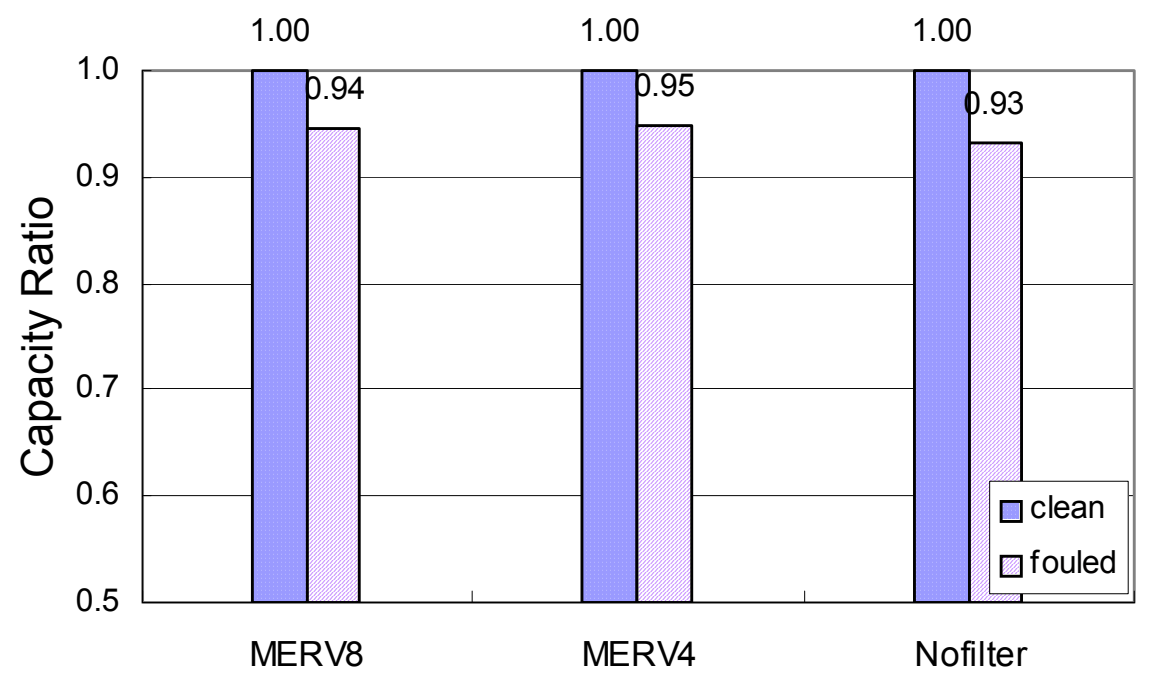

Figure A11: Capacity ratio of all filter cases for $\mathrm{HX} 4 \mathrm{~L}\left(\mathrm{~T}_{\mathrm{ci}}=35^{\circ} \mathrm{C}\right)$

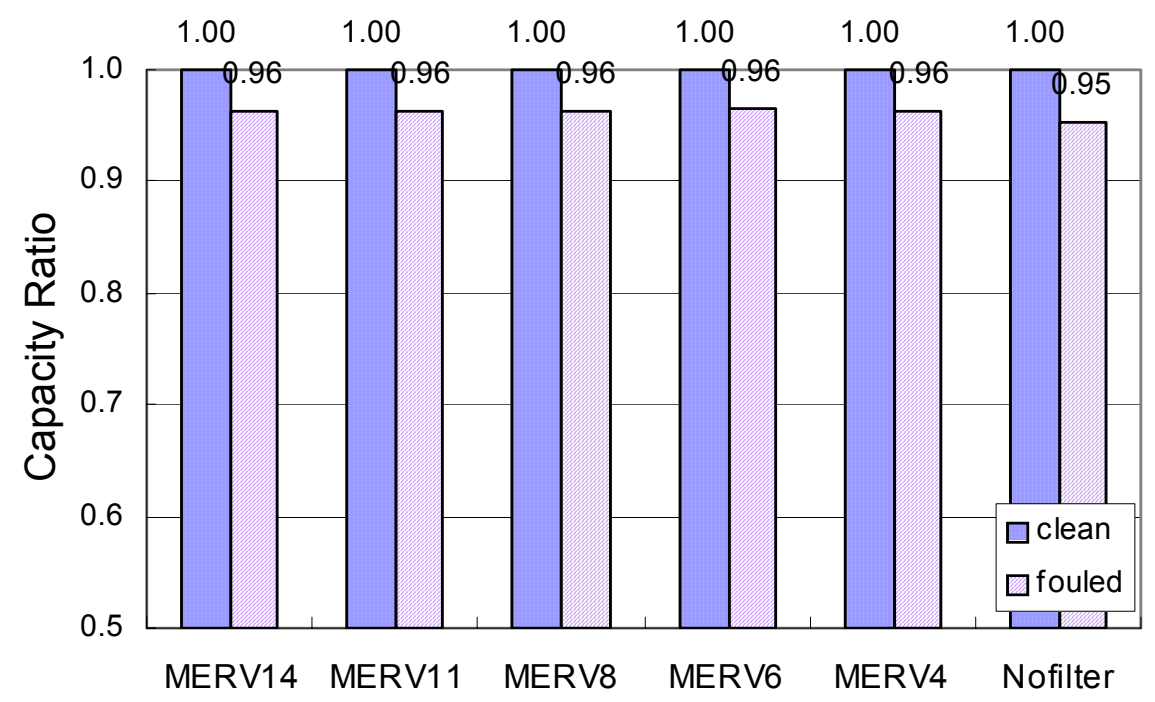

Figure A12: Capacity ratio of all filter cases for $\mathrm{HX} 2 \mathrm{~L}\left(\mathrm{~T}_{\mathrm{ci}}=35^{\circ} \mathrm{C}\right)$ 


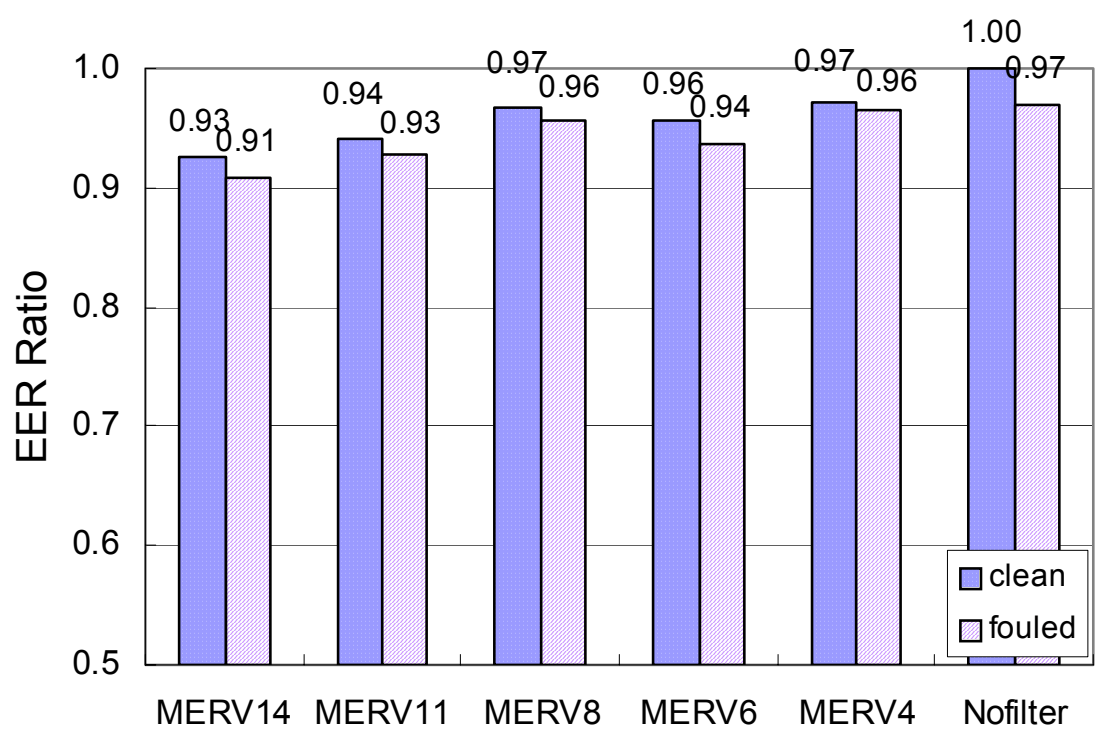

Figure A13: EER ratio of all coil-filter cases for HX8W with fan efficiency at $38 \%\left(\mathrm{~T}_{\mathrm{ci}}=35^{\circ} \mathrm{C}\right)$

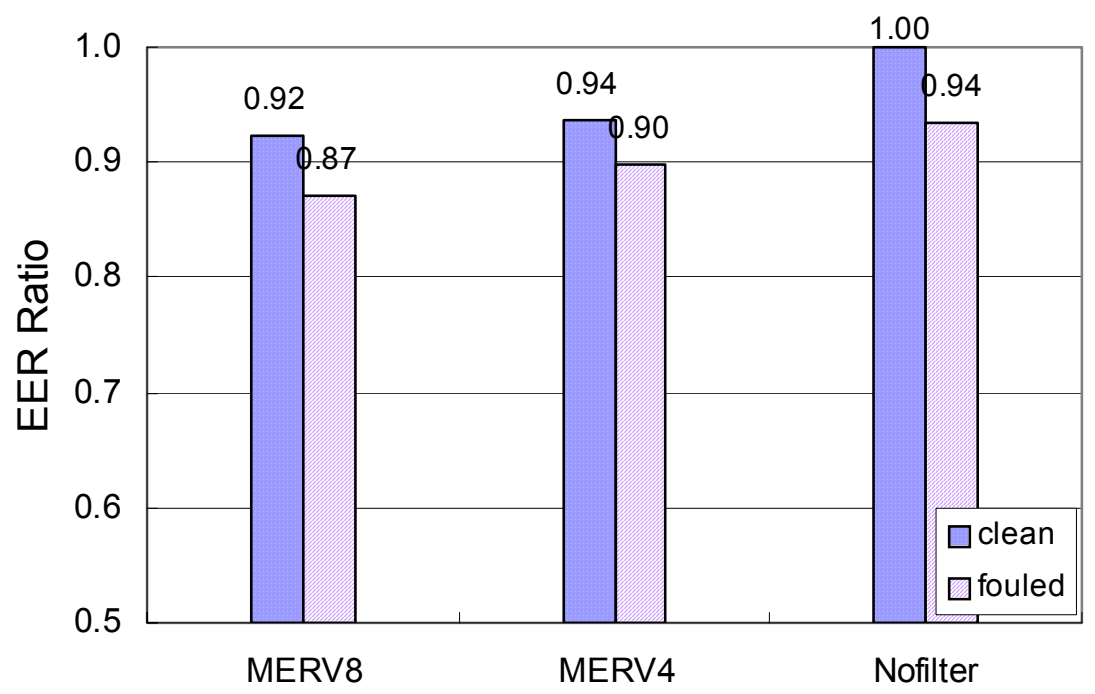

Figure A14: EER ratio of all coil-filter cases for HX4L with fan efficiency at $28 \%\left(\mathrm{~T}_{\mathrm{ci}}=35^{\circ} \mathrm{C}\right)$ 


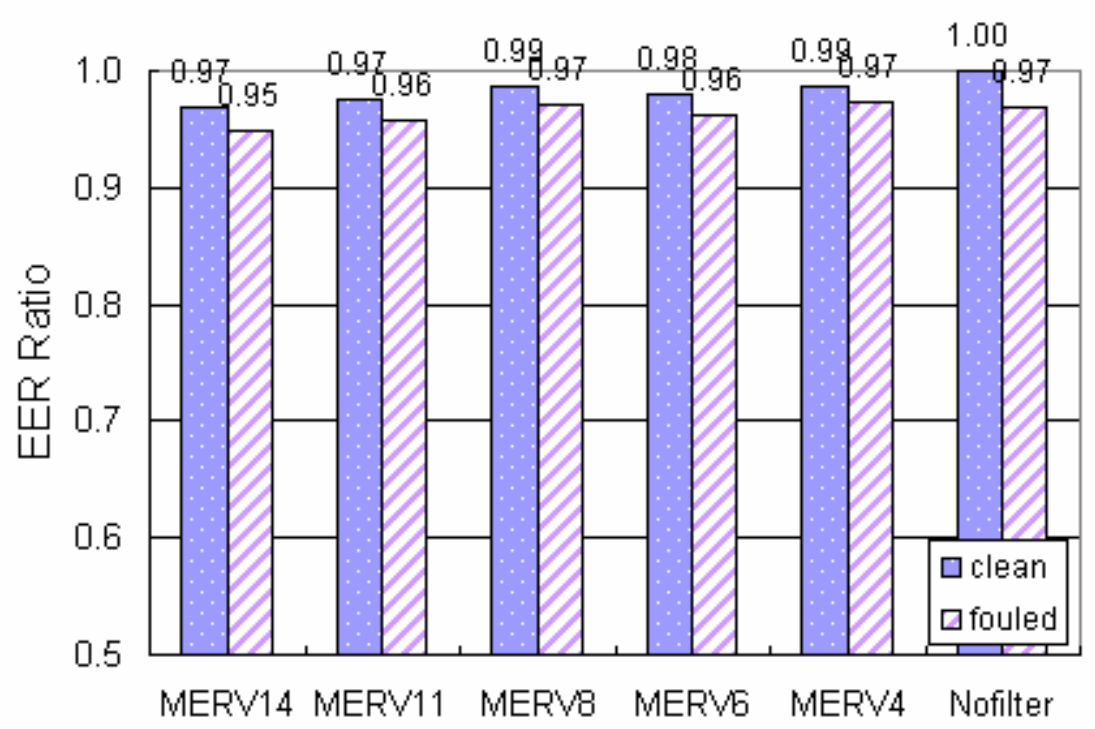

Figure A15: EER ratio of all coil-filter cases for HX8W with fan efficiency at $100 \%\left(\mathrm{~T}_{\mathrm{ci}}=35^{\circ} \mathrm{C}\right)$

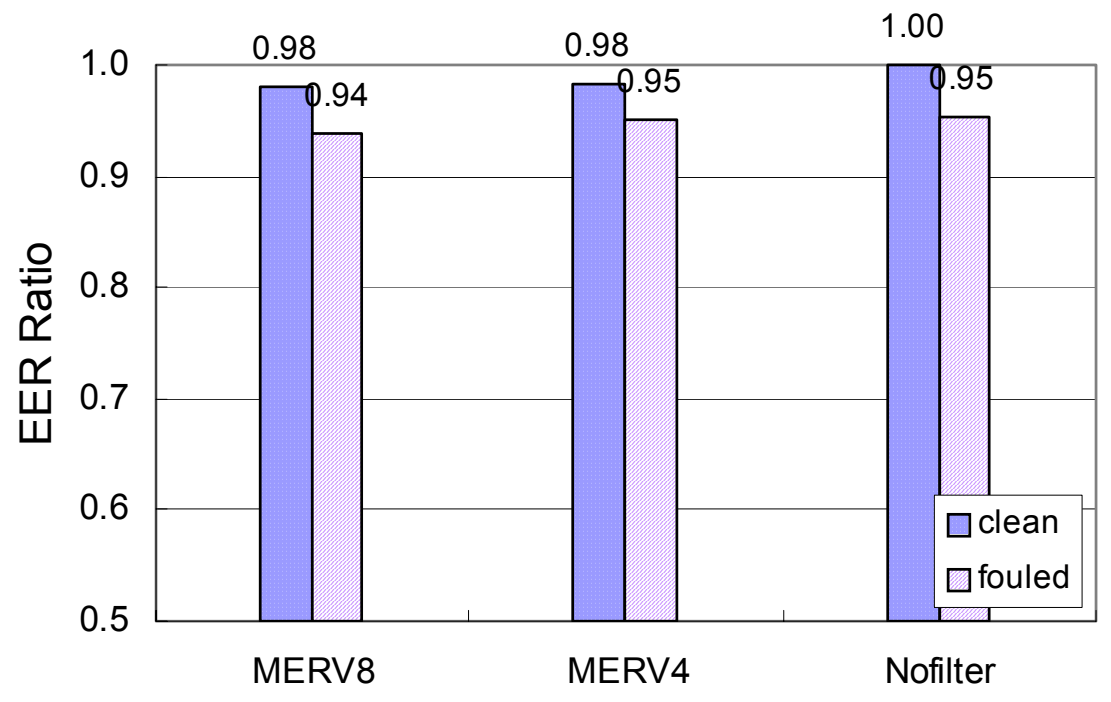

Figure A16: EER ratio of all coil-filter cases for HX4L with fan efficiency at $100 \%\left(\mathrm{~T}_{\mathrm{ci}}=35^{\circ} \mathrm{C}\right)$ 


\section{APPENDIX 3: TEST OPERATION PROCEDURE}

The detailed operation process of the test:

STEP 1: Baseline test

(1) Cleaned the original test coil as received from the manufacturer or after the previous fouling test using a detergent (Evap Pow'r-C, which is a concentrated biodegradable detergent specifically formulated for "no-rinse" application on evaporator coils). Installed the coil in the wind tunnel using a hoist. Fixed the coil to the flange of the air duct with bolts. Sealed the seam between the coil and the flange with foam tape.

(2) Weighed a new pocket filter (MERV14), opened the door downstream of the coil on the wind tunnel and installed the filter as the downstream filter. Closed the door.

(3) Turned on the PC and HP data logger.

(4) Switched on the power for multiple socket outlet on the wooden cart.

(5) Started the HP VEE data acquisition program and LABVIEW control program. As a default setting, all the setpoints for the heater, humidifier and the fan were set to low levels (e.g. setpoint of air temperature lower than room temperature), in order to make sure that the outputs were at $0 \%$ when starting the program. Only the fan speed was set to $2.54 \mathrm{~m} / \mathrm{s}(500 \mathrm{ft} / \mathrm{min})$ as a default.

(6) Turned on the power switch for the fan on the south wall. Made sure that the toggle switch on the fan frequency controller was set to "Auto" and pushed the other toggle switch to "Start". The fan would automatically start to $2.54 \mathrm{~m} / \mathrm{s}(500$ $\mathrm{ft} / \mathrm{min})$.

(7) Operated the precooler if air humidity was higher than the test condition: Opened the water valve connected to the precooler. Turned on the main power switch on the bus bar on the ceiling over the main walkway of the west wing and turned on the power switch on the south wall for the precooler. Pressed the start button.

(8) Operated the heater mounted in the wind tunnel: Turned on the main power switch on the bus bar on the ceiling and turned on the power switch on the south wall. 
(9) Operated the humidifier if air humidity was lower than the test condition: Opened the steam supply valves, opened the valve of compressed air and switched on the power on the bottom of the power supply box.

(10) Turned on the main power switch for the chiller and the water pump on the bus bar on the ceiling.

(11)Turned on the big power switch for the chiller and the water pump on the wooden cart.

(12)Before running the chiller, made sure that the big green condenser water valve (v1) and the big blue valve (v4) and the blue on/off valve (v5) were open. The valve (v2) for the green hose had to be closed except for the filling for the tank. Valve3 should be closed as well.

(13) Turned the toggle switch of the chiller for the pump on and after a minute turned on the switch for the compressor. After starting the chiller, looked on the small glass window on the compressor to make sure that it was filled with white oil bubbles within half an hour.

(14)Turned on the power switch for the pump (labeled: 2nd loop water pump). Pressed the RUN button on the frequency controller for the pump and adjusted the frequency to the maximum (mark 10).

(15)Typed in the values of the set points for all controlled parameters on the front panel in the LABVIEW program. The set points could be changed while the program was running.

(16)After the whole system was running, it usually took 0.5-1 hour to reach a stable condition. The air velocity was adjusted to four levels: $3.05 \mathrm{~m} / \mathrm{s}(600 \mathrm{ft} / \mathrm{min}), 2.54$ $\mathrm{m} / \mathrm{s}(500 \mathrm{ft} / \mathrm{min}), 2.03 \mathrm{~m} / \mathrm{s}(400 \mathrm{ft} / \mathrm{min})$ and $1.52 \mathrm{~m} / \mathrm{s}(300 \mathrm{ft} / \mathrm{min})$. It took approximately 20 minutes to reach the steady state after each variation and another 20 minutes to collect the test data.

\section{STEP 2: Dust injection}

(1) Weighed a new upstream filter. Opened the door upstream of the coil on the wind tunnel and inserted the filter. The four contact sides of the filter with the duct 
inside were sealed with tape and the weight of tape was counted in the filter calculation as well.

(2) Weighed 100 grams of ASHRAE dust and put it evenly on the dust tray of the dust injector.

(3) Turned on the three toggle switches for the aspirator, paddle wheel and tray feed, respectively, on the dust injector.

(4) During feeding of the dust, a careful watch was kept on the data windows. When the upstream filter or downstream filter reached its maximum acceptable pressure drop, it was replaced with a new one. For replacing filters, the whole air system was shut down.

(5) After dust feeding, the feeder tray was pulled all the way back and re-loaded with 100 grams of dust till all 600 grams of dust were finished.

Approximately 4-7 upstream filters and 2-3 downstream filters were used for loading 600 grams of dust in each fouling test. All the filters were weighed before and after each fouling test to determine the dust quantity captured by the filter. During dust feeding, the condensation from coil was filtered using a filter. The filtered dust was dried in the air and then weighed.

STEP 3: Performance tests after fouling

After injecting 600 grams of dust, the upstream filter and downstream filter were removed and the coil was tested with all the settings and conditions the same as for STEP 1.

After finishing the test, stopped the computer programs first. Then, shut down the chiller by switching off the toggle switch for the compressor first and turned off the pump after 30 seconds. Adjusted the water pump output to 0, and switched off the power switch for the water pump. Then switched off the power switch for the chiller on the wooden cart and the main power switch on the bus bar on the ceiling for the water loop. For air system, turned off the humidifier by switching off the power supply and closing the compressor air supply valve and steam supply valves. Shut off the power switch for the heaters on the south wall. Pressed the "stop" button on the precooler and shut off the power switch on the south wall. Then shut off both main power switches on the bus bar on the ceiling over the gangway for 
the heater and precooler. After the heaters stopped working and sufficiently cooled down, switched off the fan.

STEP 4: Cleaning process

After completion of the fouled tests, the drain pan of the test coil was dismounted first from the coil and washed using pure water. The dust deposited in the drained pan was obtained by filtering the dirty water. Then, the test coils were cleaned.

For the 8-row coils that could not be cleaned very well in the wind tunnel, they were taken out using a hoist and laid down on a large tub and cleaned using Evap Pow'r-C. The cleaner was diluted with 3 parts of water according to the instruction listed on the cleaner and sprayed onto the contaminated coil. It took approximately 10 minutes to spray the cleaner evenly on the coil surface and the cleaner was allowed to soak into the coil for 5 minutes. After soaking, the coil was carefully cleaned with pure water for 10 minutes. Then it took another 10 minutes to clean the coil with the cleaner. After that, the coil was laid on the tub for at least one day and was then cleaned with pure water.

For the next test, the coil was installed in the wind tunnel. It was operated with a high humidity inlet air stream with cooling water passed through the tubes, so that condensation occurred on the coil. The condensation cleaned the coil further and when the condensation was clear, a new baseline was performed.

It was not necessary to remove the 4-row and 2-row coils and they were cleaned in the wind tunnel. Two doors on the duct were designed at the front side and back side of the test coil so that it was easy to wash the coil from two directions in the wind tunnel. Similar to the process of cleaning 8-row coils, the 4-row and 2-row coils were cleaned twice with cleaner and pure water, but without soaking the coil for a day. The condensation process also was performed to futher clean the coil before the next test.

The duct inside of the test section was cleaned with pure water and brushed at the end of each test. The amount of dust was determined by filtering the water, drying and weighing the dust. The dust weight data for the duct, filters, condensation, injected dust and dust in the drain pan were all used to obtain filter arrestances and the amount of dust deposited on the coil. The specific computation and results are presented in section 3.3. 
After Step 4, the coil was cleaned to return to the original performance. Then, another type of filter would be inserted and Step 2-4 would be repeated till all five filter cases and one no-filter case were tested. 


\section{APPENDIX 4: LIST OF PURCHASED APPARATUS}

Air blower: Type BL, Buffalo Forge Co.

ASHRAE standard dust: Air Filter Testing Laboratories, INC.

Dust injector: LMS Technologies, INC.

Evap Pow'r-C: Nu-Calgon, Wholesaler, Inc.

Flexible impeller pump: 4UN80, Teel Company

Humidity sensors: Vaisala Company

Low differential pressure transducer: Setra Company

SCR controller for heaters: CCS-165-3-PA, Cristalcontrols Company

Thermistors: ON-403-PP, Omega Company

Viper M Scale: METTLER TOLEDO

Water flow meter: R100 Coriolis, Micrio Motion Company 